CESAR AUGUSTO ALVES DE SOUZA

\title{
CARACTERIZAÇÃO ELÉTRICA DE OXINITRETOS DE SILÍCIO ULTRAFINOS PARA PORTA PMOS OBTIDOS POR IMPLANTAÇÃO DE NITROGÊNIO NA ESTRUTURA $\mathrm{Si}-\mathrm{poli} / \mathrm{SiO}_{2} / \mathrm{Si}$
}

São Paulo 


\section{CARACTERIZAÇÃO ELÉTRICA DE OXINITRETOS DE SILÍCIO ULTRAFINOS PARA PORTA PMOS OBTIDOS POR IMPLANTAÇÃO DE NITROGÊNIO NA ESTRUTURA $\mathrm{Si}-\mathrm{poli} / \mathrm{SiO}_{2} / \mathrm{Si}$}

Dissertação apresentada à Escola Politécnica da Universidade de São Paulo para obtenção do título de Mestre em Engenharia Elétrica.

Área de concentração: Microeletrônica.

Orientador: Prof. Livre-Docente Sebastião Gomes do Santos Filho

SÃO PAULO 
Este exemplar foi revisado e alterado em relação à versão original, sob responsabilidade única do autor e com a anuência de seu orientador.

São Paulo, 29 de Maio de 2008

FICHA CATALOGRÁFICA

Souza, Cesar Augusto Alves de

Caracterização elétrica de oxinitretos de silício ultrafinos para porta PMOS obtidos por implantação de nitrogênio na estrutura Si-poli/SiO $/ 2$ Si / C.A.A. de Souza. -- São Paulo, 2008.

$140 \mathrm{p}$.

Dissertação (Mestrado) - Escola Politécnica da Universidade de São Paulo. Departamento de Engenharia de Sistemas Eletrônicos.

1. Capacitores MOS 2. Óxidos de porta ultrafino 3. Implantação iônica 4. Nitrogênio I. Universidade de São Paulo. Escola Politécnica. Departamento de Engenharia de Sistemas Eletrônicos II. t. 


\section{DEDICATÓRIA}

Dedico este trabalho aos meus pais, Zélia e Antônio (in memoriam), a quem pertence o verdadeiro mérito. 


\section{AGRADECIMENTOS}

Ao Altíssimo criador do céu e da terra e de tudo o que neles existem.

Ao professor Sebastião Gomes dos Santos Filho pela orientação cuidadosa ao longo do trabalho.

Ao corpo técnico do Laboratório de Sistemas Integráveis (LSI/USP) que mantém toda a estrutura em funcionamento, em especial ao técnico Nelson Ordonez pelas corrosões por plasma.

Ao professor Luis da Silva Zambom pelas deposições de Silício Policristalino.

Ao Centro de Componentes Semicondutores (CCS) da UNICAMP pelos processos de Implantação lônica e Recozimento Térmico Rápido.

Aos amigos do laboratório de Sistemas Integráveis (LSI/USP) e da Faculdade de Tecnologia de São Paulo (FATEC-SP).

Ao CNPq pelo apoio financeiro.

A todos que de alguma forma contribuíram com esse trabalho. 
"Pedí, dar-se-vos-á; buscai, e encontrareis; batei, e abrir-se-vos-á". "Porque, aquele que pede, recebe; e o que busca, encontra; e, ao que bate se abre".

(São Mateus. 7.7,8) 


\section{RESUMO}

Neste trabalho foram fabricados e caracterizados eletricamente capacitores MOS com óxido de silício ultrafino $(2,6 \mathrm{~nm})$ com porta de silício policristalino (Si-poli) $\mathrm{P}^{+}$e $\mathrm{N}^{+}$. Os capacitores MOS com porta de Si-poli dopados com boro tiveram a estrutura $\mathrm{Si}$-poli/ $/ \mathrm{SiO}_{2} / \mathrm{Si}$ previamente implantada com nitrogênio nas doses de $1.10^{13}, 1.10^{14}, 1.10^{15}$ e $5.10^{15}$ at.cm ${ }^{-2}$, com o pico da concentração de nitrogênio próximo à interface $\mathrm{SiO}_{2} / \mathrm{Si}$. Os capacitores MOS foram fabricados sobre lâminas de silício do tipo $p$ que passaram por uma limpeza química préoxidação tipo RCA mais imersão final em solução diluída em HF. Na seqüência, as lâminas foram oxidadas em um ambiente de $\mathrm{O}_{2}(1,5 \mathrm{l} / \mathrm{min})+\mathrm{N}_{2} / \mathrm{H}_{2}(2 \mathrm{l} / \mathrm{min}$; $10 \%)$ que proporcionou óxidos de silício com excelentes características elétricas.

Para a fabricação dos capacitores MOS com porta de Si-poli $\mathrm{P}^{+}$, utilizou-se SOG de boro seguido por difusão térmica sobre camada de Si-poli $(340 \mathrm{~nm})$. Após testes com receitas de difusão a 950, 1000, 1050 e $1100{ }^{\circ} \mathrm{C}$ todas padronizadas por um tempo de 30 min optamos por realizar a difusão a 1050 ${ }^{\circ} \mathrm{C}$ por $30 \mathrm{~min}$, pois essa receita proporcionou concentração de boro superior a $1.10^{20}$ at. $\mathrm{cm}^{-3}$ e segregação desprezível do boro em direção ao substrato de Si. A dopagem dos capacitores MOS com porta de Si-poli $\mathrm{N}^{+}$foi realizada por aplicação do SOG de fósforo seguido por difusão a $1050^{\circ} \mathrm{C}$ por 30 min.

Os resultados indicaram segregação do boro desprezível para o $\mathrm{Si}$, baixa densidade de estados de interface $\left(<1.10^{11} \mathrm{eV}^{-1} \mathrm{~cm}^{-2}\right)$ e no aumento do campo elétrico de ruptura (de $14 \mathrm{MV} / \mathrm{cm}$ para $21 \mathrm{MV} / \mathrm{cm}$ ) com o aumento da dose de nitrogênio (de $1.10^{13}$ a $5.10^{15} \mathrm{at} / \mathrm{cm}^{2}$ ). Embora ocorresse uma maior dispersão e um aumento desfavorável da tensão de banda plana com o aumento da dose de nitrogênio, os valores $1.10^{15}$ e $5.10^{15}$ at.cm ${ }^{-2}$ resultaram em capacitores MOS com tensão de faixa plana próxima ao parâmetro diferença de função trabalho $\left(\Phi_{\mathrm{MS}}\right)$ significando densidade efetiva de cargas no dielétrico de porta inferior à cerca de $1.10^{11} \mathrm{~cm}^{-2}$.

Palavra chave: Óxido de Silício, Capacitor MOS, Dielétrico de porta, Nitrogênio. 


\begin{abstract}
In this work we manufactured and electrically characterized MOS capacitors with ultrathin silicon oxides $(2,6 \mathrm{~nm})$ and polysilicon gate $\left(\mathrm{Si}-\right.$ poli), $\mathrm{P}^{+}$or $\mathrm{N}^{+} . \mathrm{P}^{+}-$ doped polysilicon gate MOS capacitors ( $\mathrm{Si}-\mathrm{poli} / \mathrm{SiO}_{2} / \mathrm{Si}$ structure) were previously implanted with nitrogen using doses of $1.10^{13}, 1.10^{14}, 1.10^{15}$ and $5.10^{15}$ at. $\mathrm{cm}^{-2}$, and implantation peak centered close to the $\mathrm{SiO}_{2} / \mathrm{Si}$ interface before boron doping. The MOS capacitors were fabricated on p-type silicon wafers, which were submitted to RCA - based cleaning procedure and a final dip in diluted HF solution. Following, the wafers were oxidize in ultrapure $\mathrm{O}_{2}$ $(1,5 \mathrm{l} / \mathrm{min})+\mathrm{N}_{2} / \mathrm{H}_{2}(2 \mathrm{l} / \mathrm{min} ; 10 \%)$ having, as a result, silicon gate oxides with excellent electrical characteristics.
\end{abstract}

To obtain $\mathrm{P}^{+}$polysilicon, it Spin On Glass (SOG) of boron the wafers was annealed at $950,1000,1050$ or $1100{ }^{\circ} \mathrm{C}$ during $30 \mathrm{~min}$. We have chosen a diffusion recipe of $1050{ }^{\circ} \mathrm{C}$ during $30 \mathrm{~min}$ to obtain volumetric concentration of boron higher than $1.10^{20} \mathrm{~cm}^{-3}$ and no boron segregation to the silicon. $\mathrm{N}^{+}$polysilicon was also obtained using phosphorus SOG and diffusion at 1050 ${ }^{\circ} \mathrm{C}$ during $30 \mathrm{~min}$.

As a result, besides no boron segregation to $\mathrm{Si}$, the interface states density was low $\left(<1.10^{11} \mathrm{eV}^{-1} \mathrm{~cm}^{-2}\right)$ and the breakdown field of the gate oxides increased (from $14 \mathrm{MV} / \mathrm{cm}$ to $21 \mathrm{MV} / \mathrm{cm}$ ) by increasing the nitrogen doses (from $1.10^{13}$ to $5.10^{15} \mathrm{at} / \mathrm{cm}^{2}$ ). Although a larger dispersion and increasing of the flat-band voltage have occurred as the nitrogen dose was increased, values of $1.10^{15}$ and $5.10^{15}$ at.cm ${ }^{-2}$ induced flat band voltage close to the parameter workfunction difference $\left(\Phi_{M S}\right)$ which meant effective charge density in the gate dielectrics lower than about $1.10^{11} \mathrm{~cm}^{-2}$.

Keywords: Silicon oxide, MOS capacitor, Gate dielectrics, Nitrogen. 


\section{SUMÁRIO}

\section{CONSIDERAÇÕES INICIAIS}

1.1 Motivação e objetivo 23

1.2 Introdução e justificativas 25

2. REVISÃO BIBLIOGRÁFICA 29

2.1 Introdução 29

2.2 Óxido de silício ultrafino 31

2.3 Corrente de tunelamento 41

2.4 Silício policristalino 46

2.4.1 Comportamento elétrico do silício policristalino 49

2.4.2 Efeito de depleção do silício policristalino 51

2.4.3 Influência da depleção do silício policristalino na medida C-V 54

2.4.4 Extração de parâmetros das curvas $\mathrm{C}-\mathrm{V}_{\mathrm{AF}}$ com de depleção do Si-poli 59

2.5 Obtenção do oxinitreto de silício 61

2.5.1 Implantação iônica de nitrogênio no sistema $\mathrm{Si}-\mathrm{poli} / \mathrm{SiO}_{2} / \mathrm{Si}$ 65

3. CARACTERIZAÇÃO ELÉTRICA E PERFILAMENTO 71

3.1 Medidas $\mathrm{C}-\mathrm{V}_{\mathrm{AF}}$ e $\mathrm{C}-\mathrm{V}_{\mathrm{BF}}$ 72

3.2 Medidas I-V 74

3.3 Técnicas de perfilamento 78

3.3.1 Medida de resistência de folha incremental 79

3.3.1.1 Metodologia para o perfilamento do boro no Si-poli 81 
4.1 Obtenção da estrutura Si-poli/ $\mathrm{SiO}_{2} / \mathrm{Si}$

4.1.1 Limpeza química 88

4.1.2 Oxidação térmica do $\mathrm{Si}$ 89

4.1.3 Deposição de Si-poli 91

4.1.4 Difusão de boro ao longo da estrutura Si-poli/SiO ${ }_{2} / \mathrm{Si}$ 92

4.2 Fabricação de capacitores MOS com Si-poli $\mathrm{P}^{+}$ 94

4.2.1 Simulação SRIM 94

4.2.2 Dopagem do Si-poli 95

4.2.3 Concentração de boro na estrutura $\mathrm{Si}-\mathrm{poli} / \mathrm{SiO}_{2} / \mathrm{Si}$ com nitrogênio 97

4.2.4 Definição da geometria dos capacitores 98

4.2.4.1 Metalização do alumínio por evaporação térmica 98

4.2.4.2 Fotogravação para definição do alumínio 98

4.2.4.3 Corrosão do Si-poli 99

4.2.4.4 Deposição de alumínio nas costas das lâminas 100

4.2.4.5 Sinterização 100

4.3 Fabricação de capacitores MOS com Si-poli N ${ }^{+}$ 101

\section{RESULTADOS E DISCUSSÕES} 102

5.1 Difusão de boro em capacitores MOS com ou sem nitrogênio 103

5.1.2 Medidas $\mathrm{C}-\mathrm{V}_{\mathrm{AF}}$ 107

5.1.3 Medidas $\mathrm{C}-\mathrm{V}_{\mathrm{BF}}$ 112

5.1.4 Medidas I-V 117

5.2 Medidas C-V e I-V em capacitores MOS com Si-poli $\mathrm{N}^{+}$ 119

6. CONSIDERAÇÕES FINAIS

6.1 Conclusões 122

6.2 Sugestões para trabalhos futuros 123 


\section{APÊNDICE A - EXTRAÇÃO DE PARÂMETROS DA CURVA C-V 134}

A.1 Parâmetros da curva $\mathrm{C}-\mathrm{V}_{\mathrm{AF}}$ 134

A.2 Extração de $D_{i t}$ na curva $C-V_{B F}$ 137 


\section{LISTA DE FIGURAS}

Figura 1.1

Figura 2.1

Figura 2.2

Figura 2.3

Figura 2.4

Figura 2.5

Figura 2.6

Figura 2.7

Figura 2.8
Estrutura de um MOSFET, mostrando as dimensões características W e L, os contatos S, G, D e B, e as regiões constituídas por: metal, óxido de silício e silício (substrato)

26

Distribuição de cargas obtidas por cálculo de mecânica quântica em um capacitor MOS com espessura de óxido de $1 \mathrm{~nm}$ e porta de Si-poli com polarização de porta de $2 \mathrm{~V}$ na condição de depleção 30 Diagrama de bandas para o sistema $\mathrm{Si}_{-} \mathrm{SiO}_{2}$. Note a diferença dos valores da barreira de energia para elétrons $(3,2 \mathrm{eV})$ e lacunas $(4,6 \mathrm{eV})$ 33

Tendência da redução da espessura do $\mathrm{SiO}_{2} \operatorname{com}$ a redução no comprimento de canal da tecnologia CMOS ao longo dos anos 34

Projeção para a espessura equivalente do dielétrico de porta (EOT), apresentando os limites da modelagem da corrente de tunelamento ( $2 \mathrm{~nm}$ ) e do próprio limite físico estabelecido pelas dimensões de suas ligações físicas SiO 37

Ligação química da estrutura $\mathrm{SiO}_{2}$ apresentando a espessura mínima do filme 37

Diferentes dielétricos de porta MOS, onde são apresentados o "gap" de energia e o alinhamento das bandas de energia em relação ao Si. As constantes dielétricas são apresentadas nos topos das barras 39 Proposta de um modelo para o mecanismo de tunelamento em filmes de oxinitreto ultrafino 41 Tipos de tunelamento: a) densidade de corrente de tunelamento Fowler Nordheim $\left(J_{\mathrm{FN}}\right)$; b) densidade de 
corrente tunelamento direto $\left(\mathrm{J}_{\mathrm{D}}\right)$ associado à barreira trapezoidal de energia para uma estrutura Si-poli $\mathrm{N}^{+} / \mathrm{SiO}_{2} / \mathrm{Si}-\mathrm{p}$ 43

Figura 2.9

Figura 2.10

Figura 2.11

Figura 2.12

Figura 2.13

Figura 2.14

Figura 2.15

Figura 2.16
Curvas da densidade de corrente de tunelamento $\left(\mathrm{J}_{\mathrm{G}}\right)$ em função da tensão aplicada à porta $\left(V_{G}\right)$ para tox variando de $\quad 2,9$ a $6,2 \mathrm{~nm}$ 43 Curvas $C-V_{A F}$ (a) e C- $V_{B F}$ (b) normalizada em função de $\mathrm{C}_{\text {ox, }}$ demonstrando a influência da corrente de tunelamento 45

Característica I-V para capacitores MOS com a estrutura Si-poli $\mathrm{P}^{+} / \mathrm{SiO}_{2} / \mathrm{Si}$-n com oxinitreto de $\mathrm{Si}$ e dose de implantação de nitrogênio de $5.10^{15}$ at.cm ${ }^{-2}$ para diferentes espessuras de óxido de porta 45 Formação de spikes com curto em contatos $\mathrm{Al} / \mathrm{Si}, \mathrm{b}$ ) Vista de cima de um transistor nMOSFET mostrando a formação de spikes sobre fonte e dreno 47 Estrutura auto-alinhada com Si-poli. (a) A área de sobreposição (L) responsável pela capacitância parasitária é muito maior (b) no transistor de Al do que no de Si-poli 48 Variação da resistividade em relação à concentração de dopantes comparados com o tamanho do grão do Si-poli e com o Si monocristalino 49 Representação esquemática do transistor MOS com porta de silício policristalino indicando a região menos dopada junto ao $\mathrm{SiO}_{2}$ 51 Diagrama de faixas de energia de uma estrutura MOS onde pode-se observar a queda de potencial na superfície do Si-poli $\left(\Psi_{\text {Sipoli }}\right)$ próximo a interface Si-poli $/ \mathrm{SiO}_{2}$ 52 
Figura 2.17

Figura 2.18

Figura 2.19

Figura 2.20

Figura 2.21

Figura 2.22

Figura 2.23

Figura 2.24

Figura 2.25
Modelo equivalente de capacitâncias para um capacitor MOS com porta de metal 54

Modelo equivalente de capacitâncias para um capacitor MOS com porta de Si-poli 56

Curva $\mathrm{C}-\mathrm{V}_{\mathrm{AF}}$ experimental com uma estrutura composta por Si-poli $\mathrm{N}^{+} / \mathrm{SiO}_{2} / \mathrm{Si}$, para alta e baixa dopagem e a presença ou não do efeito de depleção 57 Curvas $\mathrm{C}-\mathrm{V}_{\mathrm{BF}}$ simuladas com a estrutura composta por Si-poli $\mathrm{N}^{+} / \mathrm{SiO}_{2} / \mathrm{Si}$, indicando o efeito de depleção em relação as diferentes concentrações de dopagem do Sipoli 58

Perfil desuniforme de distribuição de dopantes no Si-poli. Campo elétrico gerado e região de depleção de portadores junto à interface com o óxido 60

Diagrama de fases do sistema Si-N-O 62 Detalhes do Implantador lônico GA4204 utilizado neste trabalho 64

Resistência de folha para $150 \mathrm{~nm}$ de Si-poli com diferentes doses de nitrogênio com implantação superficial do mesmo (40 keV) seguido por diferentes processos de recozimento do boro por RTP 66 Representação esquemática da difusão de boro a partir do Si-poli $\mathrm{P}^{+}$ao longo da estrutura $\mathrm{SiO}_{2}-\mathrm{Si}$. (i) estrutura Si-poli $\mathrm{P}^{+} / \mathrm{SiO}_{2} / \mathrm{Si}$ sem a presença de nitrogênio, (ii) camada de $\mathrm{SiO}_{x} \mathrm{~N}_{y}$ na interface $\mathrm{Si}-\mathrm{SiO}_{2}$ e (iii) camada de $\mathrm{SiO}_{x} \mathrm{~N}_{y}$ na interface $\mathrm{Si}-$ poli/Si 67 
Figura 2.26

Figura 2.27

Figura 2.28

Figura 3.1

Figura 3.2

Figura 3.3

Figura 3.4

Figura 3.5

Figura 4.1

Figura 4.2

Figura 5.1
Distribuições de $Q_{B D}$ em função de $\ln (-\ln (1-F)$ para capacitores com porta de Si-poli $\mathrm{P}^{+}$(símbolos vazios) recozidas por RTP a 40 s (símbolos conectados com linha) e a $20 \mathrm{~s}$ (símbolos não conectados por linha) e $\mathrm{N}^{+}$ (símbolos cheios) 68 Comportamento da tensão de banda plana com a variação da espessura do óxido para portas Si-poli $\mathrm{P}+\mathrm{e}$ Si-poli $\mathrm{N}^{+}$ 69 Perfil do nitrogênio no $\mathrm{SiO}_{2}$ para a dose de $1.10^{15} \mathrm{~cm}^{-2}$ com várias temperaturas e tempos de RTA 70 llustração de uma curva $\mathrm{C}-\mathrm{V}_{\mathrm{AF}}$ normalizada onde se apresenta o efeito de depleção profunda 73 Exemplo de uma curva experimental característica I-V para capacitores com espessura média do óxido de porta de $2,8 \mathrm{~nm}$. 74 Diagrama elétrico esquemático da montagem para a extração das curvas I-V 75 Representação geométrica no método de medida de quatro pontas 80 Correlação entre tempo de corrosão e altura do degrau formado no Si-poli 82 Etapas inicias da fabricação dos capacitores MOS 87 Simulação SRIM para $\mathrm{I} / \mathrm{l}$ 。 de nitrogênio $\left(\mathrm{N}^{+}\right)$com energia de $110 \mathrm{keV}$ 95 Gráfico da concentração de boro ao longo do Si-poli. A mobilidade adotada foi de $20 \mathrm{~cm}^{2} / \mathrm{Vs}$ 106 
Figura 5.2

Figura 5.3

Figura 5.4

Figura 5.5

Figura 5.6

Figura 5.7

Figura 5.8

Figura 5.9

Figura 5.10

Figura 5.11

Figura 5.12

Figura 5.13

Figura 5.14

Figura 5.15

Figura 5.16

Figura A.1

Figura B.1

Figura B.2
Curvas C-V $\mathrm{V}_{\mathrm{AF}}$ para a dose de $1.10^{13}$ at. $^{-2}$ 107 Curvas $\mathrm{C}-\mathrm{V}_{\mathrm{AF}}$ para a dose de $1.10^{14}$ at.cm ${ }^{-2}$ 108 Curvas $\mathrm{C}-\mathrm{V}_{\mathrm{AF}}$ para a dose de $1.10^{15}$ at.cm ${ }^{-2}$ 108 Curvas $\mathrm{C}-\mathrm{V}_{\mathrm{AF}}$ para a dose de $5.10^{15}$ at.cm $^{-2}$ 109 Medidas $\mathrm{C}-\mathrm{V}_{\mathrm{AF}}$ representativas para as quatro doses de nitrogênio empregadas 110 Medidas $\mathrm{C}-\mathrm{V}_{\mathrm{BF}}$ para a dose de $1.10^{13} \mathrm{at} / \mathrm{cm}^{2}$ 112 Medidas $\mathrm{C}-\mathrm{V}_{\mathrm{BF}}$ para a dose de $1.10^{14} \mathrm{at} / \mathrm{cm}^{2}$ 113 Medidas $\mathrm{C}-\mathrm{V}_{\mathrm{BF}}$ para a dose de $1.10^{15} \mathrm{at} / \mathrm{cm}^{2}$ 113 Medidas $\mathrm{C}-\mathrm{V}_{\mathrm{BF}}$ para a dose de $5.10^{15} \mathrm{at} / \mathrm{cm}^{2}$ 114 Curvas $\mathrm{C}-\mathrm{V}_{\mathrm{AF}}$ e $\mathrm{C}-\mathrm{V}_{\mathrm{BF}}$ do capacitor MOS. A curva $\mathrm{C}-\mathrm{V}_{\mathrm{BF}}$ corrigida da capacitância parasitária 115 Medidas $\mathrm{C}-\mathrm{V}_{\mathrm{BF}}$ representativas para as quatro doses de nitrogênio empregadas 116

Medidas I-V em típicas em capacitores com Si-poli $\mathrm{P}^{+}$, com diferentes doses de nitrogênio, polarizados na acumulação ou inversão 118 Curvas $\mathrm{C}-\mathrm{V}_{\mathrm{AF}}$ para capacitores MOS fabricados com porta de Si-poli $\mathrm{N}^{+}$ 119 Curvas $\mathrm{C}-\mathrm{V}_{\mathrm{BF}}$ para capacitores MOS fabricados com porta de Si-poli $\mathrm{N}^{+}$ 120 Medidas I-V em capacitores MOS com porta de Si-poli $\mathrm{N}^{+}$ polarizados na acumulação 121

Curva $\mathrm{C}-\mathrm{V}_{\mathrm{BF}}$ apresentando os parâmetros $\mathrm{C}_{\mathrm{MAX}}$ e $\mathrm{C}_{\mathrm{MIN}}$ a serem extraídos da curva 137

Painel de entrada de parâmetros para a simulação SRIM utilizada neste trabalho 139

Painel de saída de dados para a simulação SRIM. Desses dados, somente o gráfico (Íon Range) é utilizado neste trabalho 140 


\section{LISTA DE TABELAS}

Tabela 1.1

Tabela 2.1

Tabela 2.2

Tabela 5.1

Tabela 5.2

Tabela 5.3

Tabela 5.4

Tabela 5.5

Tabela 5.6

Tabela 5.7
Alguns parâmetros tecnológicos atuais

e futuros previstos

27

Propriedades selecionadas de filmes finos de óxido de silício utilizados como dielétricos de porta 32 Evolução da velocidade de processamento e da escala de integração dos microprocessadores da Intel ${ }^{\circledR}$

Principais parâmetros utilizados nas medidas

$\mathrm{C}-\mathrm{V}_{\mathrm{AF}}$ e $\mathrm{C}-\mathrm{V}_{\mathrm{BF}}$ 73 $\mathrm{R}_{\text {sh }}, \mathrm{P}_{\text {poli }}$ para após difusão nas temperaturas a 950, 1000, 1050 e $1100 \stackrel{\circ}{C}$ por 30 min. O valor inicial de $R_{\text {sh }}$ foi de $212 \pm 4$ [ohm/ $\square]$ 103

Profundidade removida e valor de $\mathrm{R}_{\mathrm{sh}}$ para cada uma das quatro doses utilizadas 105

Medida de $R_{\text {sh }}$ na superfície do Si e nas costas para cada uma das quatro doses utilizadas 105

Parâmetros extraídos das curvas $\mathrm{C}-\mathrm{V}_{\mathrm{AF}}$ 110

Parâmetros extraídos das curvas $\mathrm{C}-\mathrm{V}_{\mathrm{BF}}$ 116

Dados de $\mathrm{E}_{\mathrm{BR}}$ para 30 capacitores em cada uma das doses de nitrogênio empregadas 117

Parâmetros extraídos das curvas

$\mathrm{C}-\mathrm{V}_{\mathrm{AF}}, \mathrm{C}-\mathrm{V}_{\mathrm{BF}}$ e I-V 121 


\section{LISTA DE SÍMBOLOS, SIGLAS E DE ABREVIATURAS}

A

$\mathrm{ABE}$

AES

Al

$\mathrm{Al}_{2} \mathrm{O}_{3}$

$\mathrm{BHF}$

$\mathrm{Cl}_{\mathrm{S}}$

$\mathrm{C}_{\text {MAX }}$

$\mathrm{C}_{\text {MIN }}$

CMOS

$\mathrm{C}_{\mathrm{ox}}$

$\mathrm{C}_{\mathrm{Si}}$

$\mathrm{C}_{\text {Sipoli }}$

CSS

$\mathrm{C}_{\mathrm{T}}$

C-V

$\mathrm{C}-\mathrm{V}_{\mathrm{AF}}$

$\mathrm{C}-\mathrm{V}_{\mathrm{BF}}$

CVD

DI

$D_{\text {it }}$

DRAM

$\mathrm{E}_{\mathrm{BR}}$

$E_{c}$

$\mathrm{E}_{\mathrm{F}}$

$E_{G}$

$E_{i}$

EOT

$\varepsilon_{0}$

$\varepsilon_{\mathrm{OX}}$

área do capacitor MOS

altura da barreira de energia do perfil triangular

altura da barreira de energia do perfil trapezoidal

alumínio

óxido de alumínio

Buffered Oxide Etch

circuito integrado

capacitância máxima

capacitância mínima

Complementary Metal Oxide Silicon (Technology)

capacitância do óxido de silício

capacitância do silício

capacitância do silício policristalino

stress por corrente constante

capacitância total

capacitância tensão

capacitância - tensão em alta freqüência

capacitância - tensão em baixa freqüência

Chemical Vapor Deposition

água deionizada

densidade de estados de interface

Dynamic Randon Access Memory

campo elétrico de ruptura

nível mais baixo de energia da banda de condução

nível de energia de Fermi

largura energética da faixa proibida

energia do nível intrínseco

espessura equivalente do dielétrico de porta

permissividade elétrica do vácuo $\left(8,85.10^{-14} \mathrm{~F} / \mathrm{cm}\right)$

permissividade elétrica do oxido de silício $\left(3,9 . \varepsilon_{0}\right)$ 


\begin{tabular}{|c|c|}
\hline$\varepsilon_{\mathrm{si}}$ & permissividade elétrica do silício $\left(11,7 . \varepsilon_{0}\right)$ \\
\hline$E_{v}$ & nível mais alto de energia da banda de valência \\
\hline $\mathrm{H}^{+}$ & íon de hidrogênio \\
\hline $\mathrm{H}_{2} \mathrm{O}_{2}$ & peróxido de hidrogênio \\
\hline $\mathrm{HCl}$ & ácido clorídrico \\
\hline $\mathrm{HF}$ & ácido fluorídrico \\
\hline $\mathrm{HfO}_{2}$ & óxido de háfnio \\
\hline High $\mathrm{k}$ & constante dielétrica alta \\
\hline $\mathrm{HNO}_{3}$ & ácido nítrico \\
\hline $1 / I_{0}$ & implantação iônica \\
\hline IPA & álcool isopropílico \\
\hline I-V & corrente - tensão \\
\hline $\mathrm{J}$ & densidade de corrente \\
\hline$J_{D}$ & densidade de corrente de tunelamento direto \\
\hline$J_{\mathrm{FN}}$ & densidade de corrente de tunelamento Fowler - Nordheim \\
\hline$J_{G}$ & densidade de corrente de tunelamento na porta \\
\hline k & constante dielétrica \\
\hline $\mathrm{K}^{+}$ & íon de potássio \\
\hline $\mathrm{K}_{\mathrm{B}}$ & constante de Boltzmann \\
\hline $\mathrm{K}(\mathrm{OH})$ & hidróxido de potássio \\
\hline L & comprimento entre fonte e dreno \\
\hline $\mathrm{La}_{2} \mathrm{O}_{3}$ & óxido de lantânio \\
\hline LPCVD & Low Pressure Chemical Vapor Deposition \\
\hline LS & lâmina de sacrifício \\
\hline Mo & molibdênio \\
\hline MOS & Metal-Oxide - Semiconductor \\
\hline MOSFET & Metal - Oxide - Semiconductor Field Effect Transistor \\
\hline $\mathrm{M}_{\mathrm{x}} \mathrm{O}_{\mathrm{y}}$ & óxidos metálicos com proporções variadas \\
\hline $\mathrm{M}_{\mathrm{x}} \mathrm{Si}_{\mathrm{y}}$ & silicetos com proporções variadas \\
\hline$n$ & índice de refração \\
\hline $\mathrm{N}^{+}$ & íon de nitrogênio \\
\hline $\mathrm{N}_{2}$ & nitrogênio molecular \\
\hline $\mathrm{N}_{2} \mathrm{O}$ & óxido nitroso \\
\hline
\end{tabular}




\begin{tabular}{|c|c|}
\hline$N_{A}$ & concentração de impurezas aceitadoras $\left(\mathrm{cm}^{-3}\right)$ \\
\hline $\mathrm{NH}_{3}$ & gás amônia \\
\hline $\mathrm{NH}_{4} \mathrm{~F}$ & fluoreto de amônia \\
\hline $\mathrm{NH}_{4} \mathrm{OH}$ & hidróxido de amônia \\
\hline$n_{i}$ & $\begin{array}{l}\text { concentração intrínseca do Si }\left(1,45.10^{10} \mathrm{~cm}^{-3} \text {, }\right. \\
\text { temperatura de } 300 \mathrm{~K})\end{array}$ \\
\hline $\mathrm{NiSi}$ & siliceto de níquel \\
\hline$N_{\text {poli }}$ & $\begin{array}{l}\text { concentração de dopantes doadores ionizados no silício } \\
\text { policristalino }\left(\mathrm{cm}^{-3}\right)\end{array}$ \\
\hline$P_{\text {poli }}$ & $\begin{array}{l}\text { concentração de dopantes aceitadores ionizados no silício } \\
\text { policristalino }\left(\mathrm{cm}^{-3}\right)\end{array}$ \\
\hline $\mathrm{N}_{\text {ref }}$ & concentração de referência \\
\hline$N\left(x_{i}\right)$ & concentração de portadores ao longo da espessura \\
\hline $\mathrm{O}_{2}$ & oxigênio \\
\hline ppb & parte por bilhão \\
\hline$Q_{\mathrm{BD}}$ & carga para ruptura do dielétrico de porta (cargas $/ \mathrm{cm}^{2}$ ) \\
\hline$Q_{i t}$ & cargas de interface $\left(\right.$ cargas $\left./ \mathrm{cm}^{2}\right)$ \\
\hline$Q_{s s}$ & $\begin{array}{l}\text { densidade de carga efetiva no dielétrico de porta } \\
\left(\text { cargas } / \mathrm{cm}^{2}\right)\end{array}$ \\
\hline $\mathrm{RCA}$ & $\begin{array}{l}\text { limpeza química desenvolvida na empresa do mesmo } \\
\text { nome }\end{array}$ \\
\hline $\mathrm{R}_{\mathrm{sh}}$ & resistência de folha \\
\hline $\mathrm{R}_{\mathrm{sp}}$ & resistência de espraiamento \\
\hline RTP & Rapid Thermal Processing \\
\hline $\mathrm{Si}$ & silício \\
\hline Si-p & silício dopado tipo $p$ \\
\hline Si-poli & silício policristalino \\
\hline Si-poli $P^{+}$ & $\begin{array}{l}\text { silício policristalino dopado degeneradamente com } \\
\text { impurezas aceitadoras }\end{array}$ \\
\hline Si-poli N ${ }^{+}$ & $\begin{array}{l}\text { silício policristalino dopado degeneradamente com } \\
\text { impurezas doadoras. }\end{array}$ \\
\hline SiGe-poli & Silício germânio policristalino \\
\hline $\mathrm{Si}_{3} \mathrm{~N}_{4}$ & nitreto de silício \\
\hline
\end{tabular}




\begin{tabular}{|c|c|}
\hline $\mathrm{SiH}_{4}$ & gás silana \\
\hline SIMS & Secondary Ion Mass Spectroscopy \\
\hline $\mathrm{SiO}_{2}$ & óxido de silício \\
\hline $\mathrm{SiO}_{x} \mathrm{~N}_{\mathrm{y}}$ & oxinitreto de silício com proporções variadas \\
\hline SOG & Spin On Glass \\
\hline SOI & Silicon-On-Insulator \\
\hline SRIM & Stopping and Range of lons Matter \\
\hline$t_{o x}$ & espessura do oxido de silício obtida por elipsometria \\
\hline$t_{\text {poli }}$ & espessura do silício policristalino \\
\hline $\mathrm{Ta}_{2} \mathrm{O}_{5}$ & óxido de tântalo \\
\hline $\mathrm{TiO}_{2}$ & óxido de titânio \\
\hline $\mathrm{V}_{\mathrm{BD}}$ & tensão de ruptura do dielétrico \\
\hline $\mathrm{V}_{\mathrm{FB}}$ & tensão de flat-band \\
\hline$V_{G}$ & tensão na porta \\
\hline $\mathrm{V}_{\mathrm{T}}$ & tensão de limiar \\
\hline W & largura da região de depleção do silício \\
\hline$W_{\text {Sipoli }}$ & largura da região de depleção do silício policristalino \\
\hline$\chi_{\mathrm{Si}}$ & afinidade eletrônica do silício (4,15 eV) \\
\hline $\mathrm{Y}_{2} \mathrm{O}_{3}$ & óxido de ítrio \\
\hline$\lambda$ & comprimento de onda \\
\hline$\mu$ & mobilidade média dos portadores (cm²/V.s) \\
\hline$\mu_{(\mathrm{x}(\mathrm{i})}$ & mobilidade em função da posição (cm²/V.s) \\
\hline$\mu_{\min }$ & mobilidade mínima (cm²/V.s) \\
\hline$\mu_{\max }$ & mobilidade máxima (cm²/V.s) \\
\hline$\rho$ & resistividade do filme (ohm.cm) \\
\hline$\sigma$ & condutância de folha da camada removida $(S)$ \\
\hline$\Psi_{\mathrm{S}}$ & potencial de superfície do silício \\
\hline$\Psi_{\text {Sipoli }}$ & potencial na superfície do silício policristalino \\
\hline
\end{tabular}


$\omega$

$\Phi_{\mathrm{MS}}$

$\Phi_{\text {Si }}$

$\Phi_{\text {Sipoli }}$

$X_{i}$

$\mathrm{Z}_{\mathrm{MA}}$ freqüência $(\mathrm{Hz})$

diferença da função trabalho

função trabalho do silício

função trabalho do silício policristalino

profundidade removida em relação a superfície

impedância 


\section{CONSIDERAÇÕES INICIAIS}

\subsection{Motivação e objetivo}

O objetivo deste trabalho é estudar as propriedades elétricas da implantação iônica de nitrogênio através da estrutura MOS (silício policristalino/óxido de silício/silício ( $\mathrm{Si}$-poli/SiO $/ \mathrm{Si})$ ) seguido de difusão de boro através do Si-poli com espessura em torno de $340 \mathrm{~nm}$. Herden (2001) observou que certas quantidades de nitrogênio ao longo das interfaces $\mathrm{Si}$-poli/ $/ \mathrm{SiO}_{2}$ e $\mathrm{SiO}_{2} / \mathrm{Si}$ minimiza a difusão de boro para o Si pela formação de uma fina camada de oxinitreto nessas interfaces. Através da caracterização elétrica dos capacitores MOS [densidade de estados de interface $\left(D_{i t}\right)$, densidade de carga efetiva $\left(Q_{s s}\right)$, concentração efetiva de dopantes $\left(N_{A}\right)$ e medidas de resistência de folha $\left.\left(R_{s h}\right)\right]$, analisaremos a eficiência da barreira de oxinitreto formada.

A importância deste trabalho reside nas atuais dimensões dos dispositivos MOS. Para a tecnologia CMOS ( que, atualmente, ocupa mais da metade na participação no mercado de produtos eletrônicos, a redução das dimensões promove dispositivos mais velozes, além de permitir um maior número de transistores por pastilha e redução dos custos. Ao se utilizar Si-poli como eletrodo de porta, com dopagem degenerada de boro, observa-se que o dopante pode difundir substancialmente para a estrutura $\mathrm{SiO}_{2} / \mathrm{Si}$, durante os ciclos térmicos de difusão ou recozimento (PFIESTER, 1990). Altas concentrações de boro no corpo do óxido aumentam a densidade efetiva de carga $\left(Q_{s s}\right)$ reduzindo a eficiência do dielétrico. A presença de boro na superfície do Si varia à tensão de limiar $\left(\mathrm{V}_{\mathrm{T}}\right)$, obrigando o reprojeto dos dispositivos MOS (MOGAMI, 1991). Já para a dopagem degenerada de fósforo no Si-poli, não se observa a difusão do fósforo para o Si já que o mesmo tende a ficar predominantemente no Si-poli. 
Para reduzir a difusão de boro do Si-poli para $\circ \mathrm{SiO}_{2}$, pode-se reduzir a quantidade de boro próximo da interface $\mathrm{Si}-\mathrm{poli}_{\mathrm{SiO}}$. Porém, essa redução favorece a dois efeitos desagradáveis: o aumento da resistência de folha $\left(R_{\mathrm{sh}}\right)$ do Si-poli e o surgimento de uma superfície não equipotencial próxima à interface com $0 \mathrm{SiO}_{2}$, resultando em uma capacitância adicional à estrutura MOS (LIOU, 2002). Essa nova capacitância dificulta a extração de parâmetros das curvas C-V sob certas condições de polarização (LU, 2000). Diversas pesquisas tecnológicas estão sendo feitas, como a pesquisa de novos materiais para o eletrodo de porta ou para o dielétrico da estrutura MOS visando minimizar esse efeito (SHIMADA, 1995; LU, 2000; XUAN, 2003).

A introdução de nitrogênio ao longo da estrutura MOS tem algumas peculiaridades quanto à quantidade inserida. Baixa quantidade de nitrogênio nas interfaces é pouco eficiente quanto à supressão da segregação do boro (WU, 1998). Altas quantidades de nitrogênio são bastante eficientes em barrar a difusão do boro, porém, degradam em muito o funcionamento do dispositivo promovendo, dentre outros efeitos, a ruptura elétrica precoce do $\mathrm{SiO}_{2}$ (HERDEN, 2001; BAUER, 1998). Além disso, a alta concentração de nitrogênio no corpo do Si-poli resulta num aumento abrupto da resistência de folha do mesmo (HERDEN, 2001), o que é indesejável se o objetivo é reduzir o tempo de atraso em dispositivos MOS.

Portanto, uma das tarefas importante realizada no presente trabalho foi encontrar a menor concentração de nitrogênio possível para bloquear o boro sem perder e, até melhorar, as qualidades oferecidas pelo óxido térmico no que se refere à baixa densidade de estados de interface $\left(<1.10^{11} \mathrm{eV}^{-1} \mathrm{~cm}^{-2}\right)$, alto campo elétrico de ruptura ( $>20 \mathrm{MV} / \mathrm{cm}$ ); etc. 


\subsection{Introdução e justificativas}

A principal motivação deste trabalho é a aplicação que tem filmes ultrafinos dielétricos em dispositivos microeletrônicos, do tipo transistor de efeito de campo metal-óxido-semicondutor (MOSFET, Metal - Oxide - Semicondutor Field Effect Transistor). Dentre os muitos tipos de dispositivos microeletrônicos em uso, o MOSFET é, atualmente, o mais importante, por permitir uma excelente capacidade de escalamento das dimensões verticais e horizontais (WONG, 2006). Ele é o principal componente em microprocessadores e também é uma peça-chave em memórias de acesso aleatório dinâmico (DRAMs, Dynamic Random Access Memories) (BROWN, 1986). A necessidade do desenvolvimento de filmes ultrafinos dielétricos para 0 MOSFET tornou-se um ponto crucial para a evolução do mesmo dispositivo.

A figura 1.1 apresenta esquematicamente um MOSFET de largura W e comprimento de canal L. O dispositivo é composto metal, um filme de óxido de silício e silício monocristalino na região de porta. As partes metálicas fornecem os contatos elétricos designados por S, G, D e B. O óxido de silício é chamado de dielétrico de porta. É especificamente esse material dielétrico que será o mais abordado nesta dissertação. Tradicionalmente, obtém-se esse material através de tratamento térmico do $\mathrm{Si}$ em ambiente contendo $\mathrm{O}_{2}$ ultrapuro. $\mathrm{O}$ silício utilizado como substrato apresenta regiões diferentemente dopadas que constituem a fonte, o dreno e a região do canal. 


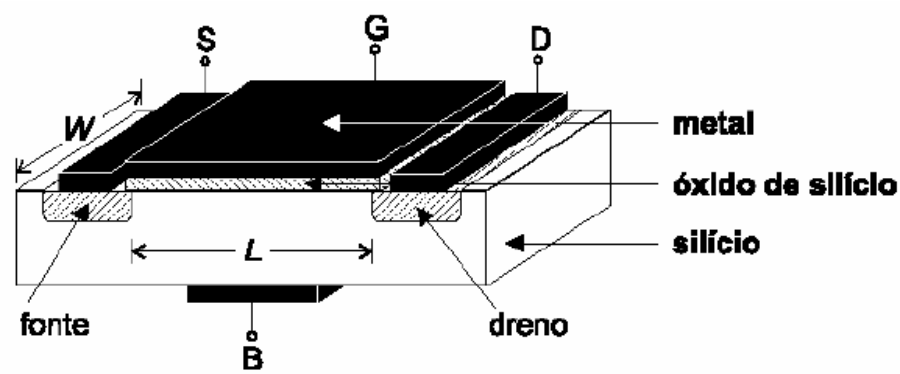

Figura 1.1 - Estrutura de um MOSFET, mostrando as dimensões características $\mathrm{W}$ e L, os contatos S, G, D e B e as regiões constituídas por: metal, óxido de silício e silício (substrato).

O MOSFET apresenta um capacitor MOS que tem como terminais um eletrodo metálico e o substrato de silício e, como dielétrico, o filme de óxido de silício. No MOSFET, o dielétrico de porta tem duas atribuições fundamentais (NICOLLIAN, 1982; FELDMAN, 2001):

1. isolamento elétrico: impedir o transporte de portadores de carga entre o eletrodo metálico e o substrato semicondutor;

2. passivação elétrica: eliminar estados eletrônicos espacialmente localizados na superfície do substrato semicondutor (isto é, na interface entre óxido de silício e silício) e energeticamente localizados no meio da banda proibida do silício.

A estrutura do MOSFET possibilitou a construção de circuitos integrados, os "Cls". Nesses circuitos, são fabricados muitos dispositivos lado a lado sobre uma única área do semicondutor (o chip). Historicamente, têm-se fabricado dispositivos cada vez menores, resultando em maior densidade nos " $\underline{\mathrm{Cls}}$ ". Essa miniaturização (scaling) tem sido um fator decisivo no aumento da funcionalidade (ou capacidade de processamento) e no barateamento de equipamentos eletrônicos (WONG, 2006). Ela se reflete na chamada "Lei de Moore" (MOORE, 1965), uma tendência observada a partir de 1965, segundo a qual o número de transistores MOS dobra a cada intervalo de 18 a 36 meses (tem variado com o passar do tempo). A tabela 1.1 (PLUMMER, 2001) 
apresenta a evolução dos parâmetros tecnológicos, onde, neste ponto, vamos atentar tão somente para a espessura do óxido.

Tabela 1.1 - Alguns parâmetros tecnológicos atuais e futuros previstos (PLUMMER, 2001).

\begin{tabular}{|c|c|c|c|c|c|c|}
\hline Ano & $\mathbf{1 9 9 9}$ & $\mathbf{2 0 0 2}$ & $\mathbf{2 0 0 5}$ & $\mathbf{2 0 0 8}$ & $\mathbf{2 0 1 1}$ & $\mathbf{2 0 1 4}$ \\
\hline $\begin{array}{c}\text { Dimensão } \\
\text { mínima (nm) }\end{array}$ & 180 & 130 & 100 & 70 & 50 & 35 \\
\hline DRAM & $1 \mathrm{G}$ & $3 \mathrm{G}$ & $\mathbf{8 G}$ & $24 \mathrm{G}$ & $64 \mathrm{G}$ & $192 \mathrm{G}$ \\
\hline $\begin{array}{c}\text { Área do chip } \\
\text { DRAM (mm }{ }^{2} \text { ) }\end{array}$ & 400 & 460 & 530 & 630 & 710 & 860 \\
\hline $\begin{array}{c}\text { Espessura } \\
\text { equivalente de } \\
\text { óxido (nm) }\end{array}$ & $2,5-1,9$ & $1,9-1,5$ & $1,5-1,0$ & $1,2-0,8$ & $0,8-0,6$ & $0,6-0,5$ \\
\hline $\begin{array}{c}\text { Res. máx. de } \\
\text { material de } \\
\text { porta }(\boldsymbol{\mu} \mathbf{\Omega} . \mathbf{c m})\end{array}$ & 60 & 43 & 33 & 23 & 16 & 11 \\
\hline $\mathbf{V}_{\mathrm{DD}}[\mathbf{V}]$ & $2,5-1,8$ & $1,8-1,5$ & $1,5-1,2$ & $1,2-0,9$ & $0,6-0,5$ & 0,5 \\
\hline
\end{tabular}

De acordo com a tabela 1.1, a miniaturização vêm sendo acompanhada pela redução na espessura do filme utilizado como dielétrico de porta - cerca de $2 \mathrm{~nm}$ em 1999 para $1 \mathrm{~nm}$ em dispositivos comerciais recentemente utilizados (ano de 2008). Tal redução em espessura é imprescindível para o funcionamento dos dispositivos miniaturizados.

Porém, para espessuras do óxido de silício abaixo de $1 \mathrm{~nm}$, a miniaturização chegará a um limite, pois o filme dielétrico ultrafino será formado por apenas uma camada. Embora numerosas dificuldades existam no que se refere à continuidade da miniaturização de MOSFETs, essa é, de acordo com diagnóstico e projeções da própria indústria microeletrônica, uma das fundamentais (SOLOMON, 2002). O limite tecnológico que se impõe à indústria microeletrônica somente será vencido com o desenvolvido científico, seja de novos filmes finos dielétricos ou dispositivos alternativos ao MOSFET.

Quanto aos dielétricos alternativos, deseja-se determinar o limite físico intrínseco de aplicação dos oxinitretos de silício (HIROSE, 2000; STATHIS, 2002; GREEN, 2001) e procurar materiais que possam substituí-lo permitindo a continuidade da miniaturização (WILK, 2001). Nesse sentido, materiais chamados high-k, tem sido muito estudados. Até o momento, contudo, não se 
demonstrou à viabilidade técnica de qualquer material high-k (ALBERTIN, 2003). Atualmente, a utilização de oxinitretos de silício é consensualmente vista como solução transitória (WONG, 2006). Nesta dissertação, apresentamos uma estrutura alternativa dielétrico/silício. Isto é, a estrutura oxinitreto de silício/silício obtida por implantação iônica de nitrogênio através de capacitor MOS.

Organizarmos esta dissertação da seguinte forma: no Capítulo 2 apresentamos as implicações da redução da espessura do $\mathrm{SiO}_{2}$, o impacto da dopagem no silício policristalino e a influência da dopagem nas características elétricas. Por último, a importância de se utilizar oxinitreto de silício por implantação iônica de nitrogênio ao longo da estrutura $\mathrm{Si}-\mathrm{poli} / \mathrm{SiO}_{2} / \mathrm{Si}$. No Capítulo 3 abordamos os procedimentos experimentais para a fabricação dos capacitores MOS com porta de Si-poli dopado com boro ou fósforo. No Capítulo 4 abordamos as caracterizações elétricas realizadas nos capacitores MOS. No Capítulo 5 apresentamos os resultados e discussão. Finalmente, no Capítulo 6, encontram-se as conclusões do trabalho e as perspectivas para trabalhos futuros. 


\section{REVISÃO BIBLIOGRÁFICA}

\subsection{Introdução}

Neste capítulo serão abordados temas associados à estrutura MOS: o tunelamento de cargas, a depleção do Si-poli, a inserção de nitrogênio ao longo da estrutura MOS e efeitos quânticos. A dificuldade em se obter filmes de $\mathrm{SiO}_{2}$ ultrafinos e a utilização de dielétricos substitutos do $\mathrm{SiO}_{2}$ são discutidos no item 2.2 .

Um efeito degradante quando se reduz à espessura do óxido de porta é o efeito de tunelamento de cargas ao longo do $\mathrm{SiO}_{2}$, que além de alterar o funcionamento normal dos dispositivos MOS, dificulta a extração dos parâmetros da curva capacitância-tensão, efeito esse tratado no item 2.3 desta dissertação.

No item 2.4 será mostrado um estudo sobre a minimização da difusão do boro para a superfície do $\mathrm{Si}$, ao se reduzir à dopagem do eletrodo de porta ou do Sipoli. A primeira implicação desta redução, conforme será visto, é que a redução da concentração de boro no Si-poli faz com que o mesmo não seja mais tratado como uma camada equipotencial. Sendo assim, tem-se a introdução de uma capacitância adicional à estrutura MOS que irá degradar a obtenção de parâmetros das curvas $\mathrm{C}-\mathrm{V}$, quando a polarização da estrutura MOS estiver na situação de depletar o Si-poli. Além do mais, reduzir a dopagem de porta acarreta o aumento do atraso "RC" das linhas de interconexão. Para tentar eliminar essas degradações, novos materiais de porta estão sendo pesquisados.

Por outro lado, a determinação elétrica da espessura fica comprometida, ou seja, uma dopagem mais baixa do eletrodo de porta (menor do que aproximadamente $10^{19} \mathrm{~cm}^{-3}$ ) torna o Si-poli mais resistivo resultando em um 
aumento da espessura equivalente do dielétrico de porta, conforme ilustra a figura 2.1.

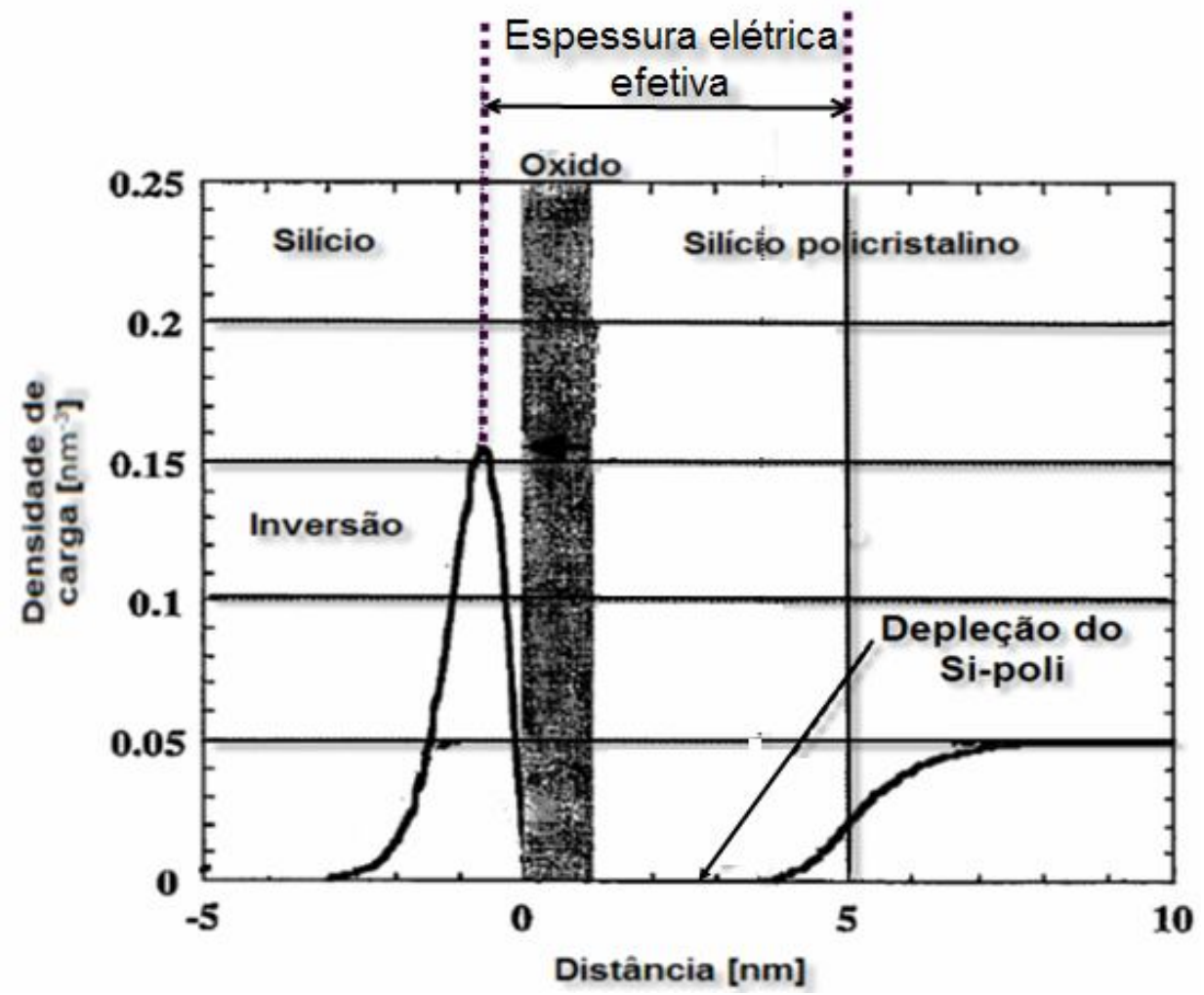

Figura 2.1 - Distribuição de cargas obtidas por cálculo de mecânica quântica em um capacitor MOS com espessura de óxido de $1 \mathrm{~nm}$ e porta de Si-poli com polarização de porta de $2 \mathrm{~V}$ na condição de depleção (PLUMMER, 2001).

No item 2.5 serão apreciadas as formas para minimizar ou eliminar os efeitos de tunelamento e da difusão de boro para o Si, através da obtenção de oxinitreto de silício obtido por implantação iônica do nitrogênio com pico próximo à interface $\mathrm{SiO}_{2} / \mathrm{Si}$, proporcionando melhoras significativas em dispositivos que utilizam à tecnologia MOS. 


\section{2 Óxido de silício ultrafino}

Em dispositivos MOSFETs, o termo "óxido de silício" como sinônimo de "dielétrico de porta", ou de "óxido de porta" é freqüentemente empregado. O $\mathrm{SiO}_{2}$ é utilizado desde 1960 como dielétrico de porta desde a fabricação do primeiro MOSFET, tornando-se o maior responsável pelo destacado papel tecnológico do Si frente a outros semicondutores (SCHULZ, 1999; KINGON, 2000). A interface entre $\mathrm{SiO}_{2}$ e Si é a interface mais conhecida que tem a qualidade exigida para a exploração comercial do MOSFET (DIMITRIJEV, 2000). As propriedades do $\mathrm{SiO}_{2}$ não apenas permitiram a fabricação original do MOSFET, mas também a sua contínua miniaturização (FELDMAN, 2001).

As propriedades do $\mathrm{SiO}_{2}$ utilizado como dielétrico de porta encontra-se resumido na tabela 2.1 (GUSEV, 2000; GREEN, 2001). O dióxido de silício, $\mathrm{SiO}_{2}$, é o único óxido estequiométrico de silício; quimicamente estável. Além disso, pode ser fabricado por processos relativamente simples; tem um elevado "gap" (largura da banda proibida) de energia, que resulta em elevadas barreiras de potencial nas interfaces $\mathrm{SiO}_{2} / \mathrm{Si}$ tanto para elétrons quanto para lacunas (figura 2.2). $\mathrm{O} \mathrm{SiO}$ também apresenta elevada resistência à ruptura dielétrica, mesmo em campos elétricos extremamente elevados. A confiabilidade dos circuitos integrados avançados depende criticamente dessas características e de outras, como uniformidade na espessura do filme de $\mathrm{SiO}_{2}$ e baixa rugosidade na interface $\mathrm{SiO}_{2} / \mathrm{Si}$ (BUCHANAN, 1996; PLUMMER, 1996; FELDMAN, 1998). Dependendo da espessura, o $\mathrm{SiO}_{2}$ também serve como barreira ou máscara de difusão e é resistente a ataques químicos, qualidade essas essenciais para passivação de superfícies (ALBERTIN, 2003). 
Tabela 2.1 - Propriedades selecionadas de filmes finos de óxido de silício utilizados como dielétricos de porta (GREEN, 2001).

\begin{tabular}{|c|c|}
\hline Densidade de defeitos na interface $\mathrm{Si} / \mathrm{SiO}_{2}$ & $\begin{array}{c}\sim 10^{10} \mathrm{eV}^{-1} \mathrm{~cm}^{-2} \text { [após recozimento em ambiente } \\
\left.\mathrm{H}_{2}: \mathrm{N}_{2}\right]\end{array}$ \\
\hline $\begin{array}{c}\text { Densidade de cargas devido a impurezas } \\
\text { e defeitos }\end{array}$ & $\sim 10^{10} \mathrm{~cm}^{-2}$ \\
\hline Gap de energia & $8,9 \mathrm{eV}$ \\
\hline Resistividade & $\sim 10^{15} \Omega . \mathrm{cm}$ \\
\hline Rigidez dielétrica & $10 \mathrm{MV} / \mathrm{cm}$ \\
\hline Constante dielétrica & 3,9 \\
\hline
\end{tabular}

A estrutura $\mathrm{SiO}_{2} / \mathrm{Si}$ tem sido amplamente estudada no âmbito da microeletrônica devido ao fato do silício formar um óxido estável na presença de $\mathrm{O}_{2}$. Um dos primeiros trabalhos nesta área foi uma descrição fenomenológica da cinética da oxidação (DEAL, 1965) - um trabalho hoje com inúmeras citações (> 1300) onde o livro "MOS (Metal Oxxide $\underline{\text { Semiconductor) }}$ Physics and Technology" de Edward H. Nicollian e John R. Brews é um dos conhecidos na atualidade.

Além disso, foi dedicado muito trabalho à compreensão, em escala atômica, do mecanismo de oxidação térmica do silício em $\mathrm{O}_{2}-0$ processo que produz interfaces $\mathrm{SiO}_{2} / \mathrm{Si}$ com as melhores propriedades elétricas (DEAL, 1965). O modelo de Deal e Grove descreve a cinética de oxidação do silício baseado na relação da espessura do filme crescido em função das variáveis de processamento como: tempo, temperatura e pressão parcial de $\mathrm{O}_{2}$. Com base nessa compreensão, foi possível modificar os processos industriais a fim de obter estruturas $\mathrm{SiO}_{2} / \mathrm{Si}$ com propriedades elétricas ainda melhores. 


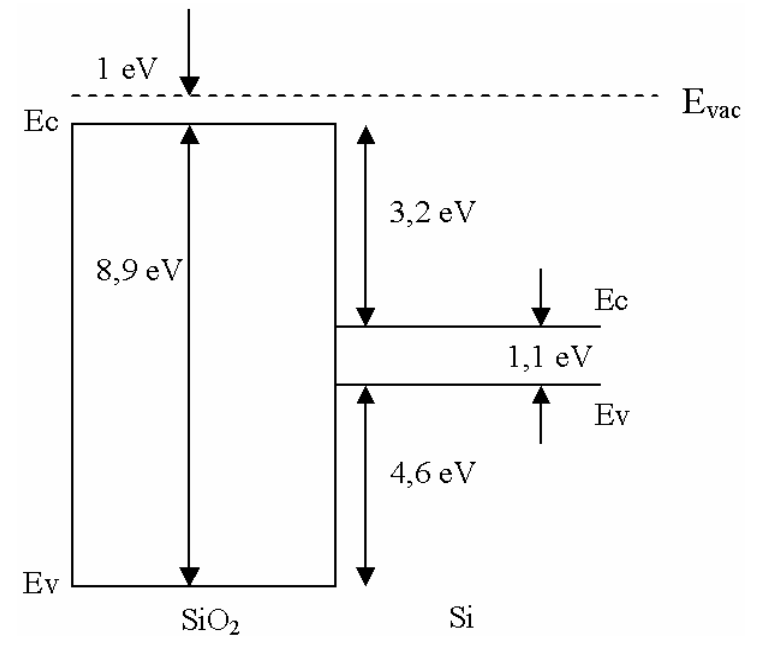

Figura 2.2 - Diagrama de bandas para o sistema $\mathrm{Si} / \mathrm{SiO}_{2}$. Note a diferença dos valores da barreira de energia para elétrons $(3,2 \mathrm{eV})$ e lacunas $(4,6 \mathrm{eV})$ (ROBERTSON, 2002; WONG, 2006).

As reduções das dimensões dos transistores conduzem à minimização das capacitâncias parasitárias promovendo $\mathrm{o}$ aumento da velocidade de chaveamento ou "clock" dos microprocessadores atuais e, além disso, possibilita um maior número de transistores por lâmina (tabela 2.2) (INTEL CORP., 21/05/2008). Conforme prediz a lei de Moore, para o ano de 2009, espessuras equivalentes de 0,8 nm para o dielétrico de porta serão necessárias (veja figura 2.3 e tabela 1.1). 
Tabela 2.2 - Evolução da velocidade de processamento e da escala de integração dos microprocessadores da Intel ${ }^{\Theta}$ (INTEL CORP., 21/05/2008).

\begin{tabular}{|c|c|c|c|}
\hline Processadores & $\begin{array}{c}\text { Velocidade } \\
\text { de Clock } \\
\text { [GHz] }\end{array}$ & $\begin{array}{c}\text { Data de } \\
\text { lançamento }\end{array}$ & $\begin{array}{l}\text { Número de } \\
\text { transistores } \\
\text { (milhões) }\end{array}$ \\
\hline $\begin{array}{l}\text { Intel }^{\oplus} \text { Itanium }^{\oplus} \\
2 \text { Processor }\end{array}$ & 0,8 & Maio/2001 & 25 \\
\hline $\begin{array}{l}\text { Intel }{ }^{\oplus} \text { Itanium }{ }^{\oplus} 4 \\
\text { Processor } M\end{array}$ & 1,4 & Março/2002 & 55 \\
\hline $\begin{array}{c}\text { Intel }^{\oplus} \text { Pentium } \\
\text { M Processor }\end{array}$ & 1,7 & Março/2003 & 77 \\
\hline $\begin{array}{c}\text { Intel }^{\circledast} \text { Pentium } \\
\text { M Processor } \\
\end{array}$ & 2,0 & Janeiro/2005 & 140 \\
\hline Intel ${ }^{\oplus}$ Core $^{\text {TMI }}$ Duo Processor & 2,16 & Janeiro /2006 & 152 \\
\hline Intel $^{\Theta}$ Core $^{T M} 2$ Duo Processor E6400 & 2,2 & Abril/2007 & 167 \\
\hline Intel ${ }^{\Theta}$ Core $^{T M} 2$ Duo Processor E6850 & 2,33 & Julho/2007 & 291 \\
\hline $\begin{array}{c}\text { Intel }^{\circledR} \text { Core }^{T M} 2 \text { Extreme Processor } \\
Q \times 6700\end{array}$ & 2,66 & Novembro/2007 & 582 \\
\hline $\begin{array}{c}\text { Intel }{ }^{\Theta} \text { Core }^{T M} 2 \text { Quad } \\
\text { Processor Q9550 }\end{array}$ & 2,83 & Janeiro/2008 & 820 \\
\hline
\end{tabular}

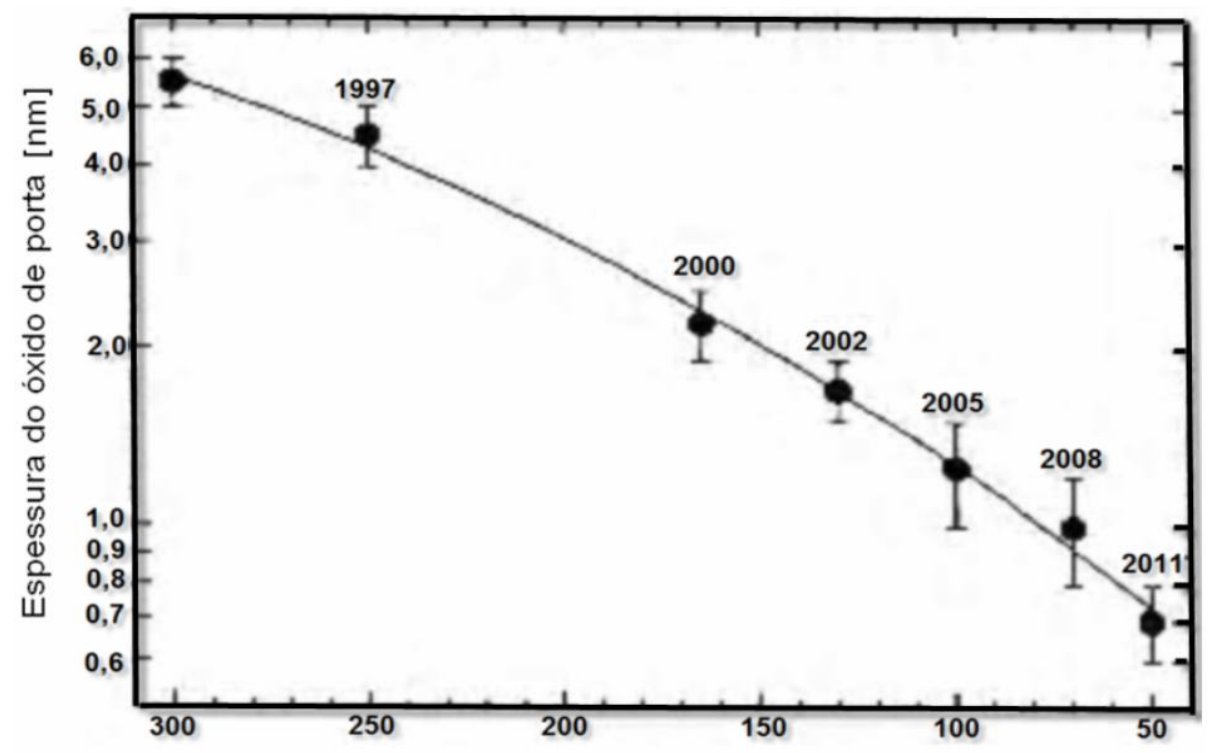

Comprimento·de $\cdot$ canal'na·tecnologia $\cdot \mathrm{CMOS} \cdot[\mathrm{nm}]$

Figura 2.3 - Tendência da redução da espessura do $\mathrm{SiO}_{2}$ com a redução no comprimento de canal da tecnologia CMOS ao longo dos anos (GREEN, 2001). 
É importante destacar que o modelo de Deal e Grove (1965) não se aplica para espessuras muito finas $(<20 \mathrm{~nm})$. Nesse modelo, observa-se a difusão intersticial de $\mathrm{O}_{2}$ (oxigênio molecular) na matriz do óxido em crescimento e uma reação com o Si numa interface $\mathrm{SiO}_{2} / \mathrm{Si}$ abrupta. Deste modo, obtém-se analiticamente uma lei de crescimento que relaciona a espessura do óxido versus tempo de oxidação, apresentando um comportamento linear e/ou parabólico. Esta imposição só é valida se ocorrer à igualdade de fluxos de $\mathrm{O}_{2}$ nas interfaces $\mathrm{O}_{2} / \mathrm{SiO}_{2}$ e $\mathrm{SiO}_{2} / \mathrm{Si}$, que chamamos de estado estacionário. Observa-se que o estado estacionário só ocorre para espessuras de óxido acima de $20 \mathrm{~nm}$ (DEAL, 1965).

Para pequenas espessuras de óxido, existe um modelo chamado "regime de crescimento anômalo". Esse modelo proposto por STONEHAM (1987) também chamado de "modelo da camada reativa" supõe que a interface $\mathrm{SiO}_{2} / \mathrm{Si}$ nos estágios iniciais do crescimento contém, majoritariamente, silício não completamente oxidado onde o $\mathrm{SiO}_{2}$ cresce no limite entre o $\mathrm{SiO}_{2}$ e a camada reativa, por reação entre moléculas de oxigênio difundindo a partir da fase gasosa e átomos de silício injetados a partir do substrato de silício. KAGESHIMA (1999) divulgou um modelo que considera a possibilidade de difusão de átomos de $\mathrm{Si}$ desde o substrato até a superfície do óxido em crescimento, porém não foi confirmado experimentalmente, embora confirmado em simulações de dinâmica molecular (PASQUARELLO, 1998).

A modelagem dos estágios inicias do crescimento térmico de filmes de $\mathrm{SiO}_{2}$ (com pequena espessura) é crítica. Determinar qual a espécie oxidante que se difunde no óxido em crescimento, ou seja, se é oxigênio molecular $\left(\mathrm{O}_{2}\right)$ ou atômico (O) (AKERMARK, 2000; HAMANN 1998) é de difícil comprovação experimental. Tem sido proposto que também o $\mathrm{Si}$ difunde no $\mathrm{SiO}_{2}$ por meio de substituição isotópica.

Há apenas um experimento prévio que aplica a substituição isotópica do $\mathrm{Si}$ ao estudo da mobilidade durante a oxidação (PRETORIUS, 1980). Esse trabalho indicou que o Si não se difunde através do dielétrico. Isso, porém, não exclui a 
possibilidade de transporte do $\mathrm{Si}$ de curto alcance do substrato para a interface $\mathrm{SiO}_{2} / \mathrm{Si}$, nos modelos de STONEHAM (1987) que, propõe que átomos de $\mathrm{Si}$ do substrato difundem (ou são injetados) através de distâncias muito curtas, tipicamente de 1 a $2 \mathrm{~nm}$.

Um outro obstáculo para dielétricos ultrafinos, menores que $1,5 \mathrm{~nm}$, é o efeito de tunelamento quântico direto (THOMPSON, 1998; FRANK, 2001; GREEN, 2001) que pode ser apreciável promovendo o aumento da geração de falhas próximo à interface $\mathrm{Si} / \mathrm{SiO}_{2}$ reduzindo a confiabilidade do dispositivo (MIAN, 1999). Mesmo assim, a mecânica quântica determina que a espessura crítica dos filmes de $\mathrm{SiO}_{x} \mathrm{~N}_{\mathrm{y}}$ tende a $0,7 \mathrm{~nm}$ (figura 2.4) o que também esta próximo das "dimensões" das ligações químicas do óxido (WONG, 2006) (figura 2.5), onde as "funções de onda" da porta e do substrato se superpõem, determinando um curto circuito através do dielétrico, tornando-o inútil como isolante (MULLER, 1999). 


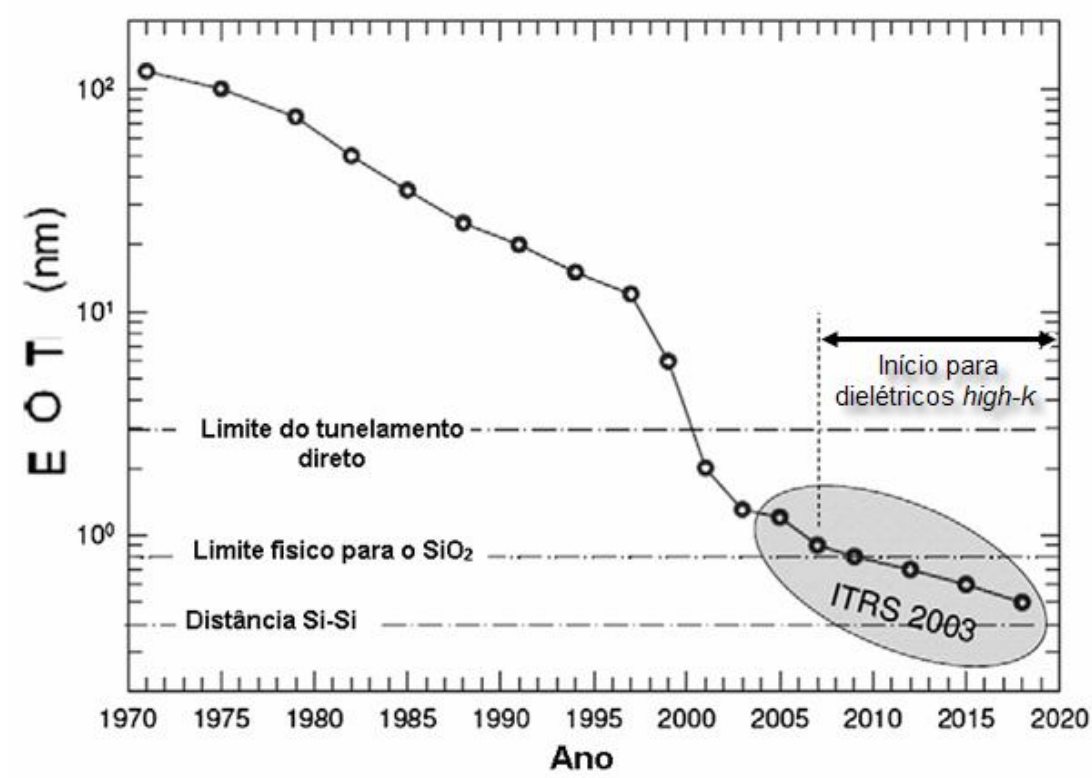

Figura 2.4 - Projeção para a espessura elétrica equivalente do dielétrico de porta (EOT), apresentando os limites da modelagem da corrente de tunelamento $(\sim 2 \mathrm{~nm})$ e do próprio limite físico estabelecido pelas dimensões de suas ligações físicas Si-O (WONG, 2006).

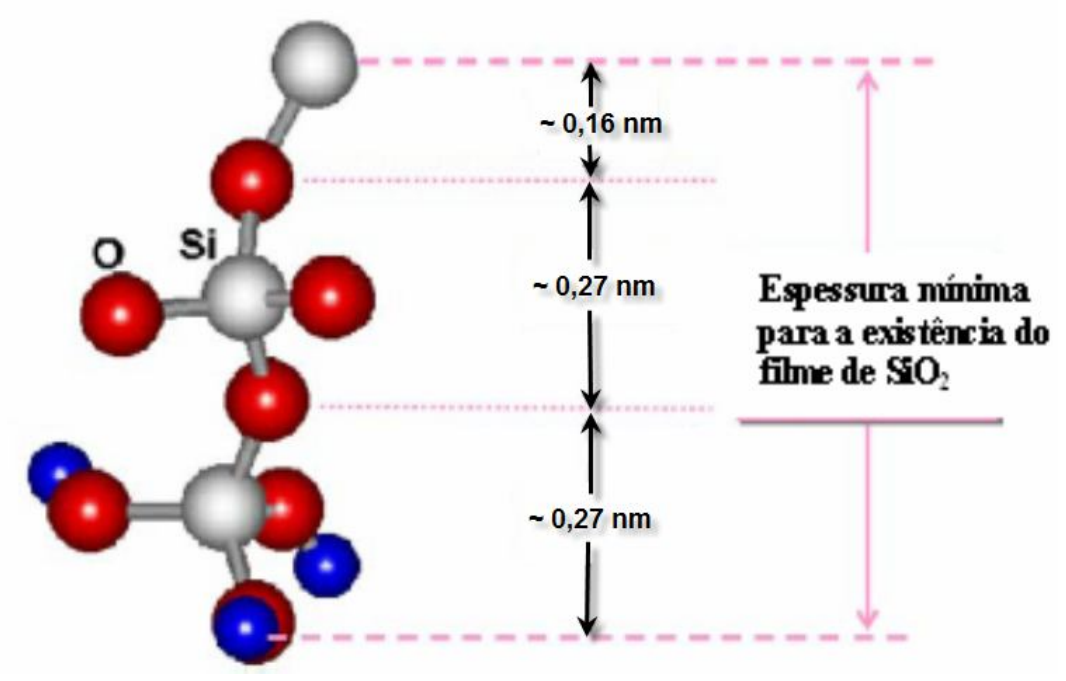

Figura 2.5 - Ligação química da estrutura $\mathrm{SiO}_{2}$ apresentando a espessura mínima do filme (WONG, 2006). 
Uma das soluções no futuro é a substituição do $\mathrm{SiO}_{2}$ como dielétrico. Porém, esse "novo" dielétrico deve possuir características, no mínimo, iguais em termos de interface, estabilidade termodinâmica e deve ser melhor no que se refere ao tunelamento de cargas, conseguida quando se aumenta a constante dielétrica $(k)$ (WU, 1999). Nessa corrida frenética, vários materiais vêm sendo investigados (WONG, 2006; ALBERTIN, 2003) conforme apresentado na figura 2.6: os óxidos binários de $\mathrm{Al}_{2} \mathrm{O}_{3}$ (óxido de alumínio, $k=8$ - 10); $\mathrm{La}_{2} \mathrm{O}_{3}$ (óxido de lantânio, $k=30$ ); $\mathrm{Ta}_{2} \mathrm{O}_{5}$ (óxido de tântalo, $k=25$ ); $\mathrm{TiO}_{2}$ (óxido de titânio, $k=80$ ); $\mathrm{HfO}_{2}$ (óxido de háfnio, $k \sim 25$ ); $\mathrm{Y}_{2} \mathrm{O}_{3}$ (óxido de ítrio, $k \sim 15$ ) e $\mathrm{Si}_{3} \mathrm{~N}_{4}$ (nitreto de silício, $k=7$ ).

Dos dielétricos apresentados anteriormente, alguns dos mais pesquisados são compostos de $\mathrm{HfO}_{2}, \mathrm{Al}_{2} \mathrm{O}_{3}, \mathrm{Y}_{2} \mathrm{O}_{3}$ e $\mathrm{La}_{2} \mathrm{O}_{3}$. Porém, eles possuem características de interface pobres, com valores medidos de densidade de estados de interface $\left(D_{\text {it }}\right)$ iguais ou superiores a $10^{12} \mathrm{eV}^{-1} \mathrm{~cm}^{-2}$. Com relação ao $\mathrm{Al}_{2} \mathrm{O}_{3}$, embora apresente um alto "gap" (largura energética da faixa proibida) em relação ao $\mathrm{SiO}_{2}$, a inviabilidade do material está na alta difusão de fósforo ou de boro ao longo de sua estrutura (ALBERTIN, 2003). 


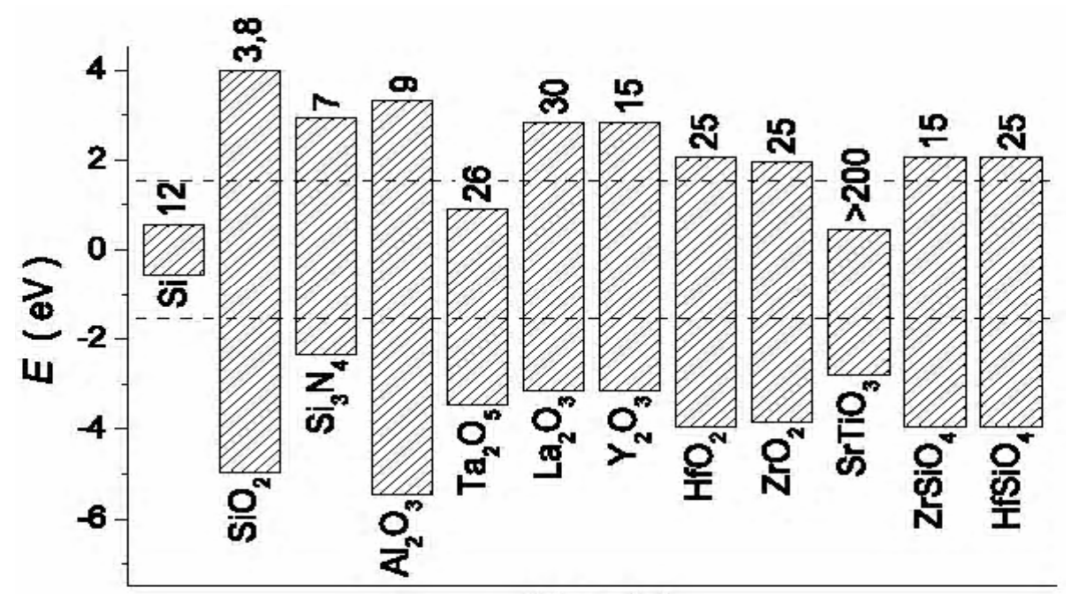

Material

Figura 2.6 - Diferentes dielétricos de porta MOS, onde são apresentados o "gap" de energia e o alinhamento das bandas de energia em relação ao $\mathrm{Si}$. As constantes dielétricas são apresentadas nos topos das barras (WONG, 2002).

Dos dielétricos indicados na figura 2.6, alguns são termodinamicamente instáveis em processos de recozimento, aparecendo outras fases dentro do material, como acontece no $\mathrm{SrTiO}_{3}$ onde silicetos $\mathrm{Ti}_{\mathrm{x}} \mathrm{Si}_{\mathrm{y}}$ podem ocorrer. Os demais, óxidos de háfnio $\left(\mathrm{HfO}_{2}\right)$ e de zircônio $\left(\mathrm{ZrO}_{2}\right)$, apesar de apresentarem alta constante dielétrica quando comparado ao $\mathrm{Si}_{3} \mathrm{~N}_{4}$ a ao $\mathrm{Al}_{2} \mathrm{O}_{3}$ (figura 2.8) e larga banda proibida ( 5,7 eV), apresentam características de interface piores que o $\mathrm{SiO}_{2}\left(\mathrm{D}_{\mathrm{it}}>1.10^{12} \mathrm{eV}^{-1} \cdot \mathrm{cm}^{-2}\right)$ (WONG, 2006). Além disso, sob tratamento térmico formam filmes policristalino, sendo que esta organização estrutural acaba resultando em alta corrente de fuga nos entorno dos grãos e constante dielétrica " $k$ " que varia ao longo do filme (WILK, 2001).

O $\mathrm{Si}_{3} \mathrm{~N}_{4}$ é excelente como barreira à umidade, íons alcalinos e especialmente contra a difusão de boro. Apresenta $k=7$ e pode ser utilizado como máscara de difusão e camada passivante. Porém, um parâmetro desfavorável é o alto valor de $D_{\text {it }}\left(\sim 10^{12} \mathrm{eV}^{-1} \mathrm{~cm}^{-2}\right)$. Dependendo da técnica a ser utilizada para a formação do $\mathrm{Si}_{3} \mathrm{~N}_{4}$, altas concentrações de $\mathrm{N}_{2}$ promovem 0 efeito de empilhamento de nitrogênio na superfície do Si, piorando as características elétricas notáveis (redução substancial do valor), como a mobilidade, transcondutância, do tempo de vida dos portadores minoritários, etc (MIAN, 1999; YAO, 1994; LUCOVSKY, 1999; HERDEN, 2001). 
Desses materiais pesquisados, o filme de $\mathrm{SiO}_{x} \mathrm{~N}_{y}$ é o que ainda apresenta viabilidade técnica, por atuar como barreira contra a difusão do boro e possuir ótimas características nas interfaces $\mathrm{Si}-$ poli $/ \mathrm{SiO} \mathrm{N}_{\mathrm{N}} / \mathrm{SiO}_{2}$ e $\mathrm{SiO}_{2} / \mathrm{SiO}_{x} \mathrm{~N}_{y} / \mathrm{Si}$ (WU, 1999; MANERA, 2004). A formação de filmes de $\mathrm{SiO}_{x} \mathrm{~N}_{\mathrm{y}}$ se dá pelo incremento das concentrações de nitrogênio nas interfaces de modo que " $k$ " acaba ficando maior que 3,9 e menor que 7 .

Dentre as possíveis técnicas utilizadas para a formação do filme de $\mathrm{SiO}_{x} \mathrm{~N}_{\mathrm{y}}$, a técnica eleita para a realização deste trabalho foi a implantação iônica de nitrogênio iônico $\left(\mathrm{N}^{+}\right)$na interface $\mathrm{SiO}_{2} / \mathrm{Si}$, após a formação da estrutura $\mathrm{Si}-$ poli $/ \mathrm{SiO}_{2} / \mathrm{Si}$. Este tipo de estrutura tem dupla vantagem: possibilitar a implantação com a estrutura já encapsulada com Si-poli e possibilitar um preciso controle da concentração e distribuição de nitrogênio ao longo da interface $\mathrm{SiO}_{2} / \mathrm{Si}$ (HERDEN, 2001). 


\subsection{Corrente de tunelamento}

Existe uma teoria de condução eletrônica para o $\mathrm{SiO}_{x} \mathrm{~N}_{\mathrm{y}}$ com espessuras em torno de $15 \mathrm{~nm}$ a qual propõe um enriquecimento de elétrons armadilhados ao longo do dielétrico. Ainda está em estudo uma modelagem para o tunelamento de $\mathrm{SiO}_{x} \mathrm{~N}_{\mathrm{y}}$ com espessuras abaixo de $3 \mathrm{~nm}$ onde a probabilidade de tunelamento através do dielétrico é muito alta. A proposta de modelagem reportada por Nguyen (1993) para dielétricos de $\mathrm{SiO}_{x} \mathrm{~N}_{\mathrm{y}}$ mostra que pode ocorrer tunelamento direto através das armadilhas localizadas próximo ao meio da banda proibida, onde se observa uma alta densidade das mesmas (figura 2.7). A condução em dielétricos de $\mathrm{SiO}_{x} \mathrm{~N}_{y}$ para espessuras abaixo de $5 \mathrm{~nm}$ é similar à condução através de $\mathrm{SiO}_{2}$ com o dobro da espessura (NGUYEN, 1993).

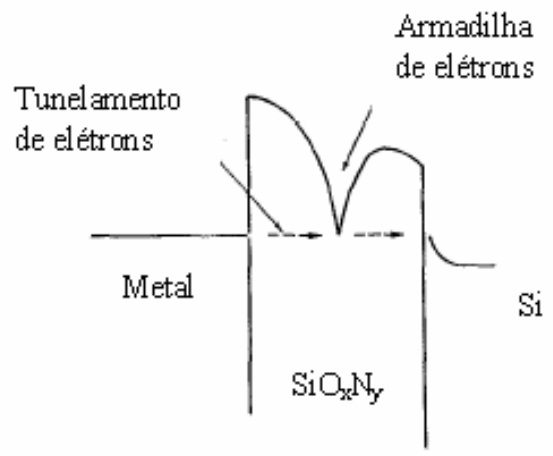

Figura 2.7 - Proposta de um modelo para o mecanismo de tunelamento em filmes de oxinitreto ultrafino (NGUYEN, 1993).

Sabendo que, no máximo, formam-se 3 monocamadas de $\mathrm{SiO}_{x} \mathrm{~N}_{\mathrm{y}}$ pela implantação iônica de nitrogênio com dose de $5.10^{15}$ at $/ \mathrm{cm}^{2}$ em $\mathrm{SiO}_{2}$ ultrafinos (<3 nm) (HERDEN, 2001), com base nesse estudo, pode-se considerar o dielétrico (em primeira aproximação) como "puramente" constituído de $\mathrm{SiO}_{2}$ nas análises dos mecanismos de condução em óxidos ultrafinos. 
Para óxidos com espessuras maiores que cerca de $5 \mathrm{~nm}$, a corrente de fuga pode ser modelada pelo tunelamento de elétrons através da barreira de energia com formato triangular (Modelo de Fowler Nordheim, figura 2.8.a). Óxidos mais finos exibem o mecanismo de tunelamento direto, pois possuem energia suficiente para atravessar a fina barreira trapezoidal (figura 2.8.b), passando direto através da banda proibida do óxido (SCHUEGRAF, 1994, DEPAS, 1995). A altura da barreira de energia triangular é a diferença de potencial "qVo" que é maior que o potencial de tunelamento $\left(\Phi_{\mathrm{T}}\right)$. A altura da barreira de energia trapezoidal apresenta " $q V_{\text {ox }}$ " menor que $\Phi_{\mathrm{T}}$. Salientamos também que o tunelamento ocorre para qualquer sentido das polarizações aplicadas ao capacitor MOS.

A figura 2.8 reporta o efeito de tunelamento, para situações de inversão do substrato e depleção do Si-poli. O tunelamento poderia ocorrer (até em maiores magnitudes) para as situações de acumulação do substrato e sem o efeito de depleção do Si-poli, mesmo porque, o efeito de depleção do Si-poli suaviza a corrente de tunelamento, ao ser encarada como um prolongamento do óxido de porta (LEE, 2001; RODRIGUES, 2006). 


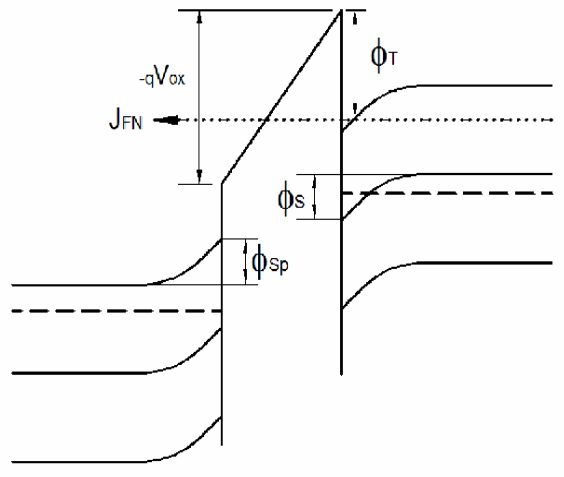

(a)

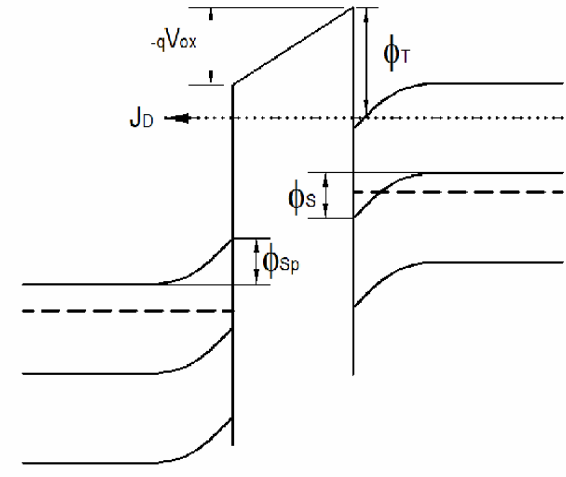

(b)

Figura 2.8 - Tipos de tunelamento: a) densidade de corrente de tunelamento Fowler Nordheim $\left(\mathrm{J}_{\mathrm{FN}}\right)$; b) densidade de corrente tunelamento direto $\left(\mathrm{J}_{\mathrm{D}}\right)$ associado à barreira trapezoidal de energia para uma estrutura Si-poli $\mathrm{N}^{+} / \mathrm{SiO}_{2} / \mathrm{Si}$-p (RODRIGUES, 2006).

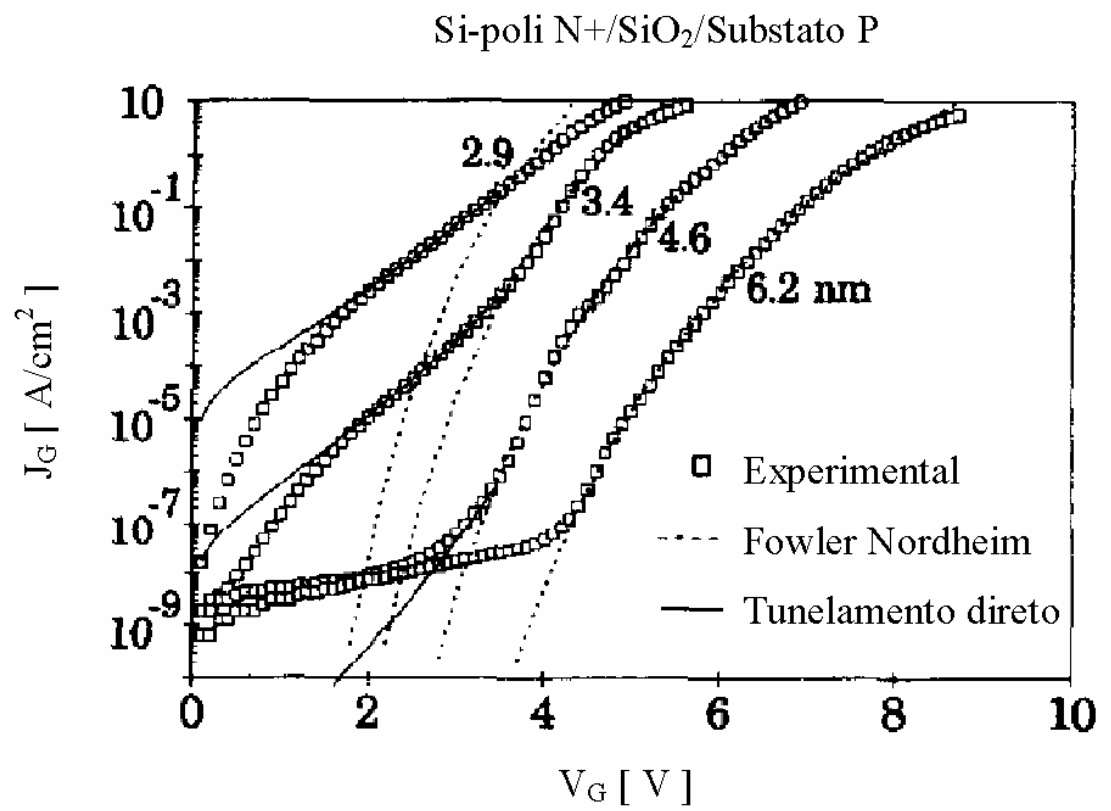

Figura 2.9 - Curvas da densidade de corrente de tunelamento $\left(\mathrm{J}_{\mathrm{G}}\right)$ em função da tensão aplicada à porta $\left(\mathrm{V}_{\mathrm{G}}\right)$ para $\mathrm{t}_{\mathrm{ox}}$ variando de $2,9 \mathrm{a}$ 6,2 $\mathrm{nm}$ (DEPAS, 1995).

Na figura 2.9 são apresentadas algumas curvas de densidade da corrente de tunelamento $\left(\mathrm{J}_{\mathrm{G}}\right)$ em função da tensão aplicada à porta $\left(\mathrm{V}_{\mathrm{G}}\right)$, para uma estrutura Si-poli $\mathrm{N}^{+} / \mathrm{SiO}_{2} / \mathrm{Si}$-p. Pode-se observar que quanto menor for à 
espessura do $\mathrm{SiO}_{2}\left(\mathrm{t}_{\mathrm{ox}}\right)$ e quanto menor for à tensão " $\mathrm{V}_{\mathrm{G}}$ " aplicada, maior é a componente da corrente de tunelamento direto (GHIBAUDO, 2000; DEPAS, 1995).

Um primeiro efeito do tunelamento nas curvas capacitância-tensão em alta freqüência $\left(C-V_{A F}\right)$ é que a capacitância do $\mathrm{Si}\left(C_{S}\right)$ que diminui, já que os portadores minoritários da banda de condução do Si-p eliminados de sua superfície, faz com que os portadores majoritários respondam ao sinal " $\mathrm{V}_{\mathrm{G}}$ ", aumentando a largura da região de depleção e o potencial de superfície " $\Psi_{\mathrm{S}}$ " e, por conseguinte, reduz o valor de $C_{S}$, conforme sugere as equações 2.1 e 2.2. Na curva $C-V_{A F}$ apresentada na figura 2.10(a) pode-se observar o efeito de tunelamento em uma estrutura $\mathrm{Al} / \mathrm{SiO}_{2} / \mathrm{Si}$. Já na curva $\mathrm{C}-\mathrm{V}$ de baixa freqüência $\left(\mathrm{C}-\mathrm{V}_{\mathrm{BF}}\right)$ ocorre uma redução da capacitância total $\left(\mathrm{C}_{\mathrm{T}}\right)$ da associação $\mathrm{Al} / \mathrm{SiO}_{2} / \mathrm{Si}$, já que a capacitância de inversão na superfície do Si não tenderá mais ao infinito, o que fará com que a capacitância resultante seja menor que a capacitância do $\mathrm{SiO}_{2}\left(\mathrm{C}_{\mathrm{ox}}\right)$, figura 2.10(b).

Para dielétricos de $\mathrm{SiO}_{\mathrm{x}} \mathrm{N}_{\mathrm{y}}$ observa-se um comportamento análogo ao mecanismo de tunelamento visto para o $\mathrm{SiO}_{2}$ (figura 2.11), porém, no oxinitreto, com fuga iniciando para maiores polarizações de porta $\left(\mathrm{V}_{\mathrm{G}}\right)$.

$$
\begin{aligned}
& W=\sqrt{\frac{2 \cdot \varepsilon_{S i} \cdot \varepsilon_{o} \cdot \psi_{S}}{q N_{A}}} \\
& C_{S}=\frac{\varepsilon_{S} \cdot \varepsilon_{o}}{W}
\end{aligned}
$$




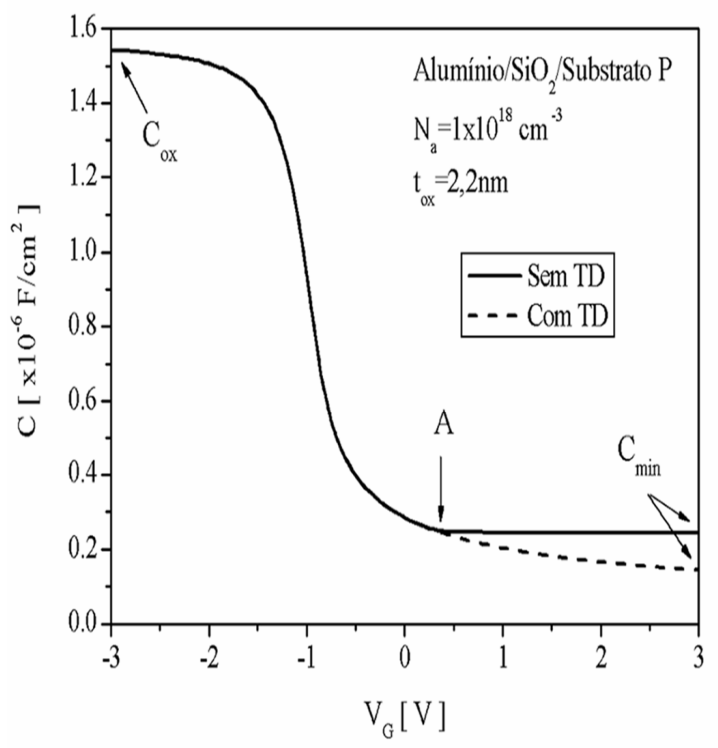

a)

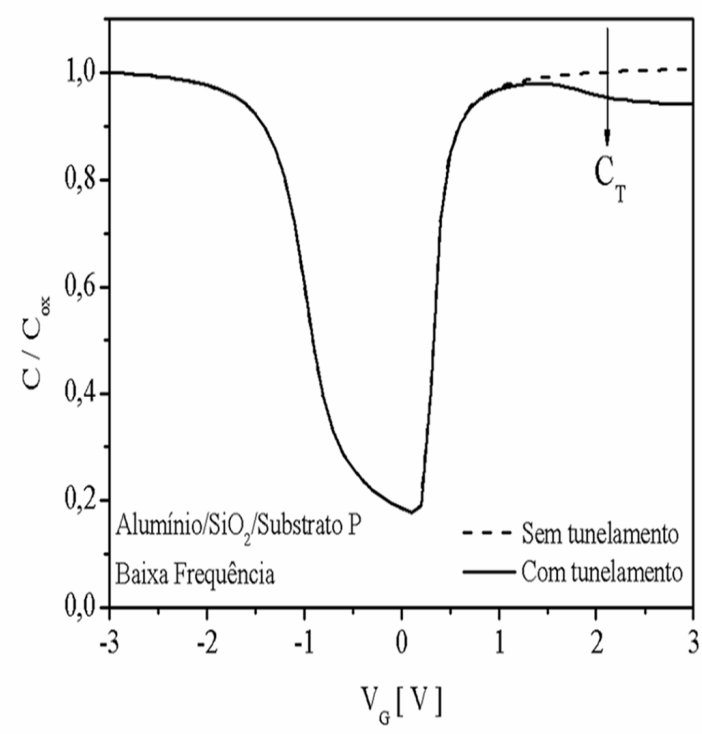

b)

Figura 2.10 - Curvas $C-V_{A F}$ (a) e $C-V_{B F}$ (b) normalizada em função de $C_{o x}$, demonstrando a influência da corrente de tunelamento (RODRIGUES, 2006).

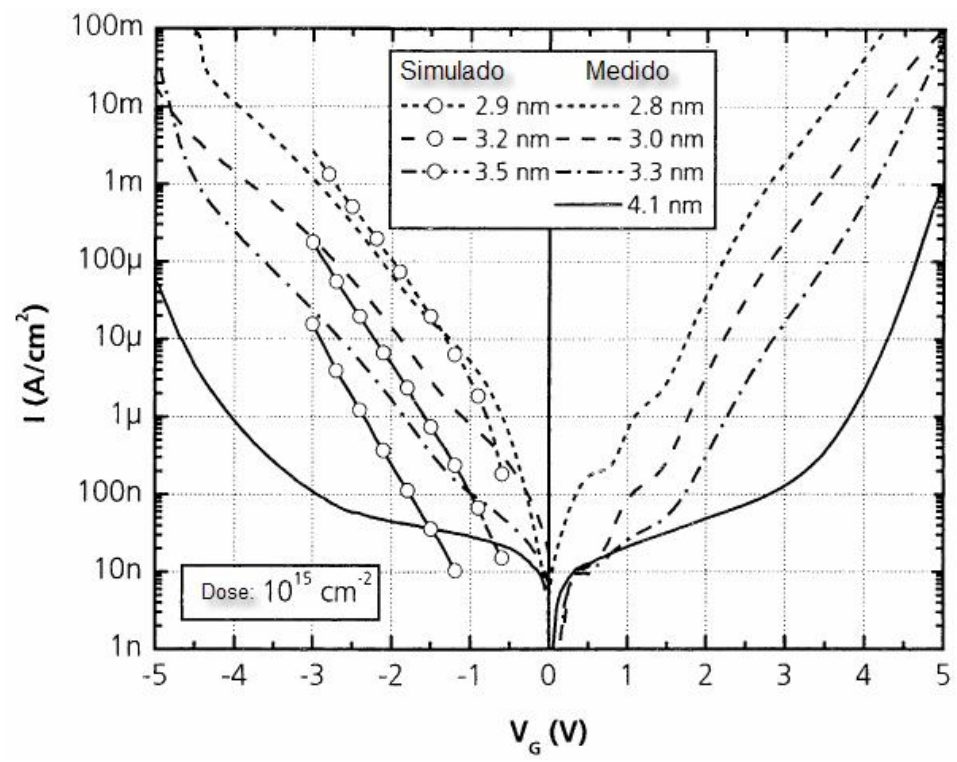

Figura 2.11 - Característica I-V para capacitores MOS com a estrutura Si-poli $\mathrm{P}^{+} / \mathrm{SiO}_{2} / \mathrm{Si}$-n com oxinitreto de $\mathrm{Si}$ e dose de implantação de nitrogênio de $5.10^{15}$ at. $^{-2}$ para diferentes espessuras de óxido de porta (HERDEN, 2001). 


\subsection{Silício policristalino}

O silício policristalino (Si-poli) é empregado industrialmente desde a década de 70 na área de microeletrônica (KAMIS, 1998; PEDRINE, 1993). Em sua aplicação na estrutura MOS, existe a possibilidade de alteração das características físicas e/ou elétricas através das formas de deposição, das condições de crescimento e por processos de dopagem dos filmes obtidos. A dopagem pode ser feita durante o crescimento do filme (in-situ) por difusão, ou, após o filme já crescido, através dos processos de difusão ou implantação iônica. A implantação iônica $\left(1 / l_{0}\right)$ produz um melhor controle sobre o perfil e quantidade de dopantes inseridos no filme.

O Si-poli começou a ser extensivamente utilizado como porta das estruturas MOS devido às inúmeras vantagens sobre o Al, conforme listado a seguir:

1. Forma-se $\mathrm{Al}_{2} \mathrm{O}_{3}$ na interface $\mathrm{Al} / \mathrm{SiO}_{2}$ durante a etapa de sinterização. Este novo óxido altera as características do dispositivo em termos da tensão de limiar $\left(V_{T}\right)$ e campo elétrico de ruptura $\left(E_{B R}\right)$, reduzindo a durabilidade do transistor em até quatro ordens de grandeza (SMITH, 1999).

2. O Al quanto submetido a certas receitas de recozimento, pode dissolver o óxido de porta. Por outro lado, o Si é solúvel em Al na porcentagem de $0.5 \%$ a temperaturas de $450{ }^{\circ} \mathrm{C}$, provocando uma difusão do $\mathrm{Si}$, proveniente do substrato, para dentro do eletrodo de Al. Como resultado, perde-se uma quantidade significativa de Si para o $\mathrm{Al}$ formando buracos no substrato que serão preenchidos pelo Al. Esta penetração do Al no substrato não ocorre uniformemente o que pode acarretar a formação de cunhas (spikes) na região de fonte/dreno, como mostrado na figura 2.12 (PLUMMER, 2000). 


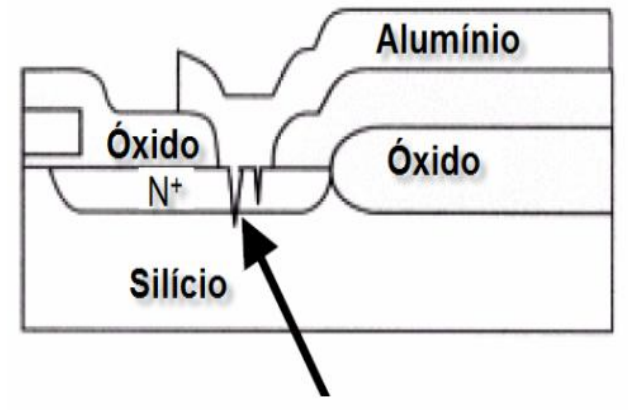

Spike com curto

a)

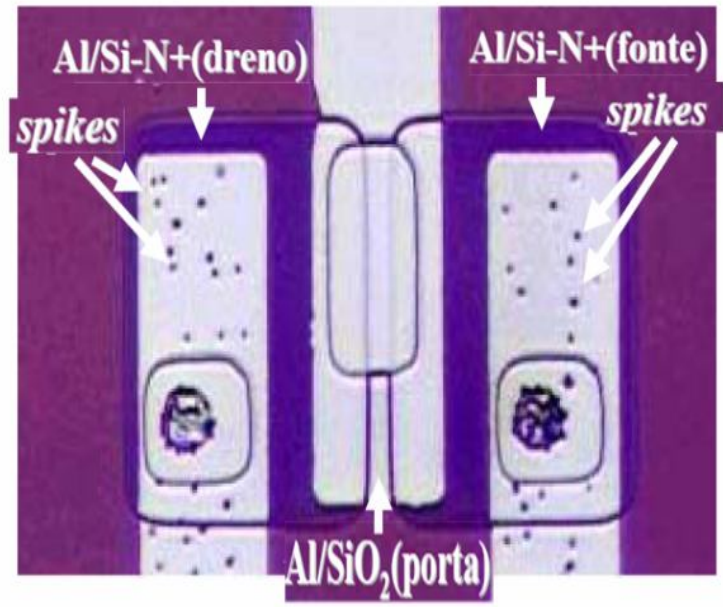

b)

Figura 2.12 - a) Formação de spikes com curto em contatos Al/Si, b) Vista de cima de um transistor nMOSFET mostrando a formação de spikes sobre fonte e dreno (PLUMMER, 2000).

3. O uso de Si-poli permite obter estruturas auto-alinhadas (veja figura 2.15), reduzindo a capacitância parasitária no transistor MOS (FERREIRA, 1987; KAMIS, 1998; MANERA, 2004). Desta forma, a área de porta é definida antes da difusão de fonte e dreno. Com isso, deficiências de alinhamento são minimizadas, o número de máscaras é reduzido e a fabricação do dispositivo fica mais barata. Por outro lado, as regiões dopadas são submetidas a uma menor quantidade de processos térmicos favorecendo junções mais rasas, resultando em um melhor desempenho dos dispositivos. Além disso, a fabricação de dispositivos na forma mais alinhada também possibilita um aumento no grau de integração dos dispositivos (MANERA, 2004), conforme sugere a figura 2.13 . 


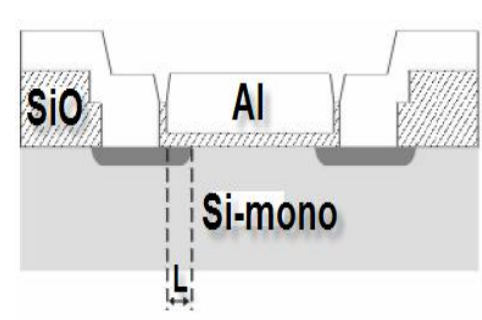

(a)

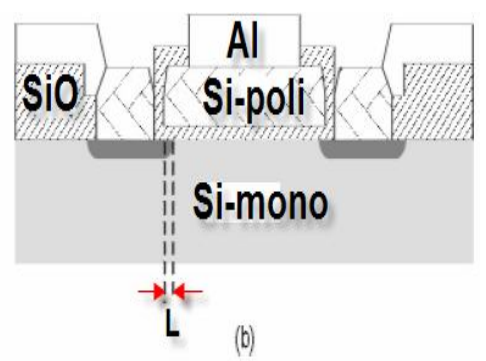

Figura 2.13 - Estrutura auto-alinhada com Si-poli. (a) A região de sobreposição (L) responsável pela capacitância parasitária é muito maior (b) no transistor de Al do que no de Si-poli (TEIXERA, 2001).

Desvantagens do Si-poli:

1. O Si-poli apresenta uma alta resistividade comparada ao Al, mesmo estando altamente dopado (KAMIS, 1998).

2. O Si-poli sobre óxidos finos são sensíveis à concentração de dopantes perto da interface Si-poli/ $\mathrm{SiO}_{2}$. Sob certas condições de polarização, ocorre o efeito de depleção do Si-poli, degradando a curva característica dos capacitores MOS e a transcondutância dos transistores (LU, 1989). Para minimizar o efeito de depleção do Si-poli, este pode ser substituído por silicetos ou intercalado com outros materiais (XUAN, 2003; SHIMADA, 1995, LU, 2000). 


\subsubsection{Comportamento elétrico do silício policristalino}

Para entender o comportamento elétrico do filme de Si-poli quando dopado, principalmente quanto aos parâmetros como resistência de folha $\left(R_{s h}\right)$ ou efeito de depleção deve-se, primeiramente, entender seu comportamento elétrico. O Si-poli se diferencia do $\mathrm{Si}$ monocristalino que tem uma dependência quase linear da resistividade $(\rho)$ com relação à concentração de dopantes (LU, 1981; JOSHI, 1984). Observa-se que pequenas quantidades de dopante podem promover uma redução substancial da " $\rho$ " do Si-poli. Da mesma forma, ao reduzir a concentração de dopantes, " $\rho$ " aumenta de forma abrupta conforme apresenta o gráfico da resistividade em função da concentração de dopantes na figura 2.14 (SETO, 1975, MANERA, 2004).

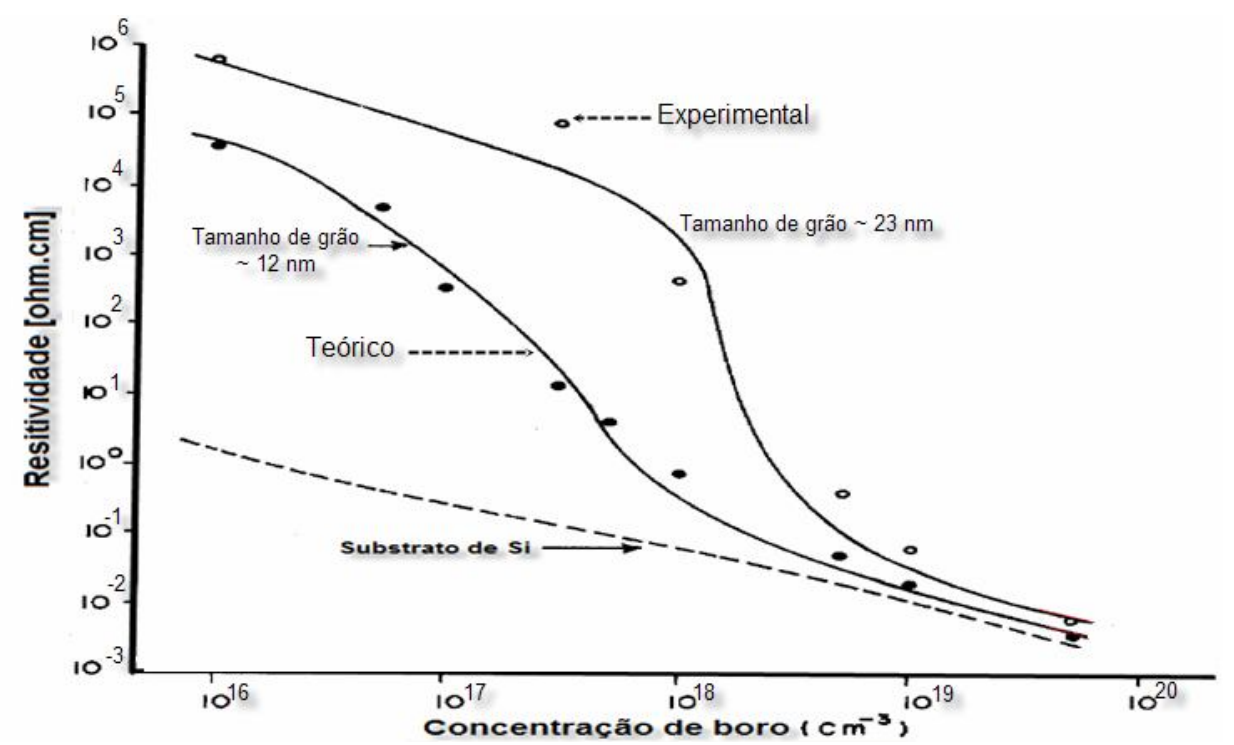

Figura 2.14 - Variação da resistividade em relação à concentração de dopantes comparados com o tamanho de grão do Si-poli e com o Si monocristalino (SETO, 1975).

Seto (1975) explica esse comportamento. Este reporta que a região amorfa de contorno de grão possui um grande número de defeitos gerados por ligações químicas incompletas, capazes de aprisionar portadores. Além de reduzir o número de portadores livres para condução de corrente, a região amorfa se torna eletricamente carregada, criando uma barreira de potencial que dificulta a 
condutividade do Si-poli. Os portadores aprisionados criam uma região de depleção que, dependendo do tamanho do grão e quantidade de dopantes, pode abranger toda a região cristalina.

Por apresentar uma grande quantidade de ligações incompletas, as regiões amorfas localizadas nos contornos dos grãos aprisionam os dopantes em uma posição não substitucional na rede cristalina e, portanto, não contribuem para a formação de corrente elétrica. Reduzindo a porção amorfa (aumentando o tamanho médio dos grãos), a quantidade de átomos dopantes aprisionados nas regiões de contorno também diminui o que reflete na redução da resistividade do Si-poli.

$\mathrm{Na}$ figura 2.14, a queda abrupta na resistividade está relacionada com o aumento da concentração de portadores após saturar as ligações incompletas.

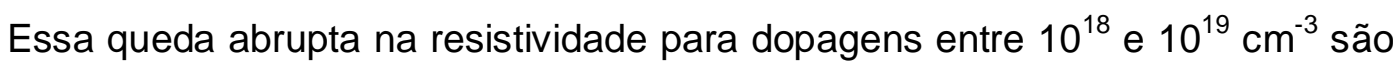
cargas absorvidas na região de contorno do grão com espessura de alguns ângstrons, correspondente à espessura da região amorfa.

O movimento dos portadores que se deslocam sobre esta barreira (formada pelo acúmulo de dopantes ao longo da região amorfa) representa a maior parte da corrente formada. Isso foi confirmado em trabalhos com Si-poli hidrogenado por Zhou (1998). Seto também verificou experimentalmente a existência de portadores livres na região cristalina do material.

Observou-se também que a influência no tamanho do grão é mais visível na região de baixa dopagem, na faixa de $10^{16} \mathrm{~cm}^{-3}$, onde a resistividade pode reduzir mais de uma ordem de grandeza. Para esta faixa de dopagem, quanto maior o tamanho dos grãos, maior é a área cristalina com comportamento próximo ao Si monocristalino (LU, 1980; JOSHI, 1984). 


\subsubsection{Efeito de depleção do silício policristalino}

Durante o processo de dopagem do Si-poli e/ou processos de recozimento térmico, certas quantidades de boro advindo do Si-poli, pode adentrar no $\mathrm{SiO}_{2}$ de porta, pelo efeito de segregação e, posteriormente, pode difundir para o $\mathrm{Si}$. Para se evitar a penetração de impurezas no $\mathrm{Si}$ durante a fabricação de dispositivos MOS, as receitas de dopagem em geral são tais que a interface Sipoli $/ \mathrm{SiO}_{2}$ fica menos dopada (figura 2.15). Esta dopagem insuficiente e, por conseguinte, não uniforme ao longo da espessura do Si-poli pode, dependendo da tensão aplicada à porta $\left(V_{G}\right)$, vir a depletar (LU, 1989).

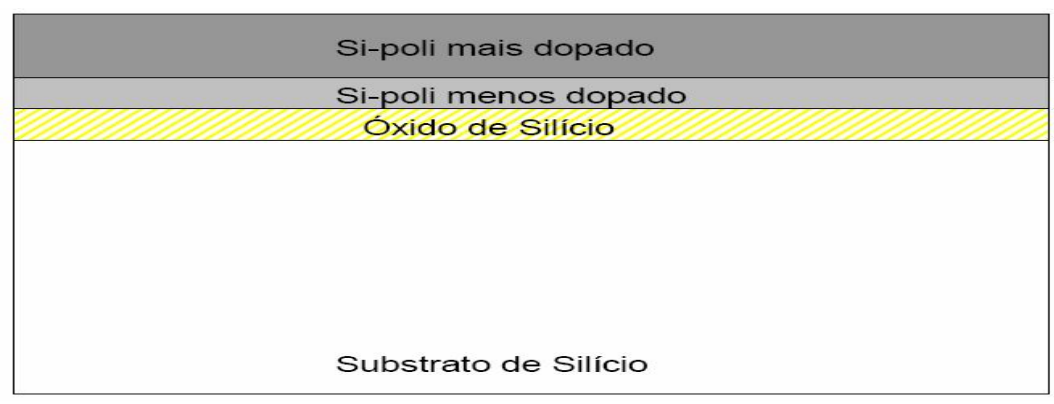

Figura 2.15 - Representação esquemática da estrutura MOS com porta de silício policristalino indicando a região menos dopada junto ao $\mathrm{SiO}_{2}$.

Pelo diagrama de faixas de energia, a depleção do Si-poli pode ser explicada como um divisor de tensão em série, conforme mostra o diagrama de bandas na figura 2.16. Pode se observar que a interface $\mathrm{Si}$-poli/ $\mathrm{SiO}_{2}$ está depletada, enquanto a interface do canal $\left(\mathrm{Si} / \mathrm{SiO}_{2}\right)$ já está invertida. Fazendo uma curtocircuitação, $V_{G}$ pode ser escrito como (ARORA, 1995):

$V_{G}=\psi_{\text {Sipoli }}+V_{o x}+\psi_{S}+\left(\phi_{\text {Sipoli }}-\phi_{S}\right)$

onde: $V_{o x}=-\frac{Q_{S}}{C_{o x}}-\frac{Q_{s s}}{C_{o x}}$

$\left(Q_{S}=\right.$ densidade de carga no $\mathrm{Si} ; \mathrm{Q}_{\mathrm{sS}}=$ densidade de cargas efetiva no óxido). 


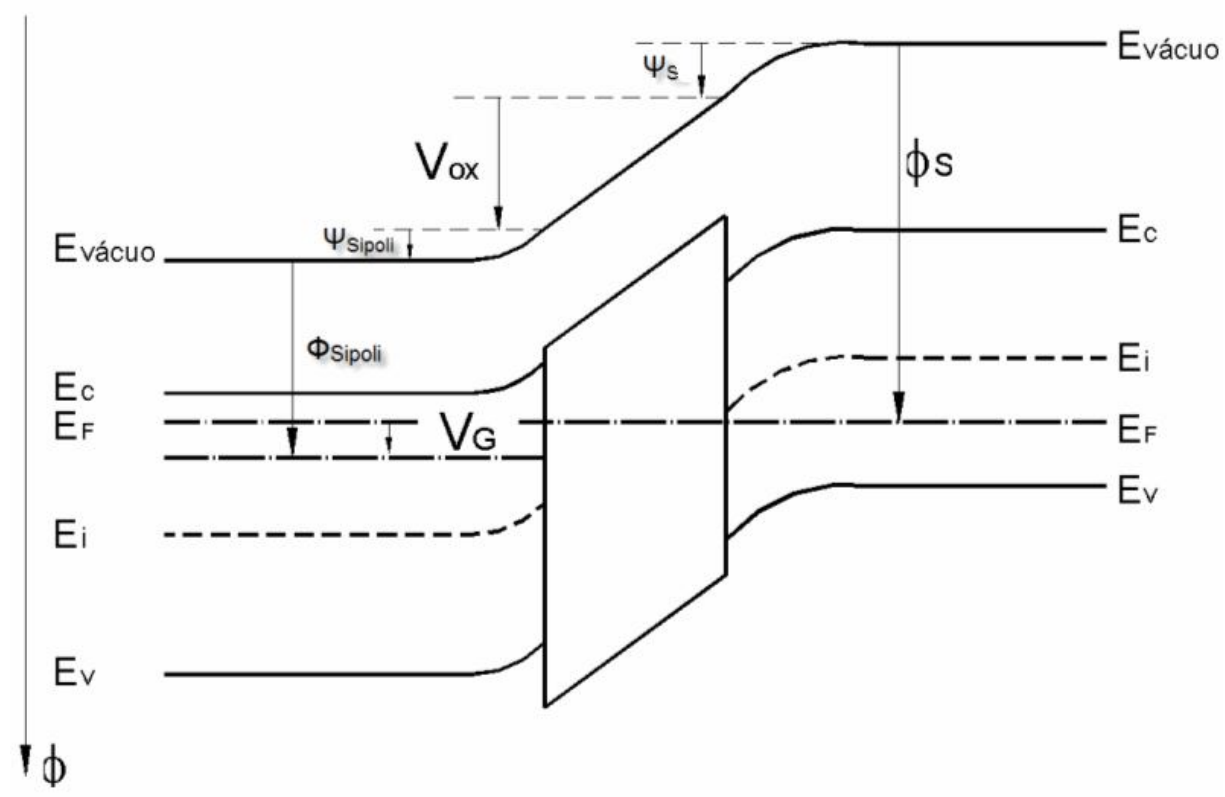

Figura 2.16 - Diagrama de faixas de energia de uma estrutura MOS onde pode-se observar a queda de potencial na superfície do Si-poli $\left(\Psi_{\text {Sipoli }}\right)$ próximo à interface Si-poli $/ \mathrm{SiO}_{2}$.

Nota-se que, para concentrações de dopantes no Si-poli abaixo de $5.10^{19} \mathrm{~cm}^{-3}$, esta não pode mais ser tratada como uma superfície equipotencial, onde há uma região de depleção com um potencial igual a " $\Psi_{\text {Sipoli" }}$ (HUANG, 1993; ARORA, 1995). Manipulando-se as equações 2.3 e 2.4, pode-se obter o efeito da depleção do Si-poli sobre a tensão de limiar $\left(V_{T}\right)$. $O$ " $\Psi_{\text {Sipoli" }}$ pode ser obtido pela solução da equação de Poisson no Si-poli acoplada a equação de Laplace na região de $\mathrm{SiO}_{2}$ de porta. Através da eq.(2.5), observa-se que, para concentrações de dopantes doadores no Si-poli $\left(\mathrm{N}_{\text {poli }}\right)$ maiores que $5.10^{19} \mathrm{~cm}^{-3}$, o efeito de depleção do Si-poli sobre " $\mathrm{V}_{\mathrm{T}}$ " pode ser desprezado já que o termo "av" torna-se muito grande (> 50) (RIOS, 1994).

$\psi_{\text {Sipoli }}=V_{G}-V_{F B}-\psi_{S}-a_{v} \cdot \sqrt{1+\frac{2}{a_{v}}\left(V_{G}-V_{F B}-\psi_{S}-1\right)}$

onde: $\quad a_{v}=\frac{q \cdot \varepsilon_{S} \cdot \varepsilon_{o} \cdot N_{p o l i}}{C_{o x}{ }^{2}}$ 
$V_{T}=V_{F B}+2 \cdot \psi_{S}-\frac{Q_{S}}{C_{o x}}+\frac{1}{2 \cdot a_{v}}\left(\frac{Q_{S}}{C_{o x}}\right)^{2}$

Pode ocorrer o efeito de depleção para dopagens acima de $5.10^{19} \mathrm{~cm}^{-3}$ se as receitas de deposição do Si-poli forem tais que promovam uma região mais amorfa que policristalina (TEIXEIRA, 2001). O excesso de nitrogênio também promove o efeito de depleção no Si-poli (HERDEN, 2001) já que o boro, por exemplo, é removido das ligações substitucionais sendo estas as responsáveis pelas características elétricas nos dispositivos semicondutores (TEIXEIRA, 2001).

O efeito do potencial " $\Psi_{\text {Sipoli" sobre a curva C-V consiste em produzir algumas }}$ anomalias que dificultam a extração de parâmetros importantes como espessura do óxido $\left(\mathrm{t}_{\mathrm{ox}},\right), \mathrm{V}_{\mathrm{T}}$, etc. Essas anomalias também promovem o deslocamento da tensão de faixa plana $\left(\mathrm{V}_{\mathrm{FB}}\right)$, deslocamento de $\mathrm{V}_{\mathrm{T}}$ (pela redução da carga invertida na superfície do $\mathrm{Si}$ ) e na redução das cargas de inversão ou da corrente entre dreno e fonte (LU, 1989; LO, 1999). A região depletada do Si-poli pode ser encarada como uma região altamente resistiva sendo considerada como uma extensão do óxido de porta (LU, 1989). 


\subsubsection{Influência da depleção do silício policristalino na medida C-V}

A figura 2.17 ilustra o perfil de um capacitor MOS com eletrodo de porta de metal onde no modelo equivalente de capacitâncias associadas à estrutura MOS se apresentam: "CS" é a capacitância do $\mathrm{Si}$ e " $\mathrm{C}_{\text {ox }}$ " é a capacitância do óxido de porta. A capacitância total $\left(\mathrm{C}_{\mathrm{T}}\right)$ é dada pela eq.(2.6).
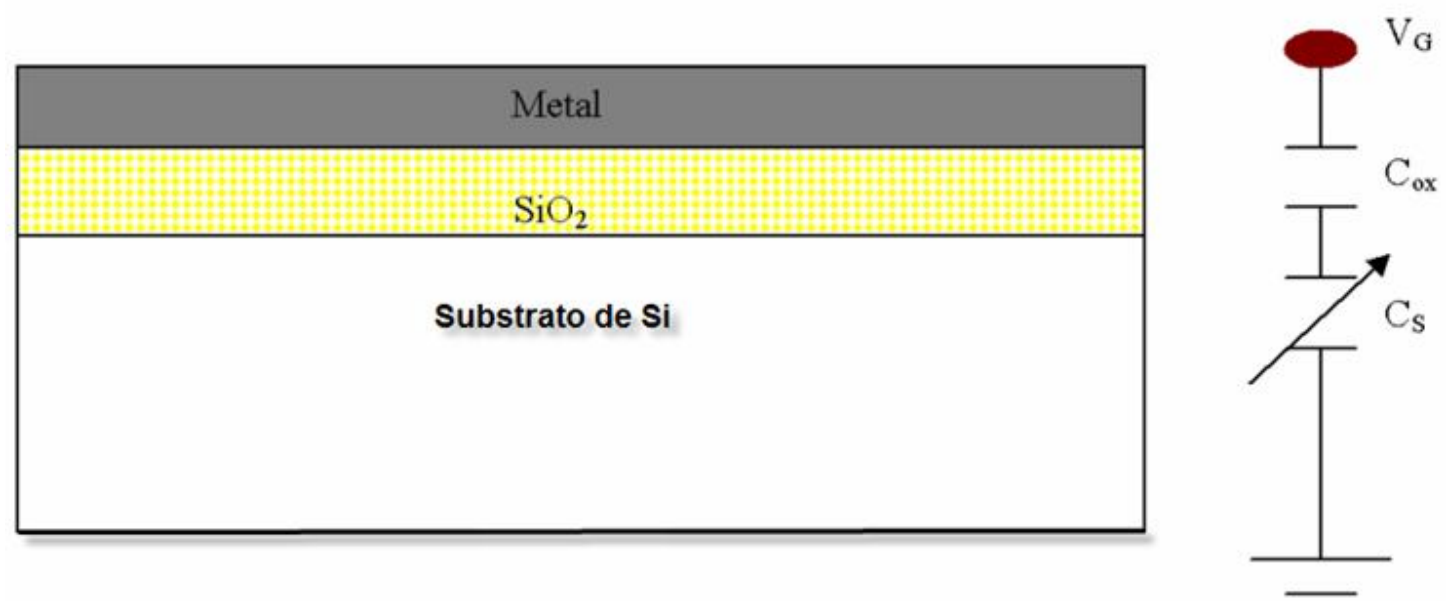

Figura 2.17 - Modelo equivalente de capacitâncias para um capacitor MOS com porta de metal.

$$
\frac{1}{C_{T}}=\frac{1}{C_{o x}}+\frac{1}{C_{S}}
$$


onde:

$$
\begin{gathered}
C_{o x}=\frac{\varepsilon_{o x} \cdot \varepsilon_{o}}{t_{o x}} \\
C_{S}=\frac{\varepsilon_{S} \cdot \varepsilon_{o}}{W}
\end{gathered}
$$

sendo " $\varepsilon_{0 x}$ " a constante dielétrica do óxido de silício, " $\varepsilon_{S \text { i }}$ a constante dielétrica do silício, " $\varepsilon_{0}$ " a permissividade do vácuo e "W" a largura da região depletada no silício.

Porém, quando se utiliza o filme de Si-poli como porta da estrutura MOS, conforme apresenta a figura 2.18, às vezes é necessário considerar uma capacitância adicional $\left(\mathrm{C}_{\text {Sipoli }}\right)$ devido à região de depleção do mesmo. Com isso a eq.(2.6) é modificada conforme apresenta a eq.(2.9).

$$
\frac{1}{C_{T}}=\frac{1}{C_{o x}}+\frac{1}{C_{S}}+\frac{1}{C_{\text {Sipoli }}}
$$

onde $C_{\text {Sipoli }}=\frac{\varepsilon_{S i}}{W_{\text {Sipoli }}}$

sendo "W Sipoli" a largura da região de depleção do Si-poli. 

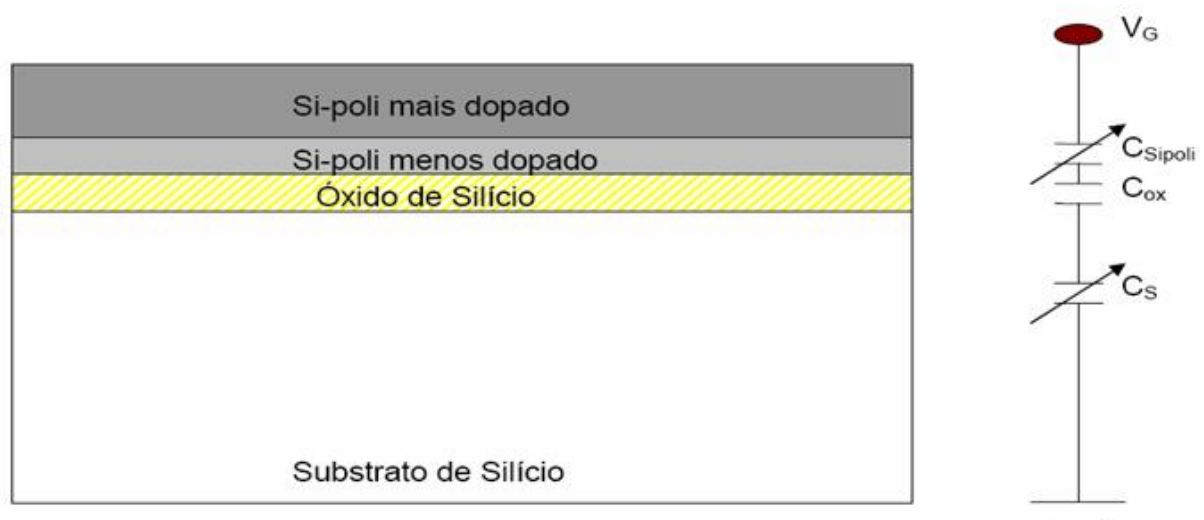

Figura 2.18 - Modelo equivalente de capacitâncias para um capacitor MOS com porta de Si-poli.

Dependendo da extensão da região de depleção do Si-poli, as distorções tornam se evidentes, na forma de variações acentuadas nas curvas $C-V_{A F}$ e C$\mathrm{V}_{\mathrm{BF}}$. Observa-se que na curva $\mathrm{C}-\mathrm{V}_{\mathrm{AF}}$, na condição de inversão, pode ocorrer uma redução da capacitância total da associação em série da capacitância do óxido $\left(\mathrm{C}_{\mathrm{ox}}\right)$ e da capacitância de depleção do Si com a capacitância do Si-poli

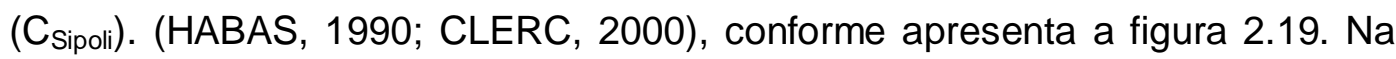
curva $\mathrm{C}-\mathrm{V}_{\mathrm{BF}}$, o efeito de depleção no Si-poli é claramente observado na região de inversão como indicado na figura 2.20, para diferentes valores de dopagem do Si-poli. 


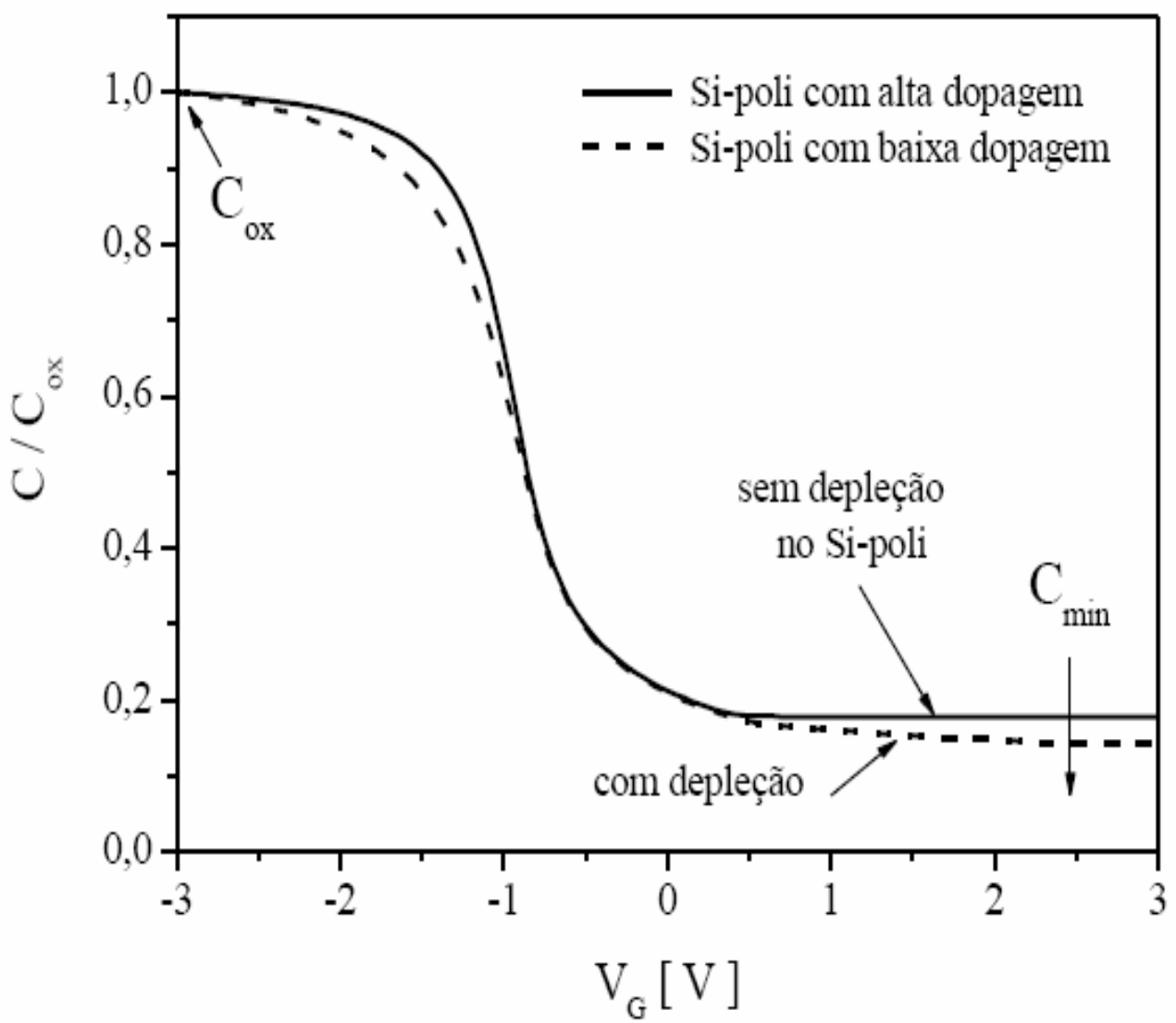

Figura 2.19 - Curva C- $\mathrm{V}_{\mathrm{AF}}$ de uma estrutura composta por Si-poli $\mathrm{N}^{+} / \mathrm{SiO}_{2} / \mathrm{Si}$, para alta e baixa dopagem e a presença ou não do efeito de depleção. 


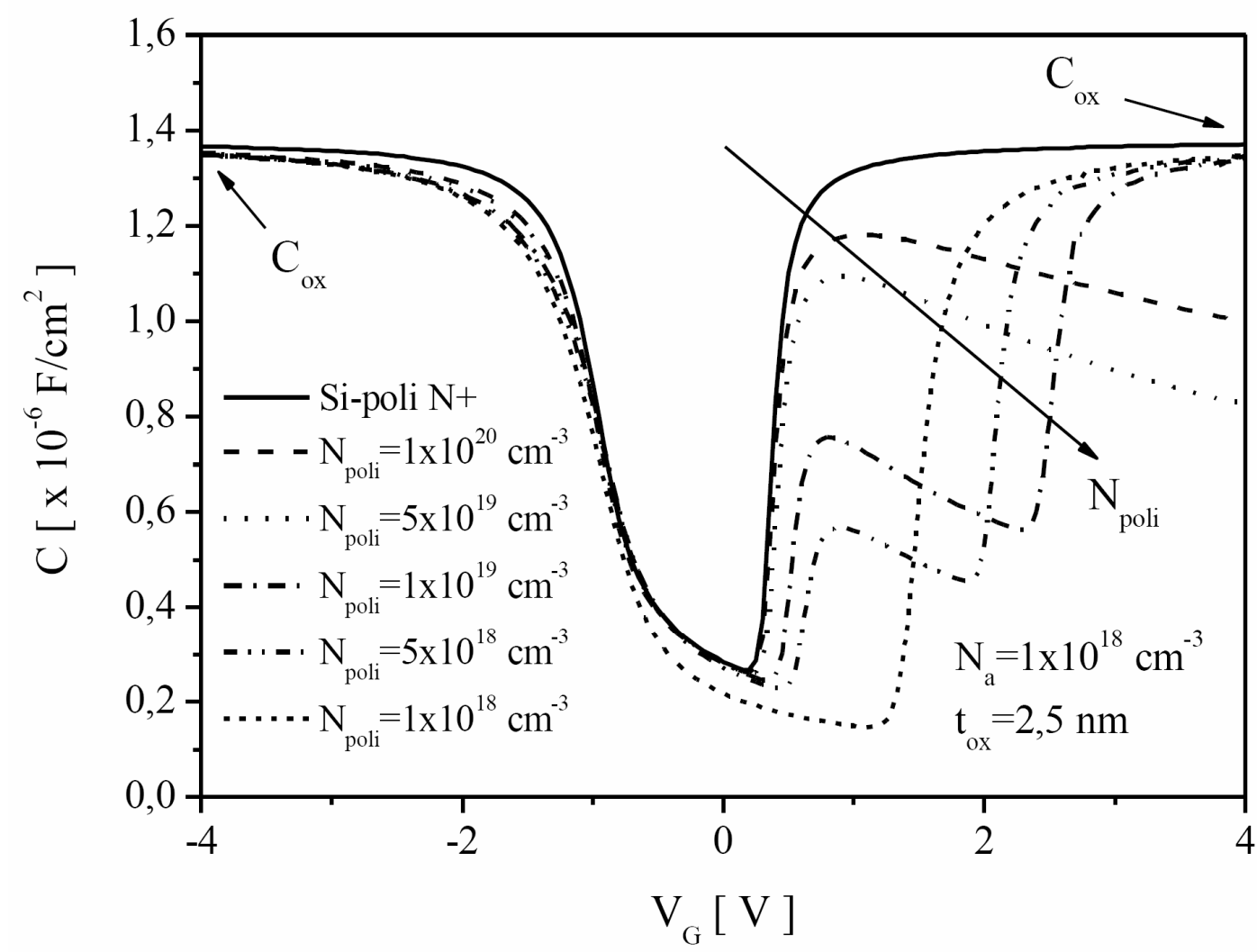

Figura 2.20 - Curvas $\mathrm{C}-\mathrm{V}_{\mathrm{BF}}$ simuladas com a estrutura composta por Si-poli $\mathrm{N}^{+} / \mathrm{SiO}_{2} / \mathrm{Si}$, indicando o efeito de depleção em relação as diferentes concentrações de dopagem do Si-poli (RODRIGUES, 2006).

Devido à depleção do Si-poli, outros materiais vêm sendo pesquisados como eletrodo de porta de forma a eliminá-la. Alguns materiais também permitem reduzir a resistência de porta, como:

1. Siliceto de titânio (TiSi) e Siliceto de níquel (NiSi) possuem as mesmas características de um metal puro com alta condutividade (XUAN, 2003);

2. Nitreto de Tântalo - Seu processo de fabricação exige baixa temperatura a fim de se evitar uma reação do mesmo com isolante (SHIMADA, 1995);

3. Molibdênio (Mo) - Sua diferença de função trabalho depende das condições de deposição, recozimento e do dielétrico de porta (LU, 2000); 
4. Silício germânio policristalino (SiGe-poli) - segrega menos boro e possui uma resistividade menor que o Si-poli (MANERA, 2004).

\subsubsection{Extração de parâmetros das curvas $C-V_{A F}$ sob efeito de depleção no Si-poli.}

Para obter o perfil de potencial ao longo do Si-poli, é necessário conhecer o perfil de concentração do dopante ao longo do filme. Essa variação origina um campo elétrico $(E)$ o qual pode ser representado pela eq.(2.11) (CHOI, 2002).

$$
E(x)=\frac{K T}{q} \cdot \frac{1}{N_{A(X)}} \cdot \frac{d N_{A(X)}}{d_{x}}
$$

onde $(\mathrm{KT} / \mathrm{q})=25,9 \mathrm{mV}(\mathrm{T}=300 \mathrm{~K}), \mathrm{N}_{\mathrm{A}(\mathrm{x})}$ é a dopagem ao longo do Si-poli e " $\mathrm{x}$ " é a posição ao longo do filme.

A equação 2.11 apresenta " $E$ " em função da dopagem no Si-poli devida à variação no perfil de dopante tipo p, obtida por processo de difusão térmica ou implantação iônica que promovem perfis não uniformes próximos à interface com $\mathrm{SiO}_{2}$, figura 2.21. Observe que quanto maior for à variação na dopagem ao longo do Si-poli maiores serão os valores de "E". Integrando a eq.(2.11) ao longo de toda a espessura, é possível obter a queda de potencial dentro do Si-poli $\left(\Psi_{\text {Sipoli }}\right)$, que será tanto maior quanto maior for à variação da dopagem ao longo do mesmo, conforme eq.(2.12) (CHOI, 2002).

$\psi_{\text {Sipoli }}=\frac{K T}{q} \cdot \ln \frac{N_{A 1}}{N_{A 2}}$

onde $\mathrm{N}_{\mathrm{A} 1}$ e $\mathrm{N}_{\mathrm{A} 2}$ são os extremos de dopagem ao longo do Si-poli (veja figura 2.22) 


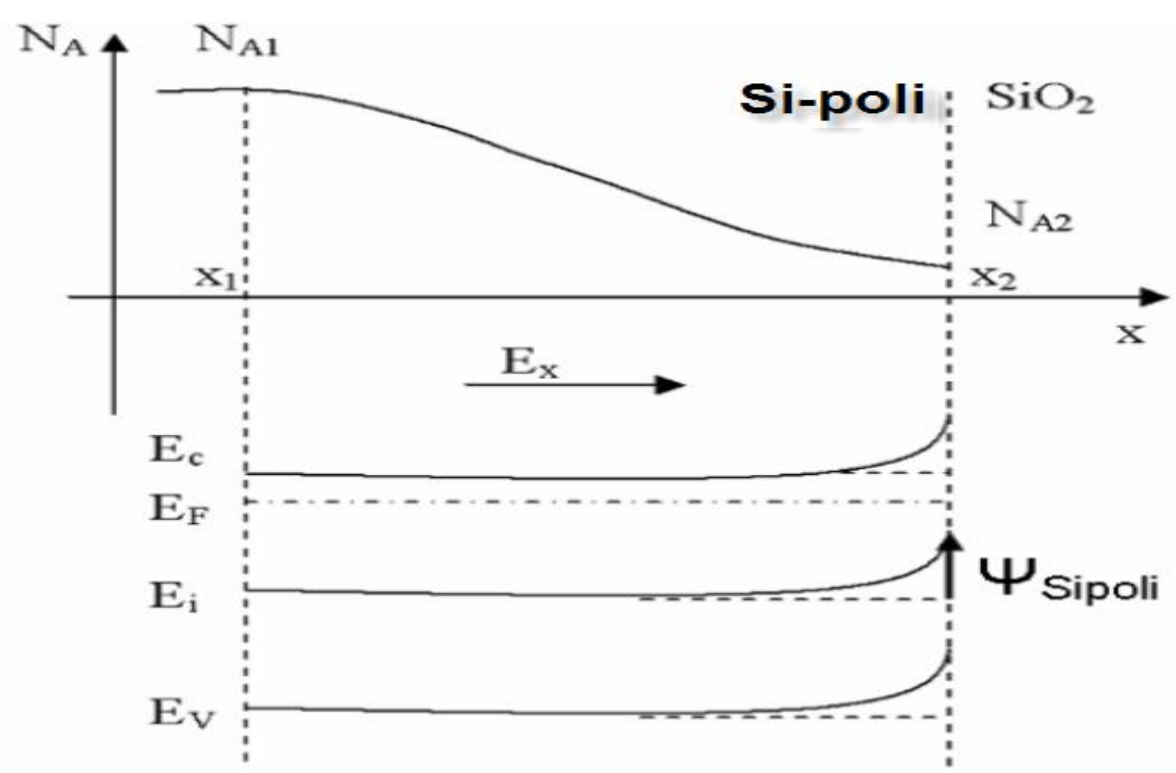

Figura 2.21 - Perfil desuniforme de distribuição de dopantes no Si-poli. Campo elétrico gerado e região de depleção de portadores junto à interface com o óxido (CHOI, 2002).

Fazendo um raciocínio análogo ao que acontece em diodos, mesmo que não seja aplicado nenhum potencial externo, haverá uma queda de potencial igual à

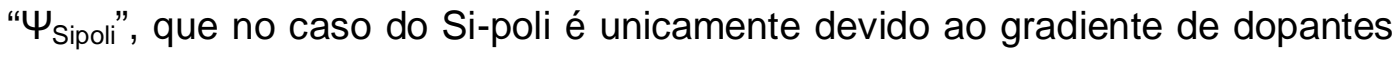
de uma mesma impureza. Portanto, ao se aplicar uma tensão " $\mathrm{V}_{\mathrm{G}}$ " na estrutura

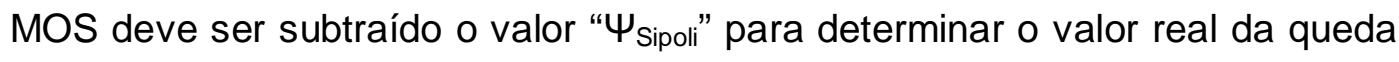
de tensão no $\mathrm{SiO}_{2}$ e demais polarizações para as condições de depleção, banda plana e acumulação (TOQUETTI, 2005). 


\subsection{Obtenção de oxinitreto de silício}

O diagrama de fases apresentado na figura 2.22 parece revelar que as fases $\mathrm{SiO}_{2}$ e $\mathrm{Si}_{3} \mathrm{~N}_{4}$ nunca coexistem (supondo condições de equilíbrio termodinâmico) e que a única forma estável termodinamicamente é a formação $\mathrm{Si}_{2} \mathrm{~N}_{2} \mathrm{O}$ (WONG, 2006; GUSEV, 1999). No entanto, na prática obtém-se $\mathrm{SiO}_{x} \mathrm{~N}_{\mathrm{y}}$ em uma ampla faixa de temperatura na presença de $\mathrm{N}_{2}$ e $\mathrm{O}_{2}$. Para explicar as observações experimentais da incorporação de nitrogênio no $\mathrm{SiO}_{2}$ pode-se recorrer a duas propostas (GREEN, 1998; GUSEV, 1999; WU, 1999):

a. aprisionamento cinético. Sabe-se que junto às interfaces $\mathrm{Si}$-poli/ $/ \mathrm{SiO}_{2}$ e $\mathrm{SiO}_{2} / \mathrm{Si}$ há ligações incompletas, tensionadas e sem ordem atômica local, onde o nitrogênio satura essas ligações Si-O não estequiométricas. Constata-se que a incorporação de nitrogênio na interface Si-poli/SiO $\mathrm{N}_{\mathrm{y}}$ pode chegar a $15 \%$ at e na interface $\mathrm{SiO}_{2}$ a $5 \%$ at, usando óxido nitroso $\left(\mathrm{N}_{2} \mathrm{O}\right)$ ou amônia $\left(\mathrm{NH}_{3}\right)_{9}$ dependendo das limitações termodinâmicas impostas pelo processo.

b. contribuições de energia livre não compreendidas que ocasiona a redução da tensão na interface $\mathrm{SiO}_{2} / \mathrm{Si}$ com a adição de nitrogênio.

Por outro lado, altas concentrações de nitrogênio no dielétrico de porta, podem induzir cargas fixas no dielétrico, diminuir a barreira de potencial na interface com o $\mathrm{Si}$ (em relação ao $\mathrm{SiO}_{2}$ ) e, quando incorporado por processamento térmico, tende a segregar para o Si degradando a mobilidade dos portadores de carga. De fato, as propriedades dos filmes de $\mathrm{SiO}_{x} \mathrm{~N}_{\mathrm{y}}$ dependem da quantidade e da distribuição de nitrogênio (BUCHANAN, 1999; WU, 1999; HERDEN, 2001). 


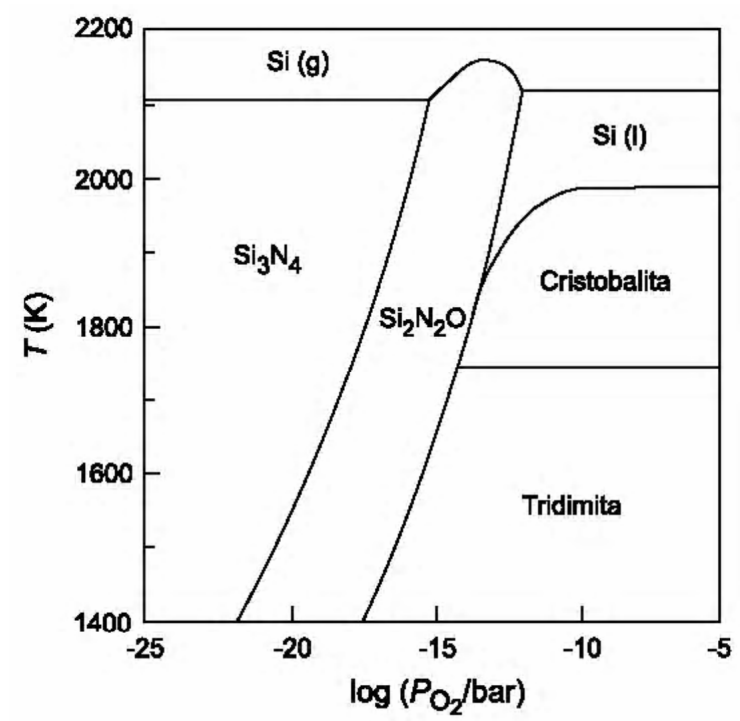

Figura 2.22 - Diagrama de fases do sistema Si-N-O (GUSEV, 1999).

Filmes de $\mathrm{SiO}_{x} \mathrm{~N}_{\mathrm{y}}$ podem ser obtidos através diversas técnicas: RTP (Rapid Thermal Processing) e CVD (Chemical Vapor Deposition), utilizando óxido nítrico (NO), $\mathrm{N}_{2}$ e gás amônia $\left(\mathrm{NH}_{3}\right)$ e Implantação iônica $\left(1 / \mathrm{I}_{0}\right)$ de íons de nitrogênio (LUCOVSKY, 1987; CEILER, 1995; HATTANGADY, 1996; GUSEV, 1999; HERDEN, 2001)

As melhores técnicas que permitem obter interfaces $\mathrm{Si}-$ poli $/ \mathrm{SiO}_{x} \mathrm{~N}_{y}$ e $\mathrm{SiO}_{x} \mathrm{~N}_{y} / \mathrm{Si}$ de alta qualidade são o RTP e a $1 / \mathrm{I}_{0}$. Os melhores resultados em termos de propriedades elétricas para dispositivos MOS são encontrados quando se utiliza a $\mathrm{I} / \mathrm{I}_{\circ}$ já que permite um controle preciso da incorporação de nitrogênio ao longo da estrutura MOS. A técnica RTP se aproxima da $\mathrm{I} / \mathrm{I}_{\mathrm{o}}$ quando utiliza incorporação de nitrogênio em superfícies de Si já oxidadas (DOMíNGUEZ, 1999).

Tem sido reportado para óxidos de $2 \mathrm{~nm}$ implantados com nitrogênio atômico $\left(\mathrm{N}^{+}\right)$, uma corrente de fuga menor em até três ordens de grandeza com relação ao óxido de silício puro com a mesma espessura (ONO, 1999). Há diversas modalidades de formação de $\mathrm{SiO}_{x} \mathrm{~N}_{\mathrm{y}}$ utilizando a $\mathrm{l} / \mathrm{I}_{0}$ de nitrogênio. Há publicações que relatam a $\mathrm{I} / \mathrm{I}_{\mathrm{o}}$ através do $\mathrm{SiO}_{2}$ sacrificial seguida de dissolução 
química do filme e oxidação térmica do substrato modificado (SOLEIMANI, 1995; LIN, 1996).

Também existe a $1 / l_{0}$ de nitrogênio na superfície do Si com energia próxima a $20 \mathrm{eV}$ seguida de oxidação térmica (BAUMVOL, 1998). As implantações de nitrogênio em menor energia, tipicamente abaixo de $50 \mathrm{eV}$, promovem mínimas modificações superficiais e danos à interface $\mathrm{SiO}_{2} / \mathrm{Si}$. Porém, carecem de um melhor entendimento quanto à:

a. descrição teórica do transporte de íons na matéria em regime de baixa energia. Para energias abaixo de $100 \mathrm{eV}$ as simulações SRIM (com base no método de Monte - Carlo) apresentam incorporações superficiais menores em relação aos dados experimentais para implantações de $\mathrm{N}^{+}$em $\mathrm{SiO}_{2}(\mathrm{KRAFT}$, 1997);

b. mudança da composição ao longo da formação do filme de $\mathrm{SiO}_{x} \mathrm{~N}_{\mathrm{y}}$ de modo a necessitar de simulações com métodos da química quântica (KRAFT, 1997).

Do processo de l//。 (Implantação lônica), tem-se (MANERA, 2004):

a) Pureza. Como todo o processo é realizado a vácuo $\left(\sim 10^{-6}\right.$ torr $)$ a concentração de impurezas na câmara de processo situa-se na faixa de p.p.b. Como os íons são selecionados por um espectrômetro de massa, a pureza das espécies iônicas é assegurada o que possibilita obter filmes com diferentes estequiometrias;

b) Controle: A energia do feixe de íons é controlada pela tensão e, a dose, ou a concentração de íons por $\mathrm{cm}^{2}$, pela corrente, significando um preciso controle da profundidade e do perfil;

c) Temperatura: A inserção de outros compostos que por ventura permaneçam adsorvidos na câmara de processo são minimizados, já que todo o processo é realizado à temperatura ambiente; 


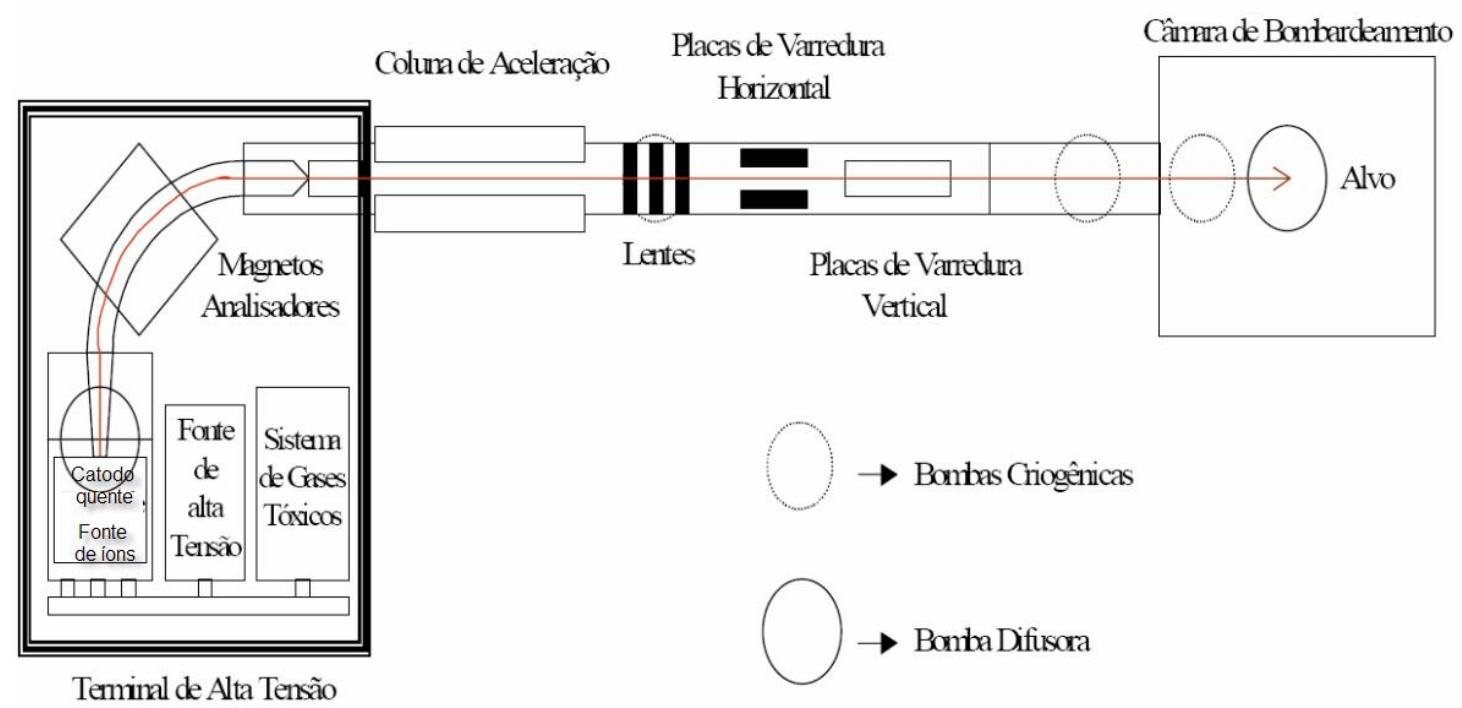

Figura 2.23 - Detalhes do Implantador lônico GA4204 utilizado neste trabalho.

A figura 2.23 apresenta um desenho esquemático de um Implantador lônico que é constituído por uma fonte de íons, um sistema de aceleração e focalização dos feixes, um sistema de varredura (responsável pela distribuição uniforme do implante no alvo), uma fonte de alta tensão e um sistema de vácuo.

A partir de compostos na fase sólida ou gasosa (que contenha a espécie química a ser implantada) pode-se gerar o plasma no catodo quente. $O$ feixe gerado será selecionado pela sua carga e massa especifica, não havendo necessidade de utilização de compostos com alto grau de pureza. Com uma descarga de $20 \mathrm{keV}$ (estabelecida pela fonte de alta tensão) e com o auxilio de um eletroímã $\left(90^{\circ}\right)$ os íons retirados da descarga são selecionados formando um feixe de íons que será acelerado por um campo elétrico (através de uma ddp entre 0-180 keV) sendo focalizado sobre a amostra com o auxílio de lentes eletrostática.

O implantador iônico GA4204 (RANGEL, 1999) tem capacidade de processamento de até 200 lâminas de 3" por hora, tendo fluências ou doses na faixa $10^{15}$ a $10^{21}$ íons $/ \mathrm{cm}^{2}$. A energia de aceleração do feixe pode ser variada 
entre alguns $\mathrm{keV}$ até $200 \mathrm{keV}$ para espécies mono-ionizadas, tornando o implantador atrativo para um vasto campo de aplicações (RANGEL, 1999).

\subsubsection{Implantação iônica de nitrogênio no sistema $\mathrm{Si}-\mathrm{poli} / \mathrm{SiO}_{2} / \mathrm{Si}$}

A técnica de implantação iônica $\left(1 / I_{0}\right)$ ao longo da estrutura $\mathrm{Si}$-poli/ $/ \mathrm{SiO}_{2} / \mathrm{Si}$ permite um controle preciso do nitrogênio incorporado em comparação às demais técnicas (WU, 1999; HERDEN, 2001).

É essencial para técnica de $\mathrm{I} / \mathrm{I}_{0}$ através do Si-poli manter "baixa" a concentração de nitrogênio na interface $\mathrm{SiO}_{2} / \mathrm{Si}$ e uma "alta" concentração do mesmo na interface do Si-poli $/ \mathrm{SiO}_{2}$. Para esta modalidade, Herden (2001) reporta alta eficiência como barreira ao boro, porém constatou-se um alto valor da resistência de folha $\left(R_{\text {sh }}\right)$ com valores maiores do que $800 \mathrm{ohm} / \square$, figura 2.24. Além disso, notou-se o efeito de depleção do boro para todas as doses e receitas de RTP empregadas. No entanto, Herden (2001) obteve uma melhora significativa nos valores da densidade efetiva de carga no dielétrico $\left(Q_{s s}\right)$ com valores próximos a $1.10^{10} \mathrm{~cm}^{-2}$ já que o boro é barrado na interface $\mathrm{Si}$-poli/SiO 2 minimizando sua presença no corpo do $\mathrm{SiO}_{2}$. 


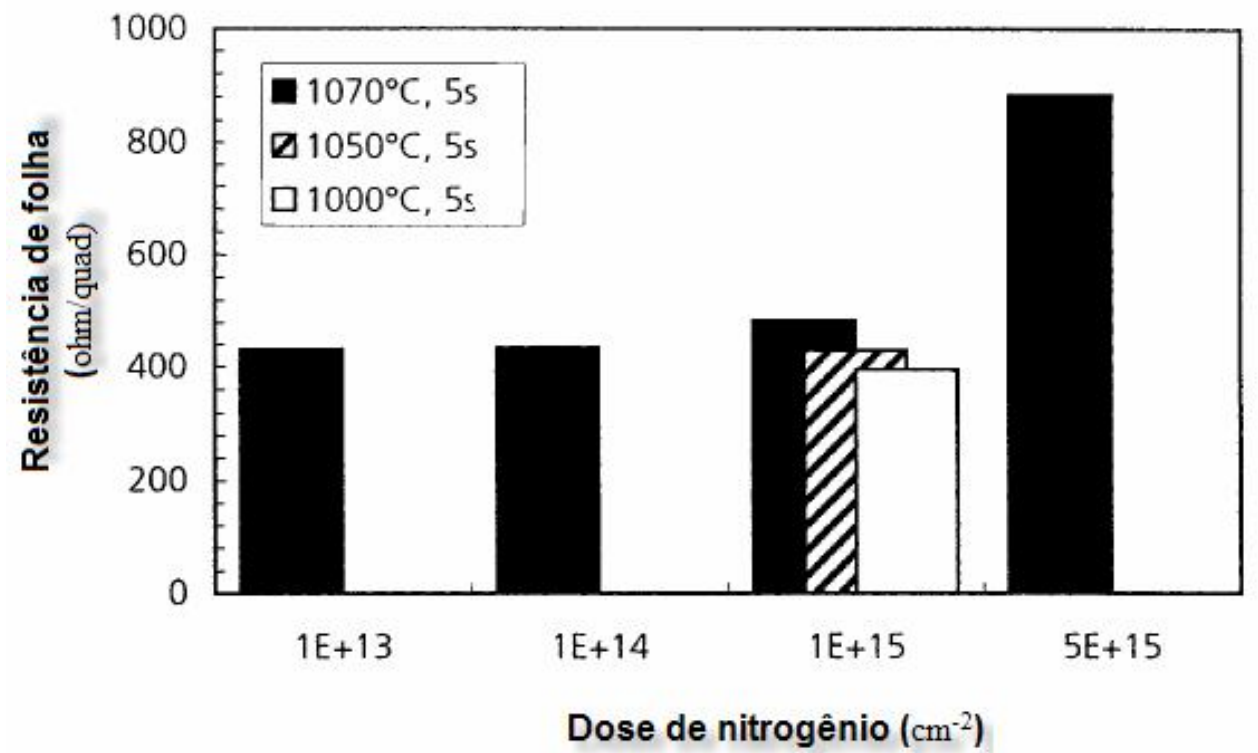

Figura 2.24 - Resistência de folha para $150 \mathrm{~nm}$ de Si-poli com diferentes doses de nitrogênio com implantação superficial do mesmo $(40 \mathrm{keV})$ seguido por diferentes processos de recozimento do boro por RTP (HERDEN, 2001).

Ao implantar nitrogênio próximo da interface $\mathrm{Si} / \mathrm{SiO}_{2}$ após a deposição do Si-poli obtém-se valores de $R_{\text {sh }}$ semelhantes aos da estrutura MOS sem a presença de nitrogênio, isto é, valores próximos a $73 \mathrm{ohm} / \square$ para $340 \mathrm{~nm}$ de Si-poli, que é um dos resultados positivos obtidos neste trabalho. Porém, como uma grande parte do nitrogênio está presente no óxido, isso pode resulta em uma variação substancial na tensão de banda plana $\left(\mathrm{V}_{\mathrm{FB}}\right)$ (BAUER, 1998; HERDEN, 2001).

A figura 2.25 apresenta um diagrama esquemático da difusão de boro e as posições das barreiras $\mathrm{SiO}_{\mathrm{x}} \mathrm{N}_{\mathrm{y}}$ formadas "restritamente" nas interfaces $\mathrm{Si}$ poli/SiO e SiO$_{2} / \mathrm{Si}(\mathrm{WU}, 1999)$. Nos capacitores MOS sem nenhuma camada de $\mathrm{SiO}_{x} \mathrm{~N}_{\mathrm{y}}$ formada (situação i) o boro oriundo do Si-poli altamente dopado difunde para dentro do $\mathrm{SiO}_{2}$ seguindo para o $\mathrm{Si}$, já que, o coeficiente de segregação do boro é menor que 1 , ou seja, ele tende a ficar no óxido e este sendo ultrafino não oferece nenhuma barreira, de forma que o boro passa para o $\mathrm{Si}$. $\mathrm{Na}$ situação (ii), a presença do filme de $\mathrm{SiO}_{x} \mathrm{~N}_{\mathrm{y}}$ na interface $\mathrm{Si} / \mathrm{SiO}_{2}$ promove uma barreira para a difusão de boro, porém este fica acumulado no $\mathrm{SiO}_{2}$, 
aumentando $Q_{\mathrm{ss}}$. Para esta situação, $R_{\mathrm{sh}}$ no Si-poli exibe valores baixos ( 50 ohm/ $\square$ ) já que a população de boro é alta em toda a sua extensão. Já para a situação (iii) a difusão de boro é barrada pela presença de $\mathrm{SiO}_{\mathrm{x}} \mathrm{N}_{\mathrm{y}}$ na interface Si-poli/ $/ \mathrm{SiO}_{2}$, resultando em baixos valores de $Q_{s s}$. Porém, $R_{\text {sh }}$ do Si-poli é alta (> 400 ohm/ $\square$ ) ocasionando o efeito de depleção devido à alta concentração de nitrogênio que retira o boro das posições substitucionais. Observe que a posição estritamente nas interfaces é uma imposição teórica (visando facilitar o entendimento da eficiência das monocamadas de oxinitreto formada nas interfaces $\mathrm{Si}$-poli/ $\mathrm{SiO}_{2}$ e $\mathrm{SiO}_{2} / \mathrm{Si}$ ), já que experimentalmente não há como evitar os espalhamentos do nitrogênio devido às variações de perfil (por exemplo, num processo de implantação iônica) ou dos processos de recozimento térmico.

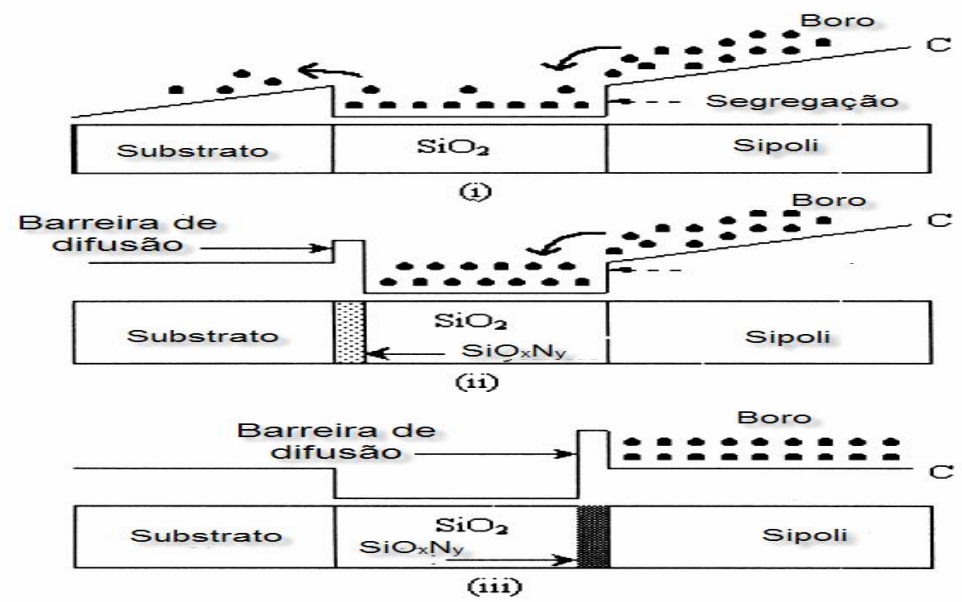

Figura 2.25 - Representação esquemática da difusão de boro a partir do Si-poli $\mathrm{P}^{+}$ao longo da estrutura $\mathrm{SiO}_{2}-\mathrm{Si}$. (i) estrutura Si-poli $\mathrm{P}^{+} / \mathrm{SiO}_{2} / \mathrm{Si}$ sem a presença de nitrogênio, (ii) camada de $\mathrm{SiO}_{x} \mathrm{~N}_{y}$ na interface $\mathrm{Si}_{-} \mathrm{SiO}_{2}$ e (iii) camada de $\mathrm{SiO}_{x} \mathrm{~N}_{y}$ na interface Si-poli/Si (WU, 1999).

O estudo da $\mathrm{I} / \mathrm{I}_{\mathrm{o}}$ de nitrogênio através do Si-poli foi estudado por Bauer (1998). Inicialmente foram fabricados capacitores MOS com processo inicial de oxidação térmica seca seguida por deposição de Si-poli por LPCVD. Na seqüência, foram realizados processos de implantação e RTP do nitrogênio, dopagem do Si-poli por $1 / I_{0}$ de boro e fósforo, RTP do boro e metalização com Al. Finalmente, definiu-se a geometria dos capacitores por litografia e removeuse o óxido da costa seguida pela metalização e sinterização. 
Após a construção dos capacitores, o efeito da dose de nitrogênio foi estudado através de diversos parâmetros elétricos e físicos, como: carga para ruptura ou $\mathrm{Q}_{\mathrm{BD}}$ (Charge to breakdown), característica corrente-tensão (I-V), medida de $\mathrm{R}_{\mathrm{sh}}$ e perfilamento do nitrogênio por SIMS (Secondary Ion Mass Spectroscopy).

Para a análise de $\mathrm{Q}_{\mathrm{BD}}$ foram fabricados capacitores com porta de Si-poli $\left(\mathrm{P}^{+} \mathrm{e}\right.$ $\mathrm{N}^{+}$) os quais foram mantidos sob injeção de corrente de $80 \mathrm{~mA} / \mathrm{cm}^{2}$. O gráfico de Weibull da figura 2.26 apresenta as distribuições de $\mathrm{Q}_{\mathrm{BD}}$ em relação à taxa de falhas para esses capacitores com doses de $\mathrm{I} / \mathrm{I}_{\mathrm{O}}$ de nitrogênio variando de $5.10^{14}$ a $5.10^{15} \mathrm{~cm}^{-2}$ e RTP realizado em $1030{ }^{\circ} \mathrm{C}$ por 30 segundos. Os símbolos cheios indicam porta de Si-poli $\mathrm{N}^{+}$e os vazios, $\mathrm{P}^{+}$. Os símbolos conectados com linhas representam o tratamento RTP de $40 \mathrm{~s}$ e os sem linha, $20 \mathrm{~s}$, todos na temperatura de $1050^{\circ} \mathrm{C}$.

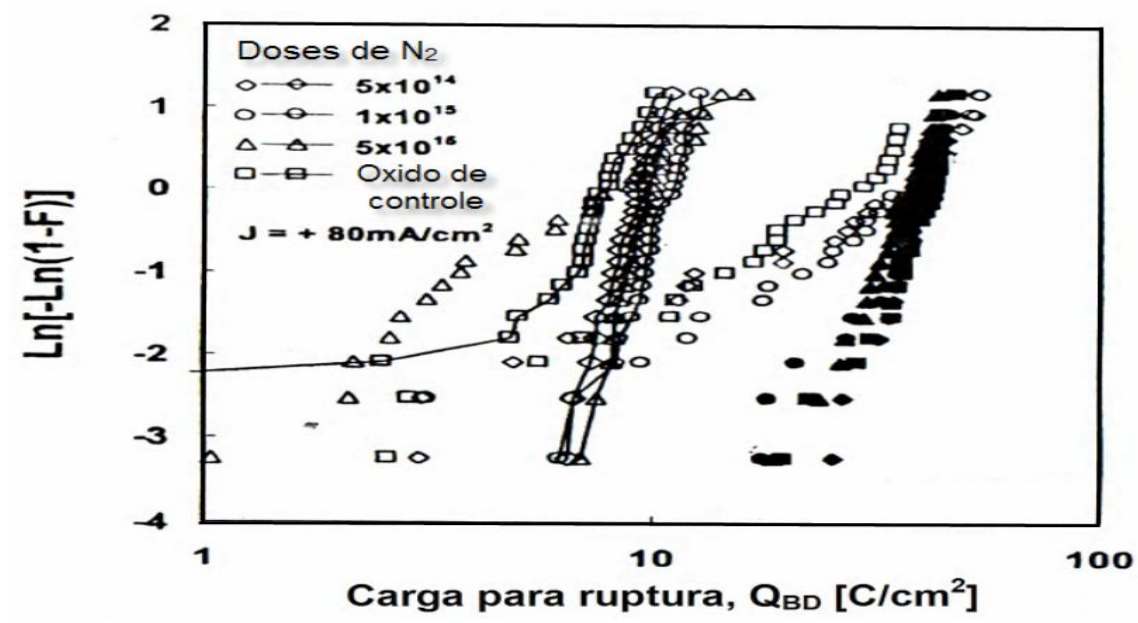

Figura 2.26 - Distribuições de $Q_{\mathrm{BD}}$ função de $\ln (-\ln (1-\mathrm{F}))$ para capacitores com porta de Si-poli $\mathrm{P}^{+}$(símbolos vazios) recozidas por RTP a $40 \mathrm{~s}$ (símbolos conectados com linha) e a $20 \mathrm{~s}$ (símbolos não conectados por linha) e $\mathrm{N}^{+}$(símbolos cheios) (BAUER, 1998).

Num primeiro momento se esperaria um excelente resultado para a dose de $5.10^{15}$ at. $\mathrm{cm}^{-2}$. Porém, pela figura 2.26 não é isso que é observado, mas sim, uma baixa qualidade (baixo valor de $\mathrm{Q}_{\mathrm{BD}}$ ) até para processo RTP de ativação de boro de $20 \mathrm{~s}$, resultado esse que será explicado adiante. Doses baixas de nitrogênio, como $5.10^{14} \mathrm{at} / \mathrm{cm}^{2}$, tem baixo valor de $Q_{\mathrm{BD}}$ já que o boro não foi retido substancialmente pelo $\mathrm{SiO}_{\mathrm{x}} \mathrm{N}_{\mathrm{y}}$. Os melhores resultados são encontrados para a dose de $1.10^{15} \mathrm{at} / \mathrm{cm}^{2}$ para tempos de recozimento do boro a $20 \mathrm{~s}$, 
aproximando-se dos resultados encontrados para capacitores MOS com porta de Si-poli $\mathrm{N}^{+}$. Os resultados são comparados com o Si-poli $\mathrm{N}^{+}$já que não há segregação de fósforo em direção ao $\mathrm{SiO}_{2}$ já que o coeficiente de segregação do fósforo é maior que 1, ou seja, ele tende a ficar no Si-poli, confirma ilustra a figura 2.27 (PFIESTER, 1990). Note que a presença do boro no corpo do $\mathrm{SiO}_{2}$ e na superfície do Si altera substancialmente com maior ou menor intensidade todos os parâmetros que dependam da dopagem, onde um deles a tensão de banda plana.

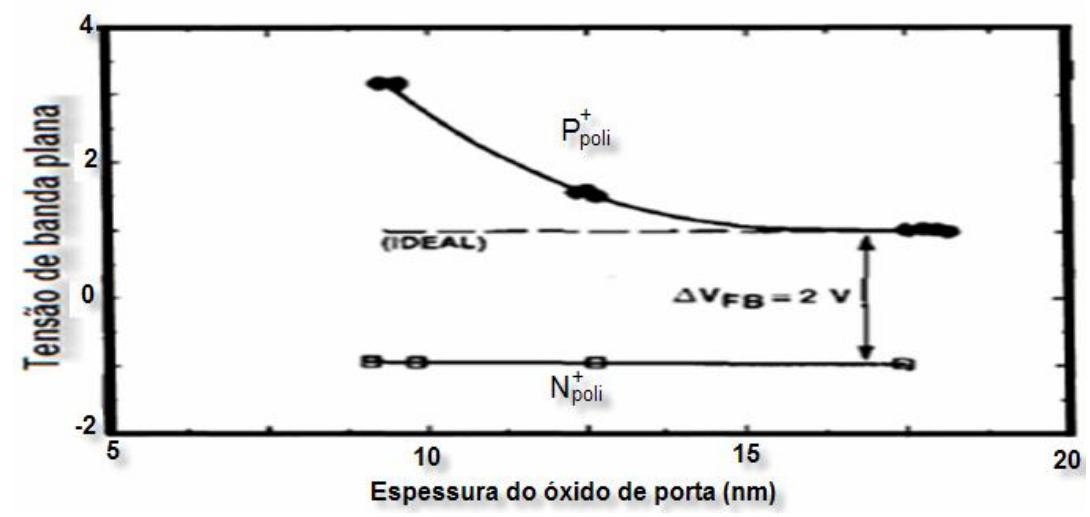

Figura 2.27: Comportamento da tensão de banda plana com a variação da espessura do óxido para portas Si-poli $\mathrm{P}^{+}$e Si-poli $\mathrm{N}^{+}$(PFIESTER, 1990).

Retornando a figura 2.26, observa-se que o aumento da dose de nitrogênio $\left(5.10^{14}<\right.$ dose $<5.10^{15}$ at. $\left.\mathrm{cm}^{-2}\right)$ resulta em aumento de valor de $\mathrm{Q}_{\mathrm{BD}}$ para processo de RTP de boro de $20 \mathrm{~s}$. Porém, quando se aumenta o RTP do boro para $40 \mathrm{~s}$, a degradação de $\mathrm{Q}_{\mathrm{BD}}$ é substancial. Por outro lado, realizar processo RTP a 40 s pode reduzir $R_{\text {sh }}$ pelo maior grau de ativação no Si-poli. Realizar RTP a 20 s aumenta a qualidade (altos valores de $\mathrm{Q}_{\mathrm{BD}}$ ) com a redução da dopagem e aumento do valor de $\mathrm{R}_{\text {sh }}$ substancialmente.

A concentração de nitrogênio ao longo das interfaces depende das receitas de RTP empregadas. Bauer (1998) estudou diversas receitas de RTP do nitrogênio para a dose que apresentou os melhores valores de $Q_{B D}$, que é a dose de $1.10^{15}$ at.cm ${ }^{-2}$. A figura 2.28 apresenta um gráfico de concentração de nitrogênio em relação à profundidade (trabalhado a partir de uma medida 
SIMS) para diversos tempos e temperaturas de RTP. A concentração de nitrogênio a $1100{ }^{\circ} \mathrm{C}$ por $30 \mathrm{~s}$ é de $4.10^{20} \mathrm{~cm}^{-3}$, resultou em larga degradação nas medidas elétricas. O ponto ótimo foi encontrado para temperaturas próximas a $900{ }^{\circ} \mathrm{C}$ por 30 minutos ou para RTP a $1000{ }^{\circ} \mathrm{C}$ por $30 \mathrm{~s}$, onde a concentração máxima (de pico) de nitrogênio está em torno de $7.10^{19} \mathrm{~cm}^{-3}$.

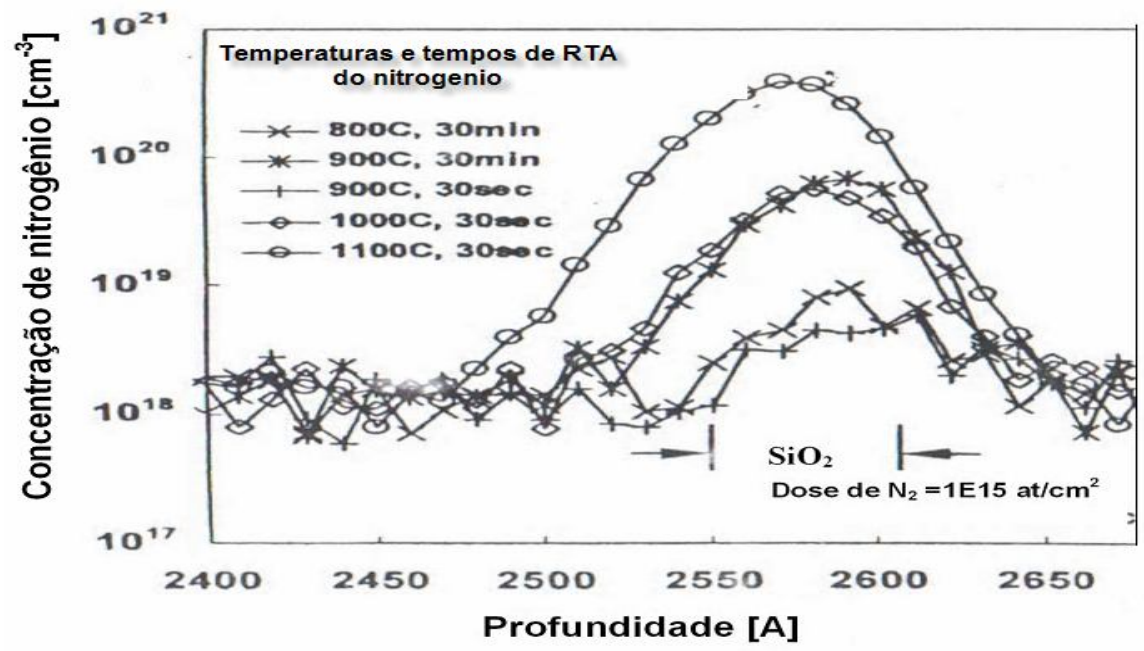

Figura 2.28 - Perfil do nitrogênio no $\mathrm{SiO}_{2}$ para a dose de $1.10^{15} \mathrm{~cm}^{-2}$ com várias temperaturas e tempos de RTA (BAUER, 1998).

Um outro estudo dirigido por Herden (2001) em um processo de fabricação dos capacitores MOS semelhante ao de Bauer, apresentou a correlação do ponto ótimo da concentração de nitrogênio e de boro, onde a concentração de boro se aproxima das receitas de difusão estudadas neste trabalho. A melhor receita para o RTP do nitrogênio é a $1070^{\circ} \mathrm{C}$ por $10 \mathrm{~s}$ para uma concentração de boro em torno de $1.10^{20}$ at.cm ${ }^{-3}$. 


\section{CARACTERIZAÇÃO ELÉTRICA E PERFILAMENTO}

Neste capítulo, são descritos os procedimentos experimentais empregados nas caracterizações elétricas dos capacitores MOS com porta de Si-poli $\left(\mathrm{P}^{+}\right.$e $\left.\mathrm{N}^{+}\right)$e no perfilamento do boro ao longo do Si-poli. Foram realizadas as medidas capacitância-tensão $(\mathrm{C}-\mathrm{V})$ em alta $\left(\mathrm{C}-\mathrm{V}_{\mathrm{AF}}\right)$ e baixa $\left(\mathrm{C}-\mathrm{V}_{\mathrm{BF}}\right)$ freqüência e as medidas corrente-tensão (I-V). A partir das medidas $\mathrm{C}-\mathrm{V}$ foram extraídos parâmetros elétricos típicos: "EOT", " $\mathrm{N}_{\mathrm{A}}$ " e " $\mathrm{V}_{\mathrm{FB}}$ ", conforme descrito no Apêndice $A$, e o parâmetro " $D_{\text {it" }}$ " conforme procedimento reportado por (DECLERK, 1973). Através das medidas I-V, foi obtido o campo elétrico de ruptura $\left(E_{B R}\right)$. Foram também realizadas medidas de resistência incremental do Si-poli nas mesmas amostras em que foram implementados os capacitores MOS com porta $\mathrm{P}^{+}$. 


\subsection{Medidas $C-\mathrm{V}_{\mathrm{AF}}$ e $\mathrm{C}-\mathrm{V}_{\mathrm{BF}}$}

Para obter a medida $\mathrm{C}-\mathrm{V}_{\mathrm{AF}}$, à temperatura ambiente, deve-se determinar a capacitância diferencial. Para isto, deve-se aplicar à porta do capacitor uma tensão de rampa suficientemente lenta, ou pequenas variações em " $V_{G}$ " $e$, sobreposta a esta tensão, um pequeno sinal alternado de freqüência suficientemente alta.

Para minimizar erros de medidas como o efeito de depleção profunda (figura 3.1), nas curvas $C-V_{A F}$, é conveniente que, se façam medidas da inversão para a acumulação nos instantes iniciais da medida na presença de luz.

Utilizando os equipamentos HP4280 $(1 \mathrm{MHz})$ e o medidor HP4140 foram obtidas as curvas $C-V_{A F}$ e $C-V_{B F}$, respectivamente nos capacitores MOS com área de $300 \mu \mathrm{m} \times 300 \mu \mathrm{m}$ em cada uma das lâminas fabricadas, para as doses de $1.10^{13}, 1.10^{14}, 1.10^{15}$ e $5.10^{15}$ at $/ \mathrm{cm}^{2}$ de nitrogênio. Os parâmetros de entrada utilizados para as medidas $\mathrm{C}-\mathrm{V}_{\mathrm{AF}}$ e $\mathrm{C}-\mathrm{V}_{\mathrm{BF}}$ estão na tabela 3.1.

Os equipamentos HP4280 e HP4140 estão conectados a uma caixa fechada onde os experimentos podem ser realizados com ou sem a presença de luz. Trata-se de uma caixa de paredes escuras e um suporte de lâminas com movimento " $x y$ ", permitindo assim o posicionamento da amostra. A lâmina fica presa por vácuo num suporte conhecido como "chuck". Através de um microscópio óptico foi feito o posicionamento das agulhas (ponta de prova) que, por sua vez, fazem o contato elétrico com os dispositivos da superfície da lâmina. Os equipamentos são comandados por um computador PC para aquisição automática de dados no laboratório (LSI/PSI/EPUSP). Assim, é possível acompanhar a extração dos pontos de capacitância através de um gráfico em função da tensão aplicada à porta já subtraída das capacitâncias parasitárias. 


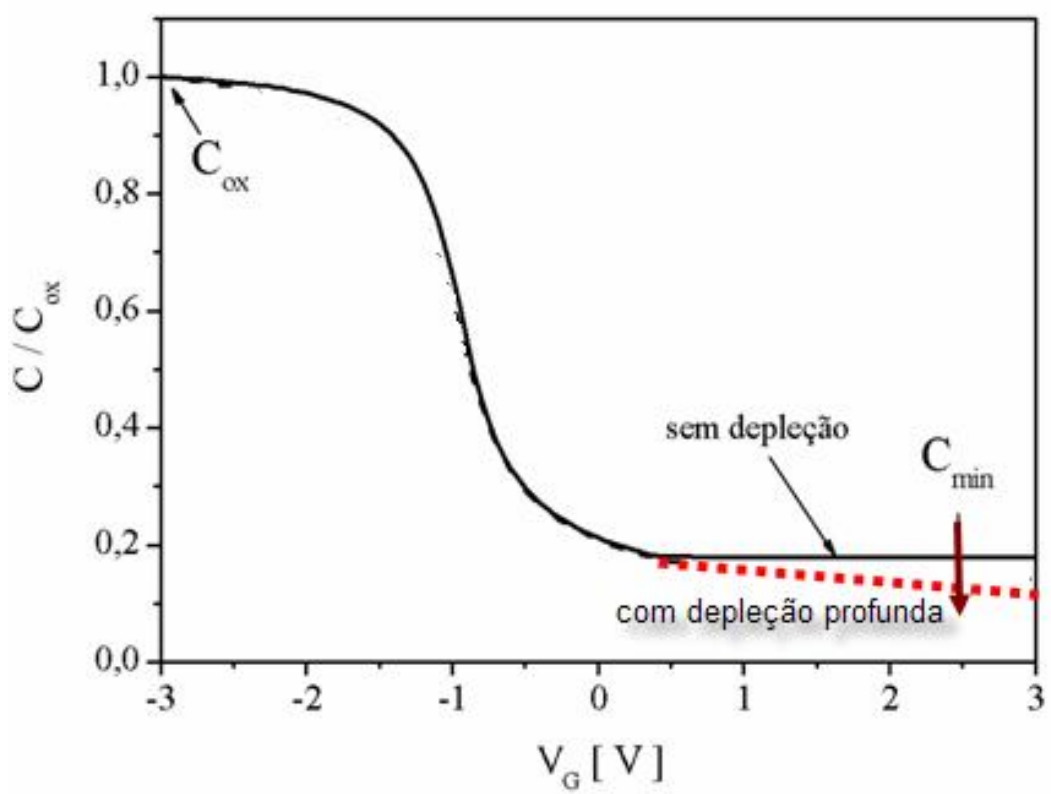

Figura 3.1 - llustração de uma curva $\mathrm{C}-\mathrm{V}_{\mathrm{AF}}$ normalizada onde se apresenta o efeito de depleção profunda.

Tabela 3.1 - Principais parâmetros utilizados nas medidas $C-V_{A F}$ e $C-V_{B F}$

\begin{tabular}{|l|l|}
\hline Tensão inicial & $3 \mathrm{~V}$ \\
\hline Tensão final & $-3 \mathrm{~V}$ \\
\hline Passo & $0,1 \mathrm{~V} / \mathrm{s}$ \\
\hline
\end{tabular}




\subsection{Medidas I-V}

As medidas corrente-tensão (I-V) foram levantadas no equipamento HP4140 com a ajuda do mesmo aparato das medidas C-V que permite o controle de posicionamento e luminosidade na amostra. A figura 3.2 apresenta um exemplo de curva típica de corrente versus tensão. O critério utilizado para a determinação da tensão de ruptura é a ocorrência de um salto no nível de corrente. A figura 3.3 apresenta o diagrama elétrico esquemático da montagem para a extração das curvas I-V.

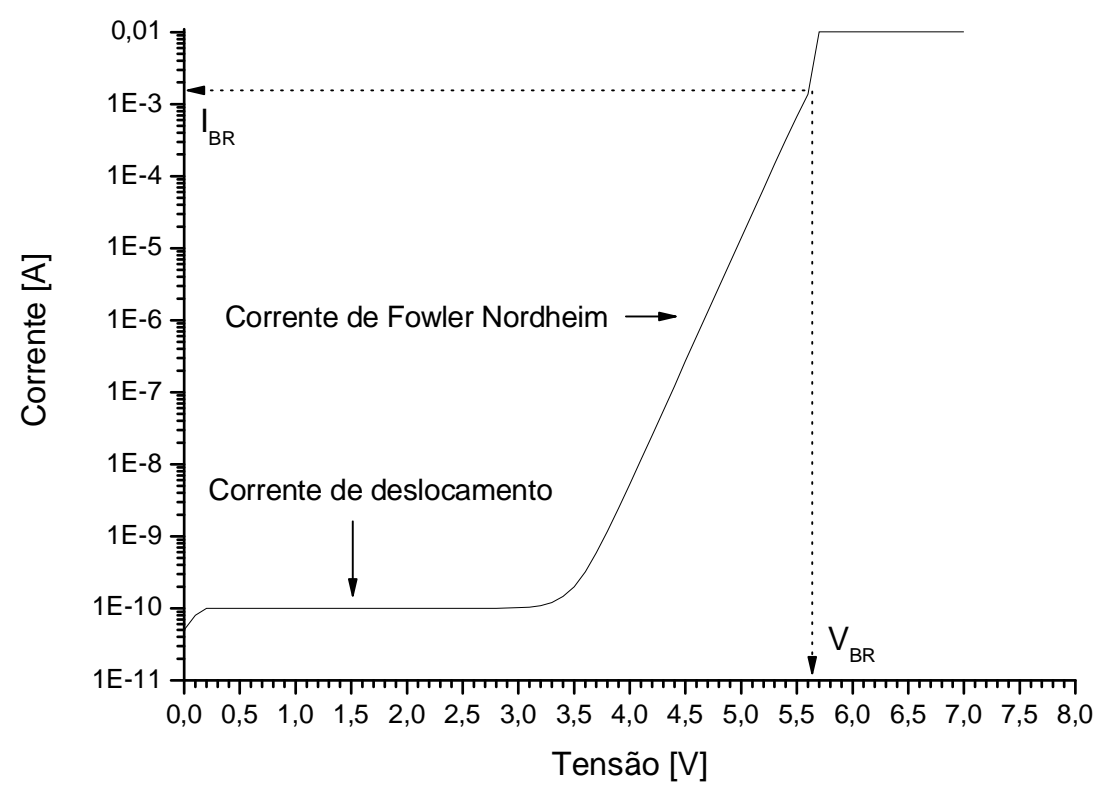

Figura 3.2 - Exemplo de uma curva experimental característica I-V para capacitores com espessura média do óxido de porta de $2,8 \mathrm{~nm}$. 


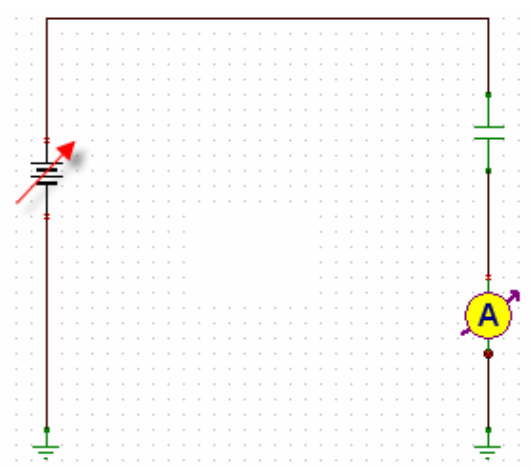

Figura 3.3 - Diagrama elétrico esquemático da montagem para a extração das curvas I-V.

Destaca-se na curva típica da figura 3.2 que o patamar de corrente a baixas tensões corresponde a uma corrente de deslocamento. Por fim, nota-se que antes de atingir o patamar de $10^{-2}(\mathrm{~A})$, a corrente apresenta um ligeiro salto constituindo a tensão de ruptura da rigidez dielétrica do capacitor $\left(\mathrm{V}_{\mathrm{BD}}\right)$.

Os experimentos com a rampa de tensão permitiram determinar os campos de ruptura. As medidas foram realizadas com os capacitores em acumulação ou em inversão, na ausência de luz e com inclinação da rampa de tensão de 0,1 $\mathrm{V} / \mathrm{s}$. As medidas sempre partiram do zero, indo até a tensão aonde ocorresse à ruptura da rigidez dielétrica do capacitor.

Desse modo, tendo uma espessura de $20 \mathrm{~nm}$ de $\mathrm{SiO}_{2}$ pode-se definir o campo intrínseco externo de aproximadamente $11 \mathrm{MV} / \mathrm{cm}$. O campo elétrico local a que uma dada molécula típica dentro do óxido estaria sujeita é de $22 \mathrm{MV} / \mathrm{cm}$ (NOGUEIRA, 2003).

Este campo local de $22 \mathrm{MV} / \mathrm{cm}$ pode ser entendido como aquele que está associada ao limite de deformação eletrônica das moléculas típicas do óxido. À medida que a espessura do óxido decresce, a constante dielétrica " $\varepsilon$ " pode deixar de ser característica. Desta forma, para um campo local intrínseco em torno de $20 \mathrm{MV} / \mathrm{cm}$ resulta em campo externo de ruptura maior. 
Assim, a tendência do campo externo de ruptura aumentar com a redução da espessura do óxido fica compreensível. Segundo Harari (1997), o campo externo pode chegar a valores tão alto quanto $28 \mathrm{MV} / \mathrm{cm}$ e que, por sua vez, está próximo do valor de $22 \mathrm{MV} / \mathrm{cm}$. Portanto, é muito provável que o campo realmente "intrínseco" é o "campo local" cujo valor pode situar-se em torno dos $22 \mathrm{MV} / \mathrm{cm}$. À medida que a espessura diminui, o campo externo de ruptura parece tender para o campo local.

Harari (1997) observou campos de ruptura da ordem de $28 \mathrm{MV} / \mathrm{cm}$ para óxidos de aproximadamente $3 \mathrm{~nm}$, muito acima dos $13 \mathrm{MV} / \mathrm{cm}$ (valor intrínseco segundo a literatura para óxidos mais espessos). Outro fato observado por Harari foi o elevado valor da densidade de corrente $(J)$ para capacitores com óxido fino, algo próximo a $50 \mathrm{~A} / \mathrm{cm}^{2}$, já para polarizações de porta igual a $1 \mathrm{~V}$. Neste trabalho constatou-se um valor médio baixo de $1,5 \mathrm{~A} / \mathrm{cm}^{2}$ para uma polarização de porta critica de $5 \mathrm{~V}$.

Apte (1993) reporta que os danos físicos no dielétrico, que promovem a ruptura do óxido, dependem do sentido da polarização na medida I-V. Foi observado que os danos físicos na interface $\mathrm{SiO}_{2} / \mathrm{Si}$ são maiores quando se realiza injeção de cargas pela porta do capacitor MOS, ou seja, quando se polariza o capacitor MOS, com substrato tipo $p$, na situação de acumulação. A interface $\mathrm{SiO}_{2} / \mathrm{Si}$ se caracteriza por ser uma interface mais frágil devido à existência de ligações pendentes, contaminantes, etc., propiciando uma densidade maior de danos acelerando o processo de ruptura do mesmo.

A injeção de cargas pelo substrato do capacitor MOS, ou seja, quando se polariza o capacitor MOS, com substrato tipo $p$, na situação de inversão o valor de " $D_{\text {it }}$ " tende a ser menor e o valor de " $E_{B R}$ " maior (APTE, 1993). Apesar das granulações do Si-poli e da rugosidade da interface $\mathrm{Si}$-poli//SiO${ }_{2}$ ser maior do que na interface $\mathrm{SiO}_{2} / \mathrm{Si}$, a interface $\mathrm{Si}$-poli/SiO $\mathrm{S}_{2}$ costuma se apresentar mais resistente e com maiores valores de "E $E_{B R}$ " (APTE, 1993). 
O valor de " $E_{B R}$ " foi obtido no presente trabalho através da seguinte equação (NOGUEIRA, 2003):

O valor de $E_{B R}$ foi tomado pela seguinte equação:

$$
E_{B R}=\frac{\left|V_{B R}\right|-\left|R_{S} \cdot I_{B R}\right|-\left|V_{F B}\right|}{t_{o x}}
$$

Os parâmetros "I $\mathrm{BR}_{\mathrm{BR}}$ " e "V $\mathrm{V}_{\mathrm{BR}}$ " são coletados da curva I-V conforme apresentado na figura 3.2. Os parâmetros " $\mathrm{V}_{\mathrm{FB}}$ " $\mathrm{e}$ "t $\mathrm{tox}_{\mathrm{ox}}$ ( EOT) foram obtidos a partir das curvas C-V $\mathrm{V}_{\mathrm{AF}}$ (veja Apêndice $\mathrm{A}$ ). 


\subsection{Técnicas de perfilamento}

Para obter o perfil de boro ao longo do Si-poli optamos pelo método da resistência de folha incremental. Os métodos a seguir (que não constituem a totalidade) são aqueles que permitem a determinação do perfil de portadores no substrato, através das técnicas destrutivas ou não. Basicamente podemos distinguir os seguintes grupos:

1. Técnicas incrementais conjugadas a uma das seguintes medidas:

a. Resistência de folha $\left(R_{s h}\right)$;

b. Resistência de espraiamento $\left(R_{\mathrm{sp}}\right)$;

c. Efeito Hall;

2. Técnicas de capacitância diferencial:

a) Curva C-V numa junção abrupta;

b) Medida de característica C-V pulsada

3. Métodos radioquímicos;

4. Absorção por portadores livres pela técnica de ressonância por plasma.

Além dos grupos citados, é importante destacar as técnicas de RBS (Rutherford Backscattering Spectroscopy), AES (Auger Electron Spectroscopy) e SIMS (Secondary Ion Mass Spectroscopy), entre outras. A técnica SIMS é semi-quantitativa e permite obter o perfil total de impurezas, devendo ser utilizada conjuntamente com um método elétrico para se determinar às partes eletricamente ativas, enquanto a técnica RBS se mostra útil para medir a distribuição de elementos pesados (como o arsênio, platina, etc...) no $\mathrm{Si}$, não servindo, entretanto, para a medida de perfis de boro ou fósforo (BRAGA, 1990). 


\subsubsection{Medida de resistência de folha incremental}

A escolha desta técnica se refere ao fato de não requerer aparelhagem especial, podendo ser implementada com os equipamentos comumente encontrados em laboratórios de microeletrônica.

Neste método utilizamos uma combinação de duas etapas de processo: a remoção uniforme e sucessiva de finas camadas de Si-poli, desde a sua superfície até a profundidade desejada, conjugada com as medidas de resistência de folha $\left(R_{\text {sh }}\right)$ entre cada etapa de remoção, caracterizando o método como destrutivo. A medida de " $\mathrm{R}_{\mathrm{sh}}$ " é realizada pelo método de quatro pontas e a remoção das camadas de Si-poli é feita por remoção química na temperatura ambiente.

A exatidão do perfil de impurezas vai depender, basicamente, da posição da medida de "Rsh" na amostra e da uniforme remoção dos incrementos mensuráveis de Si-poli a partir da superfície. A solução BHF, também chamado de BOE (Buffered Oxide Etch) foi utilizada para corroer o Si-poli. Esta também é utilizada para corroer $\mathrm{SiO}_{2}$ (óxido de silício) e $\mathrm{Si}_{3} \mathrm{~N}_{4}$ (nitreto de silício). Agentes renovadores são adicionados à solução de BHF para manter a taxa de corrosão constante como, por exemplo, $\mathrm{NH}_{4} \mathrm{~F}$ (fluoreto de amônia). Por isso o nome "buffered HF'. Quando se aumenta a concentração de $\mathrm{NH}_{4} \mathrm{~F}$ remove-se o filme de Si-poli em taxas maiores (PLUMMER, 2000).

O equipamento conhecido como quatro pontas (Four Point Probe) possibilita a medida da " $\mathrm{R}_{\text {sh }}$ ", da resistividade $(\rho)$ e do tipo de dopante inserido ( $p$ ou $n$ ) sob a superfície da lâmina. A medida é obtida por um conjunto de quatro pontas alinhada na qual se aplica corrente pelas duas pontas externas e mede-se a diferença de potencial pelas duas pontas internas sob a superfície de um filme homogêneo, sempre exercendo uma pressão por uma força externa, conforme figura 3.4. A medida é simples, visto que não necessita de calibração prévia, 
não é destrutiva e mede qualquer superfície sem nenhum tratamento da mesma.

$R_{s h}=\frac{\rho}{t_{p o l i}}$

onde " $\rho$ " é a resistividade do filme (no caso, Si-poli) e "tpoli" é a espessura do Si-poli.

$\rho=\frac{1}{q \cdot \mu_{p} \cdot N_{p o l i}}$

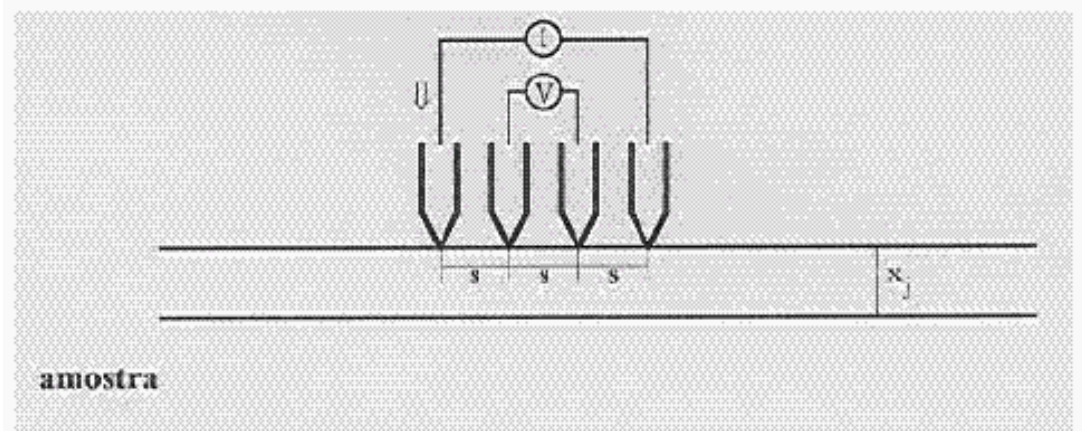

Figura 3.4 - Representação geométrica no método de medida de quatro pontas. 


\subsubsection{Metodologia para o perfilamento do boro no Si-poli}

Antes de fazer o perfilamento do boro no Si-poli, foi realizado a calibração entre tempo de corrosão e a altura do degrau formado. A partir de uma lâmina com Si-poli com 3 polegadas e orientação $\langle 100\rangle$, foi clivada em diferentes formatos geométricos para a identificação dos cacos. Após a clivagem, foi realizado um enxágüe de 3 minutos seguido em um "dip" de HF (na proporção $1 \mathrm{HF} / 10 \mathrm{H}_{2} \mathrm{O}$ ) até que os cacos saíssem secos ( 100 s).

Na seqüência, os cacos foram transferidos para a capela de eletrodeposição onde a metade dos cacos foi pintada com Apiezon ${ }^{\circledR}$. Após duas rodadas na seqüência de pintar e secar por dez minutos, os cacos foram submetidos a uma solução DLV (6 $\mathrm{NH}_{4} \mathrm{~F} / 1 \mathrm{HF}$ ) em que cada caco permaneceu nessa solução nos seguintes tempos: 5, 10, 20 e 40 minutos. Após a completa retirada do Apiezon $^{\circledR}$, seguiram-se às etapas de litografia, com a permanência dos cacos na acetona previamente aquecida por 10 minutos seguida por secagem em IPA por 10 minutos. Posteriormente, por se observar algumas manchas, alguns cacos foram submetidos à receita de limpeza química na seguinte ordem:
a) enxágüe inicial em água DI por 3 minutos;
b) 10 minutos de imersão na solução piranha;
c) enxágüe em água DI por 3 minutos;
d) Dip final na solução $1 \mathrm{HF} / 10 \mathrm{H}_{2} \mathrm{O}$;

Para a medida de degrau foi promovida uma varredura em toda a superfície dos mesmos já que qualquer marcação era removida após os processos de limpeza química dos mesmos. Nas medidas dos degraus, utilizou-se o perfilômetro DEKTAK 3030 onde os resultados são apresentados na figura 3.5, onde são correlacionados o tempo de corrosão e a altura do degrau formado. 


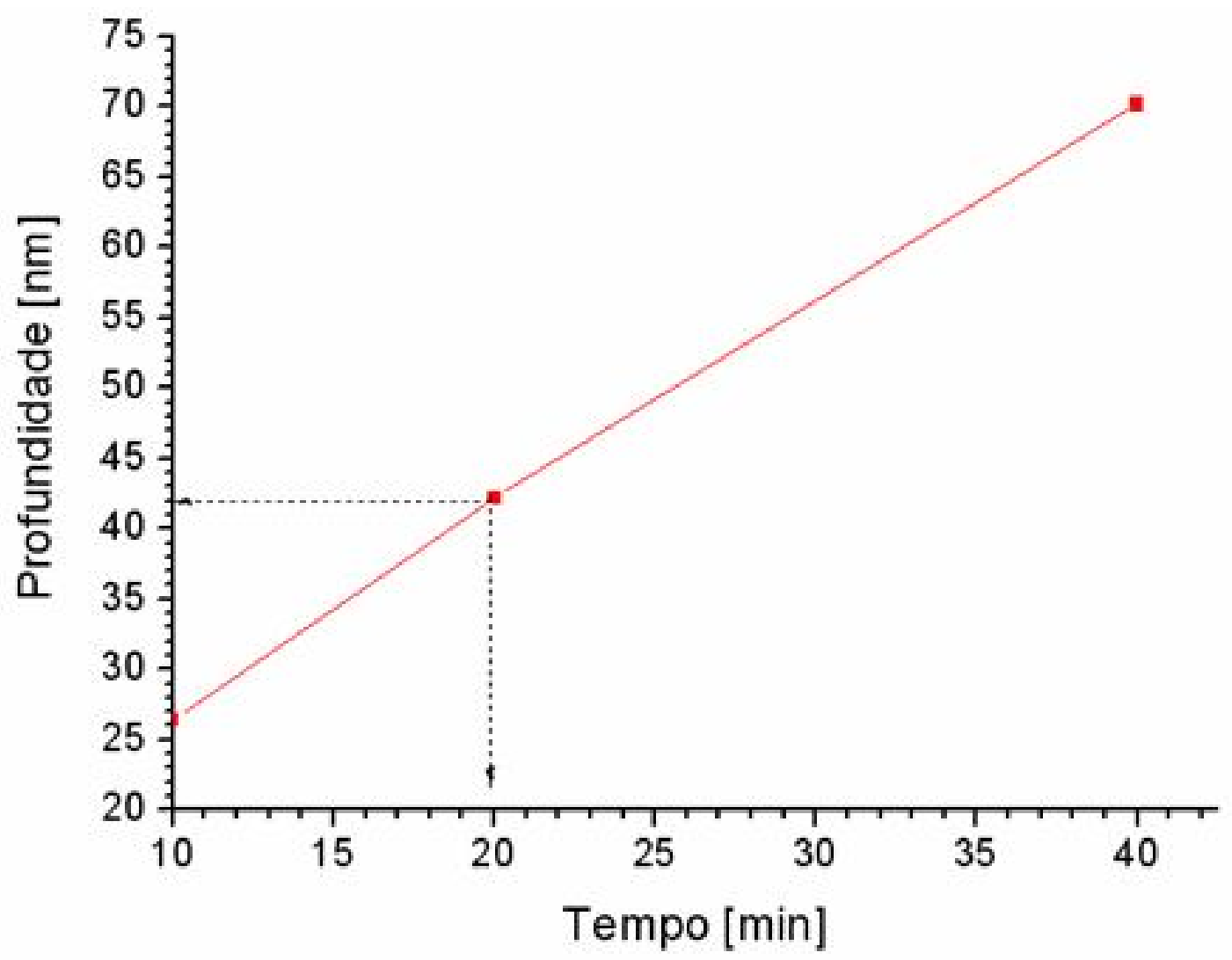

Figura 3.5 - Correlação entre tempo de corrosão e altura do degrau formado no Si-poli. 
Tendo o valor inicial da " $R_{\text {sh }}$ " na superfície do Si-poli com a correspondente espessura corroída pode-se determinar a carga ponto a ponto, conforme as eq.(3.4) e eq.(3.5).

$$
\begin{aligned}
& N\left(x_{i}\right)=\frac{\left(\sigma_{x}\right)_{i}}{q \cdot \mu_{i} x_{i}} \\
& \mu=\frac{\mu_{\max }-\mu_{\min }}{1+\frac{N\left(x_{i}\right)}{N_{r e f}}}+\mu_{\text {min }}
\end{aligned}
$$

onde:

$$
\begin{array}{ll}
N\left(\mathrm{x}_{\mathrm{i}}\right) & \text { concentrações de portadores ao longo da espessura a ser } \\
& \text { removida; } \\
\sigma_{\mathrm{x}} & \text { é a condutância de folha ao longo da camada removida; } \\
\mu & \text { mobilidade média dos portadores. }
\end{array}
$$

Com isso, é possível obter o gráfico que relaciona a carga inserida com a profundidade. Sendo reservado um quarto das lâminas aonde foram fabricados os capacitores MOS, foram feitos os seguintes procedimentos: 
a) Clivar as lâminas e retirar um quarto aonde não foram feitos os capacitores;

b) Remover o Alumínio na solução contendo $420 \mathrm{ml} \mathrm{H}_{3} \mathrm{PO}_{4} / 50 \mathrm{ml} \mathrm{H} \mathrm{H}_{2} \mathrm{O} / 30 \mathrm{ml}$ $\mathrm{HNO}_{3}$

c) Enxaguar os cacos em água DI por 10 min;

d) Preparo da solução Tampão: $6 \mathrm{NH}_{4} \mathrm{~F} / 1 \mathrm{HF}$;

e) Medida da Resistência de folha na frente do Si-poli.

Para cada uma das doses foram feitas dez medidas para cada camada removida, aonde foi adotado um tempo de 20 min de corrosão na solução tampão que corresponde a $(42,2 \pm 1,3) \mathrm{nm}$ de Si-poli removido, totalizando oito pontos de corrosão. As medidas para cada ponto de corrosão adotado são apresentadas na tabela 5.2, capítulo 5. 


\section{FABRICAÇÃO DOS CAPACITORES MOS}

Este capítulo será dividido em três partes. Na primeira parte são apresentados os procedimentos experimentais empregados na fabricação dos capacitores MOS formados pela estrutura $\mathrm{Si}-\mathrm{poli}_{\mathrm{SiO}} / \mathrm{Si}$. Na seqüência, os procedimentos para a fabricação dos capacitores MOS com porta de Si-poli dopada com boro (Si-poli $\mathrm{P}^{+}$) serão detalhados. A terceira parte será constituída pelas etapas de fabricação dos capacitores MOS com porta de Si-poli dopada com fósforo $\left(\right.$ Si-poli $\left.\mathrm{N}^{+}\right)$.

Na primeira parte são detalhados os processos de limpeza química inicial RCA, oxidação térmica do $\mathrm{Si}$, deposição de Si-poli e medidas no elipsômetro e no perfilômetro para a obtenção das espessuras dos filmes de $\mathrm{SiO}_{2}$ e Si-poli. $\mathrm{Na}$ seqüência, foram realizados testes de difusão, utilizando SOG (Spin-On-Glass) de boro em quatro temperaturas $\left(950,1000,1050\right.$ e $1100{ }^{\circ} \mathrm{C}$ ) a fim de avaliar o quanto de boro se difundi para a superfície do Si. Foram realizadas medidas de resistência de folha $\left(R_{\mathrm{sh}}\right)$ na superfície do Si-poli e na superfície do Si após a remoção do Si-poli, por plasma e a remoção do $\mathrm{SiO}_{2}$ por dip em solução de $1 \mathrm{HF} / 10 \mathrm{H}_{2} \mathrm{O}$.

Na segunda parte são abordadas as etapas subseqüentes da fabricação dos capacitores MOS com porta de Si-poli $\mathrm{P}^{+}$onde são discutidos: 
1. Simulação SRIM (Stopping and Range of lon in Matter) para a obtenção da energia de implantação iônica $\left(\mathrm{l} / \mathrm{I}_{\mathrm{o}}\right)$ de nitrogênio;

2. Realização da limpeza química RCA para a etapa de $1 / I_{0}$ com nitrogênio iônico $\left(\mathrm{N}^{+}\right)$;

3. Realização da limpeza química RCA para a etapa de recozimento térmico rápido (RTP) do nitrogênio;

4. Testes de difusão utilizando SOG de boro a fim de avaliar sua concentração ao longo da estrutura Si-poli/SiO $/ 2 / \mathrm{Si}$ implantada com nitrogênio;

5. Definição da geometria dos capacitores MOS.

$\mathrm{Na}$ terceira parte mencionam-se as etapas de fabricação dos capacitores MOS com porta de Si-poli $\mathrm{N}^{+}$com a determinação da receita de difusão, após a aplicação do SOG de fósforo e a definição da geometria dos capacitores MOS. 


\subsection{Obtenção da estrutura $\mathrm{Si}-\mathrm{poli} / \mathrm{SiO}_{2} / \mathrm{Si}$}

A figura 4.1 apresenta as etapas iniciais empregadas na fabricação dos capacitores MOS. Foram utilizadas lâminas de Si de 3 polegadas, com orientação cristalográfica $\langle 100\rangle$ tipo p e com resistividade entre 1 e 10 ohm.cm.

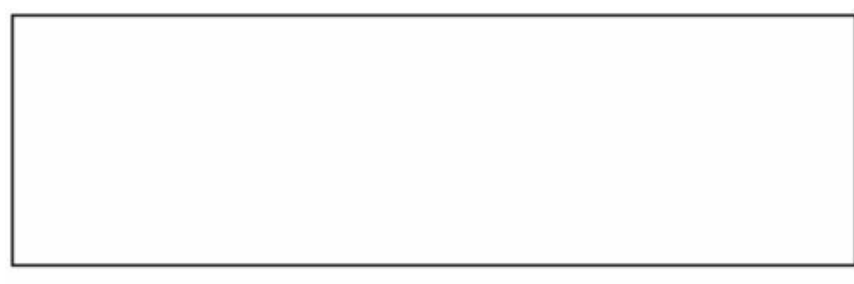

Limpeza química

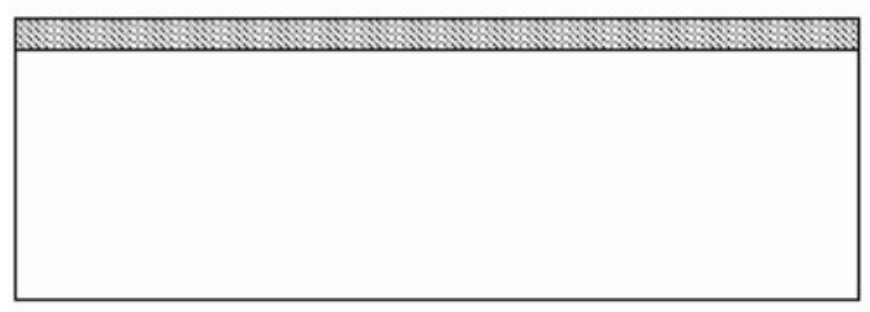

Oxidação témica

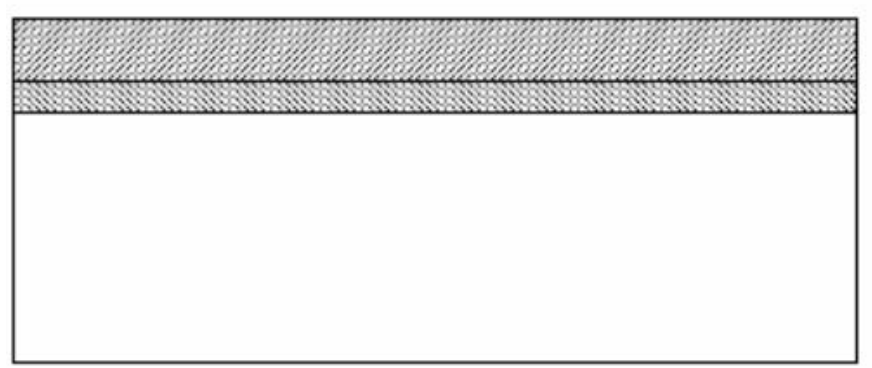

Deposição de Si-poli

Figura 4.1 - Etapas iniciais da fabricação dos capacitores MOS. 


\subsubsection{Limpeza química}

Para iniciar a fabricação dos capacitores MOS, um conjunto de 16 lâminas foram limpas com a seguinte receita:

a) Enxágüe das lâminas em água DI (deionizada) por 5 minutos;

b) Imersão em solução fervente de $0,25 \mathrm{NH}_{4} \mathrm{OH}(35 \%) / 1 \mathrm{H}_{2} \mathrm{O}_{2}(30 \%) / 4 \mathrm{H}_{2} \mathrm{O}$ por 13 minutos;

c) Enxágüe em água DI por 5 minutos;

d) Imersão em solução fervente de $1 \mathrm{HCl}(36,5 \%) / 4 \mathrm{H}_{2} \mathrm{O}$ por 13 minutos;

e) Enxágüe das lâminas em água DI por 5 minutos;

f) Imersão em solução de $1 \mathrm{HF}(49 \%) / 40 \mathrm{H}_{2} \mathrm{O}$ por 90 segundos a temperatura ambiente;

g) Enxágüe das lâminas em água DI por 5 minutos.

No preparo das soluções $0,25 \mathrm{NH}_{4} \mathrm{OH} / 1 \mathrm{H}_{2} \mathrm{O}_{2} / 4 \mathrm{H}_{2} \mathrm{O}$ e $1 \mathrm{HF} / 40 \mathrm{H}_{2} \mathrm{O}$ utilizou-se o método da diluição, objetivando uma maior precisão nas proporções $\begin{array}{llllllll}\text { empregadas. A solução de } 0,25 \quad \mathrm{NH}_{4} \mathrm{OH} / 1 & \mathrm{H}_{2} \mathrm{O}_{2} / 4 & \mathrm{H}_{2} \mathrm{O} & \text { foi preparada do }\end{array}$ seguinte modo: primeiramente colocou-se $400 \mathrm{ml}$ de água (DI) e $100 \mathrm{ml}$ de $\mathrm{NH}_{4} \mathrm{OH}$, obtendo assim uma concentração de 4:1, respectivamente. Em seguida, descartou-se $250 \mathrm{ml}$ desta solução. Em seguida, acrescentou-se mais $200 \mathrm{ml}$ de água DI, indo até a marca de $450 \mathrm{ml}$ no béquer. Nesta situação, a concentração é de $4 \mathrm{H}_{2} \mathrm{O} / 0,5 \mathrm{NH}_{4} \mathrm{OH}$. Descartou-se então $225 \mathrm{ml}$ desta solução e em seguida preencheu-se com mais $200 \mathrm{ml}$ de água DI, até a marca de aproximadamente $425 \mathrm{ml}$. Nesta situação, a concentração da solução é de $4 \mathrm{H}_{2} \mathrm{O} / 0,25 \mathrm{NH}_{4} \mathrm{OH}$. A solução completa da RCA $1\left(0,25 \mathrm{NH}_{4} \mathrm{OH} / 1 \mathrm{H}_{2} \mathrm{O}_{2} / 4 \mathrm{H}_{2} \mathrm{O}\right)$ é obtida ao acrescentar mais $100 \mathrm{ml}$ de $\mathrm{H}_{2} \mathrm{O}_{2}$, indo até a marca dos $525 \mathrm{ml}$.

A escolha da proporção $0,25 \mathrm{NH}_{4} \mathrm{OH} / 1 \mathrm{H}_{2} \mathrm{O}_{2} / 4 \mathrm{H}_{2} \mathrm{O}$ resulta em uma superfície menos rugosa (LEl, 1998; IMAI, 1998). Superfícies mais planas implicam em menor corrente de fuga através do dielétrico, menor concentração de armadilhas próxima à superfície do Si e um alto valor do campo elétrico de 
ruptura $\left(E_{B R}\right)$. Essas melhoras ocorrem devido à menor proporção da relação $\mathrm{NH}_{4} \mathrm{OH} / \mathrm{H}_{2} \mathrm{O}_{2}$, (MEURIS, 1992) e na eliminação do $\mathrm{H}_{2} \mathrm{O}_{2}$ da etapa RCA 2 conforme reporta (MERTENS, 1999). Ambas as modificações não perdem em eficiência de remoção dos contaminantes ao longo da superfície do Si.

\subsubsection{Oxidação térmica do $\mathrm{Si}$}

Após a etapa de limpeza química, foi realizada a etapa de oxidação térmica das lâminas de Si no forno da Minibrute 80 fabricado pela Thermco Systems. Inicialmente, foi realizado um processo de oxidação em uma lâmina de Si tipo $p$ (LS), com parâmetros iguais aos que foram usados para a oxidação das 16 lâminas processadas. Os objetivos desse processo em uma única lâmina foram:

1. aferir a espessura do $\mathrm{SiO}_{2}$, já que o equipamento empregado na medida da espessura (elipsômetro) se situa fora da sala limpa. Além disso, a espessura obtida nessa etapa inicial é mais confiável já que a obtenção da espessura quando se tem outra camada sobreposta ao $\mathrm{SiO}_{2}$ ou quaisquer composições de nitrogênio mascara a medida. Somando-se a esses inconvenientes, na medida de espessura por métodos elétricos deve ser levado em conta o efeito quântico e, a possível depleção do Si-poli, em óxidos de porta ultrafinos.

2. detectar uma possível redução dos contaminantes, como metais e íons alcalinos, nos processos de limpeza (nos béqueres) e no tubo do forno de oxidação;

3. fazer teste da simulação da energia de $\mathrm{I} / \mathrm{I}_{\mathrm{o}}$ do nitrogênio, onde o valor da espessura do $\mathrm{SiO}_{2}$ entra no cálculo da energia.

A lâmina LS foi limpa, com a mesma receita, um dia antes da limpeza das 16 lâminas. Na seqüência, objetivando uma espessura do óxido de silício 
$\left(\mathrm{SiO}_{2}\right)$ de $2 \mathrm{~nm}$, realizou-se o processo de oxidação que resultasse em excelentes propriedades físico-químicas (NOGUEIRA, 2003), ou seja, realizar a oxidação térmica do $\mathrm{Si}$ em ambiente de $\mathrm{O}_{2}$ seco à $800{ }^{\circ} \mathrm{C}$ durante 10 minutos num fluxo de 1,5 $\mathrm{l} / \mathrm{min}$ de $\mathrm{O}_{2}$ mais um fluxo de $2 \mathrm{l} / \mathrm{min}$ de nitrogênio $\left(\mathrm{N}_{2}\right)$ mais $10 \%$ de $\mathrm{H}_{2}$. Após este processo, foi realizado um recozimento da lâmina LS em ambiente de $\mathrm{N}_{2}$ durante 10 minutos.

A lâmina LS foi introduzida no forno com a face polida voltada para a entrada das espécies oxidantes, através de um carregador de quartzo após a estabilização da temperatura a $800{ }^{\circ} \mathrm{C}$. A introdução da lâmina foi lenta e gradual, durante cinco minutos, até alcançar a região central. Esse procedimento foi feito para evitar grandes gradientes de temperatura os quais poderiam causar choque térmico na lâmina e empenamento da mesma.

As medidas elipsométricas foram realizadas para a determinação da espessura dos filmes formados. Utilizou-se o equipamento Rudolph, modelo Auto-EL NIR 3 (RUDOLPH, 1989), que utiliza uma fonte de laser He-Ne de comprimento de onda $(\lambda)=405,0$ ou $632,8 \mathrm{~nm}$ e de ângulo de incidência $=70^{\circ}$. Este elipsômetro permite determinar a espessura e 0 índice de refração $(n)$ dos filmes obtidos. Para verificar a calibração do equipamento, mediu-se uma lâmina de Si padrão recoberta com $\mathrm{SiO}_{2}$ de $144,2 \mathrm{~nm}$. O valor de " $n$ " convergia para todas as medidas realizadas, ou seja, realizava-se a medida de espessura óptica do óxido (tox') informando como parâmetro de entrada " $n$ " = 1,462 que, posteriormente, o equipamento fornecia o mesmo " $n$ " informado. Observe que, esse valor denota um óxido de silício estequiométrico (GREEN, 2001).

Após a medida de tox em várias regiões da lâmina LS de teste, constatou-se uma espessura média de 2,6 $\mathrm{nm}$. Mais tarde, realizou-se o processo de oxidação térmica das 16 lâminas da mesma forma e com os mesmos parâmetros utilizados na lâmina LS. Em seguida, as lâminas foram mantidas próximas à entrada do forno de oxidação, numa vazão de $0,5 \mathrm{l} / \mathrm{min}$ de $\mathrm{N}_{2}$, até o dia seguinte, para a etapa posterior de deposição do Si-poli. 


\subsubsection{Deposição de Si-poli}

Após a passivação do filme de $\mathrm{SiO}_{2}$ (por $10 \mathrm{~min}$ em ambiente de $2 \mathrm{l} / \mathrm{min}$ de $\mathrm{N}_{2}$ ), foi realizada a deposição de Si-poli (material de porta do transistor) no reator LPCVD (Thermo System MB-80). Tal processo foi realizado a $630{ }^{\circ} \mathrm{C}$ durante 30 minutos em ambiente composto de $\mathrm{SiH}_{4}(49,5 \mathrm{sccm})+\mathrm{N}_{2}(280 \mathrm{sccm})$ numa pressão de 600 mtorr, objetivando uma espessura de $250 \mathrm{~nm}$. Esse processo foi realizado em duas etapas, onde cada etapa continha oito lâminas.

Para a medida de espessura do Si-poli, uma lâmina com a estrutura $\mathrm{Si}-$ poli $/ \mathrm{SiO}_{2} / \mathrm{Si}$ foi dividida em duas partes, para que, posteriormente, fossem destinadas à medida de espessura no perfilômetro e no elipsômetro, respectivamente. Em uma das partes foi definido um degrau. Na lâmina destinada a perfilometria, em sua metade foi aplicado o Apiezon $^{\oplus}$, através de um pincel. Após Apiezon seco, o Si-poli foi removido através da solução de $1 \mathrm{DLV} / 50 \mathrm{HNO}_{3} / 20 \mathrm{H}_{2} \mathrm{O}$ por $70 \mathrm{~s}$. O Apiezon ${ }^{\circledR}$ foi removido através da solução de tricloro-etileno em duas placas de petri. A solução de corrosão do Si-poli foi preparada pelo método de diluição, semelhante ao utilizado nas limpezas das lâminas com a receita $\mathrm{RCA}$, item 4.1 .

A medida perfilométrica foi realizada no perfilômetro DEKTAK 3030, disponível no LSI/EPUSP, que possui uma agulha de tungstênio de $100 \mu \mathrm{m}$ que possibilita medir espessuras de $100 \mathrm{~nm}$ com resolução de $10 \mathrm{~nm}$. Num primeiro momento, a lâmina foi limpa com jato de nitrogênio a fim de tirar qualquer particulado grosseiro sobre a superfície. Logo em seguida, foi posicionada na parte central do prato com o degrau perpendicular ao movimento da agulha (no mesmo plano espacial) visualizado através do SPOT luminoso. Das diversas medidas realizadas em diferentes regiões da metade da lâmina, a média e o desvio padrão das medidas realizadas foram de $(341 \pm 15) \mathrm{nm}$.

As medidas elipsométricas foram realizadas no equipamento Rudolph, modelo Auto-EL NIR 3 (RUDOLPH, 1989). Do mesmo modo em que foi medida a 
espessura do $\mathrm{SiO}_{2}$ na lâmina LS, foi feita a calibração do equipamento, onde se mediu uma lâmina padrão com estrutura $\mathrm{SiO}_{2} / \mathrm{Si}$, com $\mathrm{SiO}_{2}$ de $309 \mathrm{~nm}$, mais próxima da espessura obtida por perfilometria do Si-poli $(\sim 340 \mathrm{~nm})$. O valor obtido da espessura foi de $(321 \pm 1) \mathrm{nm}$.

\subsubsection{Difusão de boro ao longo da estrutura $\mathrm{Si}-\mathrm{poli} / \mathrm{SiO}_{2} / \mathrm{Si}$}

Neste item foram realizados testes de difusão de boro nas temperaturas de $950,1000,1050$ e $1100^{\circ} \mathrm{C}$ por 30 min em uma lâmina de Si, clivada em quatro partes iguais, a fim de avaliar a concentração de boro ao longo da estrutura $\mathrm{Si}$-poli/SiO$/ \mathrm{Si}$.

Primeiramente, realizou-se o processo de limpeza química utilizando a receita RCA padrão em uma lâmina contendo a estrutura $\mathrm{Si}-\mathrm{poli}_{\mathrm{SiO}} / \mathrm{Si}$. Após o enxágüe em água DI, por 3 minutos, foi realizado um "dip" em $1 \mathrm{HF} / 20 \mathrm{H}_{2} \mathrm{O}$. Estando o forno na temperatura de trabalho, nas diferentes temperaturas de processo, as lâminas foram aquecidas a $200{ }^{\circ} \mathrm{C}$ por $5 \mathrm{~min}$ no hot plate para eliminação de umidade na superfície, onde em seguida, depositou-se o SOG (Spin-On-Glass) de boro em uma rotação de 3000 rpm por $10 \mathrm{~s}$. O SOG foi retirado da geladeira antes do procedimento de limpeza de modo a permitir a redução da viscosidade do mesmo. Após o spin-on, seguiu-se a cura do SOG a $200{ }^{\circ} \mathrm{C}$ por 30 min para eliminação do solvente. Em seguida, a lâmina foi clivada e os cacos foram colocados recozidos em um fluxo de $2 \mathrm{l} / \mathrm{min}$ de nitrogênio. As lâminas foram inseridas vagarosamente no forno num intervalo de 5 min até o centro das lâminas ou de acordo com a calibração para cada temperatura.

Os cacos com a estrutura $\mathrm{Si}-$ poli $/ \mathrm{SiO}_{2} / \mathrm{Si}$ na posição de patamar (ou de processo) ficaram em repouso por 20 min e foram retirados vagarosamente, por 5 minutos. Como não se conhece o "pacote" térmico na entrada e na saída, 
computou-se os tempos de carregamento e descarregamento no tempo de difusão, de modo que, o tempo total de difusão foi de $\underline{30 \mathrm{~min}}$.

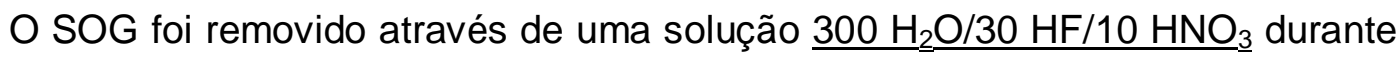
300 segundos. Na seqüência, foram medidas a " $R_{\text {sh", conforme descrito em }}$ 3.3.1.1. Os resultados são apresentados no capítulo 5, na tabela 5.1. 


\subsection{FABRICAÇÃO DE CAPACITORES MOS COM Si-poli P $^{+}$}

Para a fabricação de capacitores MOS com porta de silício policristalino dopado com boro, foram feitos os seguintes procedimentos:

1. Simulação SRIM;

2. Implantação de nitrogênio;

3. Recozimento térmico do nitrogênio;

4. Dopagem do Si-poli através da aplicação de SOG de boro seguido por difusão térmica;

5. Definição da geometria dos capacitores

\subsubsection{SIMULAÇÃO SRIM}

Através dos dados de espessura do $\mathrm{SiO}_{2}$ e do $\mathrm{Si}$-poli, foram realizadas as simulações SRIM (Stopping and Range of lons Matter). Nas simulações, aproximamos ao máximo o pico de concentração de nitrogênio na interface $\mathrm{Si} / \mathrm{SiO}_{2}$, conforme já discutido em 2.5, onde a eficiência de nitrogênio é mais apreciável na interface $\mathrm{SiO}_{2} / \mathrm{Si}$. Como se tem uma diferença entre as medidas de espessura do Si-poli pela perfilometria e por elipsometria ( $20 \mathrm{~nm}$ ), decidiuse deixar o pico de $\mathrm{N}_{2}$ um pouco antes da interface $\mathrm{SiO}_{2} / \mathrm{Si}$, conforme figura 4.2. A energia obtida foi de $\underline{110 \mathrm{keV}}$. 


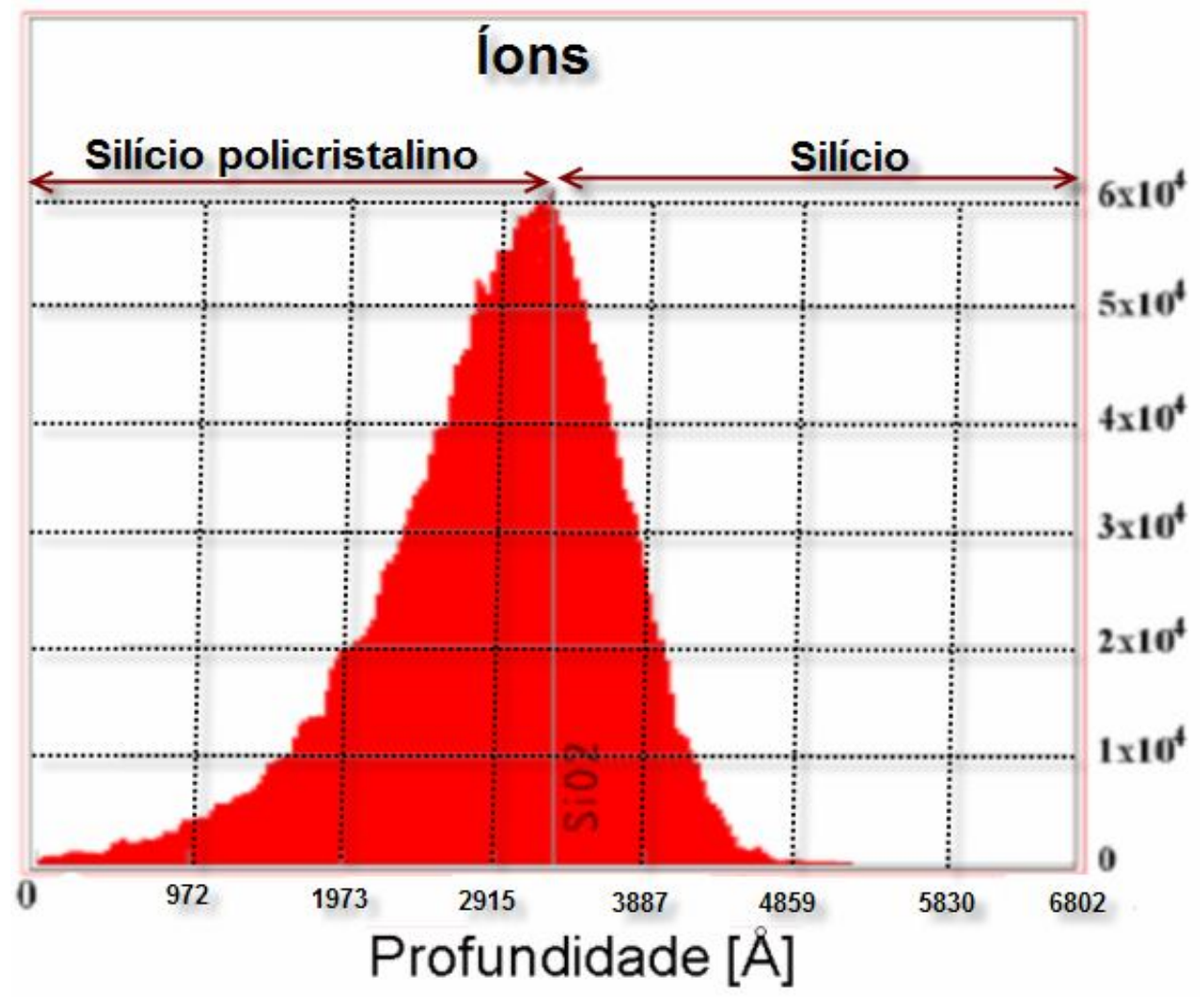

Figura 4.2 - Simulação SRIM para I//o de nitrogênio $\left(\mathrm{N}^{+}\right)$com energia de $\underline{110 \mathrm{keV}}$.

\subsubsection{Dopagem do Si-poli.}

Algumas etapas foram realizadas antes da dopagem do Si-poli, como: limpeza química, implantação iônica de nitrogênio e recozimento térmico do nitrogênio.

Antes da implantação iônica $\left(\mathrm{l} / \mathrm{I}_{0}\right)$, quatro lâminas (do primeiro grupo de deposição do Si-poli) foram limpas com a receita RCA padrão, precedida por um enxágüe por 3 minutos em água DI e "dip" final em solução de 1 HF/20 $\mathrm{H}_{2} \mathrm{O}$. As lâminas foram acondicionadas no dessecador e encaminhadas ao

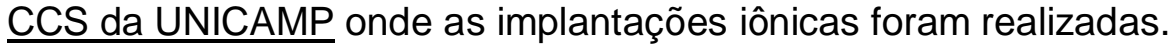


A receita $R C A$ empregada foi a seguinte:

a) $\mathrm{NH}_{4} \mathrm{OH} / \mathrm{H}_{2} \mathrm{O}_{2} / \mathrm{H}_{2} \mathrm{O}$ na proporção de $1 / 1 / 5,70-90{ }^{\circ} \mathrm{C}, 10-15$ minutos (RCA 1);

b) Enxágüe em água deionizada (DI);

c) $\mathrm{HCl} / \mathrm{H}_{2} \mathrm{O}_{2} / \mathrm{H}_{2} \mathrm{O}$ na proporção de $1 / 1 / 5,70-90{ }^{\circ} \mathrm{C}, 10-15$ minutos (RCA 2);

d) Enxágüe em água DI.

As implantações iônicas nas doses de $\underline{1.10^{13}, 1.10^{14}, 1.10^{15} \text { e } 5.10^{15} \text { at.cm }^{-2}}$ com energia de $\underline{110 ~ \mathbf{~ k e V}}$ foram realizadas no implantador iônico Eaton GA4204, da UNICAMP. Após as implantações, foi feito o Recozimento Térmico Rápido (RTP) do nitrogênio para as quatro doses, tomando como base as características elétricas reportadas por Herden (2001).

Herden estudou receitas de RTP a $1070{ }^{\circ} \mathrm{C}$ por $10 \mathrm{~s}$ que são muito eficientes em termos de características elétricas, com concentração de nitrogênio em torno de $2.10^{20} \mathrm{at} / \mathrm{cm}^{3}$ a qual utilizamos neste trabalho.

A dopagem do Si-poli foi realizada por aplicação do SOG de boro seguido por difusão térmica a $1050^{\circ} \mathrm{C}$ por 30 min, conforme será discutido no capítulo 5 na tabela 5.1. Os procedimentos realizados para a difusão do boro são idênticos aos reportados no item 4.1.4. 


\subsubsection{Concentração de boro na estrutura Si-poli $\mathrm{P}^{+} / \mathrm{SiO}_{2} / \mathrm{Si}$ com nitrogênio}

A fim de avaliar se houve boro difundido para a superfície do $\mathrm{Si}$, realizou-se a corrosão do Si-poli, por plasma. A corrosão foi feita com gás $\mathrm{SF}_{6}$ num fluxo de $25 \mathrm{sccm}$ proporcionando uma boa seletividade entre o Si-poli e O $\mathrm{SiO}_{2}$. O término da corrosão foi estabelecido após a corrosão do Si-poli nas costas, onde se observou a mudança de cor do plasma (das bordas para o centro, observadas por uma janela lateral) com tempo igual a $120 \mathrm{~s}$ para a face polida. $\mathrm{O} \mathrm{SiO}_{2}$ foi removido por um "dip" em solução $1 \mathrm{HF} / 20 \mathrm{H}_{2} \mathrm{O}$. Os resultados da concentração de boro na superfície do Si-poli e na superfície do Si, para cada temperatura são apresentados no capítulo 5 , na tabela 5.1 .

As quatro lâminas implantadas com nitrogênio e recozidas a $1070^{\circ} \mathrm{C}$ por $10 \mathrm{~s}$ sofreram difusão de boro (SOG) na temperatura de $1050{ }^{\circ} \mathrm{C}$ por $30 \mathrm{~min}$ com procedimento similar ao realizado no item 4.1.4. Antes das etapas de implantação iônica, recozimento térmico e difusão térmica, foram realizados os procedimentos de limpeza química com receita tipo RCA. 


\subsubsection{Definição da geometria dos capacitores}

\subsubsection{Metalização do alumínio por evaporação térmica}

O próximo passo para a fabricação dos capacitores MOS foi à realização da evaporação térmica do Al. Inicialmente foram realizados alguns testes de evaporação com filetes de $\mathrm{Al}$, onde $10 \mathrm{~cm}$ de fios com grau de pureza igual a 99,9\% foram cortados em forma de " $V$ " e foram limpos por cinco minutos em solução fervente de álcool isopropílico (IPA). Em seguida, esses filetes foram colocados no filamento de tungstênio. Em seguida, uma lâmina foi colocada na parte central do carregador, a $9 \mathrm{~cm}$ desse filamento, onde foi realizado um degrau com auxilio de uma máscara metálica. Uma espessura média de $150 \mathrm{~nm}$ de degrau foi indicada pelo perfilômetro.

O processo de evaporação foi feito em alto vácuo (5.10 ${ }^{-6}$ torr) em uma evaporadora térmica da marca Edward (modelo Auto 306). Uma corrente de 42 A foi constatada após o aumento súbito no medidor de pressão que indica o fim do processo.

\subsubsection{Fotogravação para definição do alumínio}

Primeiramente, cada uma das lâminas foi colocada no spinner, equipamento que fixa a lâmina por vácuo e impõem uma rotação controlada em tempo e velocidade. IPA foi depositado sobre toda a superfície seguido de rotação a 3500 rpm por 20 segundos para efeito de secagem. Logo após, foi depositado o promotor de aderência cobrindo toda superfície. Novamente, a lâmina foi rotacionada a 3500 rpm por 20 segundos. Finalmente depositou-se o fotorresiste positivo (ONPR 500 da Tokyo Ohka Kogyo Co. Ltd.) cobrindo toda 
a superfície, submetida então a uma rotação de 3500 rpm por 20 segundos (NOGUEIRA, 2003).

Para que posteriormente fosse feito o perfilamento do boro ao longo do Si-poli, foi reservado um quarto de cada lâmina de modo a não conter os capacitores.

Após a rotação da rotação da lâmina, esta foi colocada sobre o prato quente a uma temperatura de $115{ }^{\circ} \mathrm{C}$ por 60 segundos para fazer a pré-cura do fotorresiste. Em seguida, foi feita a exposição do fotorresiste à luz ultravioleta, por $15 \mathrm{~s}$.

O fotorresiste sensibilizado pela luz ultravioleta (UV) foi revelado em solução de hidróxido de potássio em água $\mathrm{DI}\left(2 \mathrm{~K}(\mathrm{OH}) / 1 \mathrm{H}_{2} \mathrm{O}\right)$ por intervalos entre a solução e o enxágüe de $18 \mathrm{~s}$. O tempo total de revelação foi de $75 \mathrm{~s}$ observados através de uma inspeção visual seguida com o auxílio do microscópio. Em seguida a lâmina foi levada ao prato quente onde permaneceu por 15 minutos a $115^{\circ} \mathrm{C}$.

\subsubsection{Corrosão do Si-poli}

Observou-se que após a remoção do fotorresiste não sensibilizado, o Al foi removido. Sendo assim, foi realizada a remoção do fotorresiste em uma solução aquecida de acetona por 10 minutos seguida por secagem em fervura em IPA por 5 minutos encerrando com um enxágüe em água DI por 5 minutos. Tendo já definido a geometria dos capacitores MOS, o próprio Al foi usado como máscara de corrosão do Si-poli por corrosão a plasma. 


\subsubsection{Deposição de alumínio nas costas das lâminas}

De forma semelhante ao que foi feito na face polida das lâminas, será feito à evaporação nas costas. Antes, objetivando um melhor contato ôhmico e ausência de erros nas medidas de caracterização elétrica, o filme de $\mathrm{SiO}_{2}$ das costas foi removido por uma haste umedecida com algodão em uma solução de $1 \mathrm{HF} / 10 \mathrm{H}_{2} \mathrm{O}$.

\subsubsection{Sinterização}

Após a metalização com Al no lado rugoso das lâminas, promoveu-se a etapa de sinterização. A sinterização tem como objetivo reduzir a densidade de estados de superfície e promover um melhor contato do Al com o Si-poli e do Al com a face rugosa da lâmina. O processo de sinterização se deu a $430^{\circ} \mathrm{C}$ por 30 minutos em um ambiente contendo $90 \%$ de $\mathrm{N}_{2}$ e $10 \%$ de $\mathrm{H}_{2}$, conforme reporta Nicollian (1982). Sendo assim, os capacitores MOS estão prontos para a caracterização elétrica. 


\subsection{Fabricação de capacitores MOS com Si-poli $\mathbf{N}^{+}$}

Para a fabricação dos capacitores MOS com porta de Si-poli dopadas com fósforo foram realizados os mesmos procedimentos quando: a aplicação do SOG (porém, com SOG de fósforo); as etapas de cura do SOG (exceto quando a rotação do spinner, que foi de 2000 rpm); aos procedimentos de difusão térmica no forno, onde optamos por utilizar a receita de difusão a $1050{ }^{\circ} \mathrm{C}$ por 30 min que minimiza $R_{s h}$ e não promove o efeito de depleção e evita a sob-difusão de fósforo para a superfície do Si. Observe que a difusão de fósforo é muito menor do que a difusão de boro, pois o fósforo tende a ficar no Si-poli e o boro no $\mathrm{SiO}_{2}$ (devido ao coeficiente de segregação). Porém, como o $\mathrm{SiO}_{2}$ é ultrafino, é pouco eficiente como máscara para o fósforo e tão pouco para o boro. 


\section{RESULTADOS E DISCUSSÕES}

Vamos iniciar o presente capítulo apresentando os resultados C-V e I-V dos capacitores MOS com porta de Si-poli $\mathrm{P}^{+}$. Na seqüência são apresentados os resultados $\mathrm{C}-\mathrm{V}$ e I-V dos capacitores MOS com porta de Si-poli $\mathrm{N}^{+}$. O equacionamento empregado para extrair das curvas $C-V_{A F}$ e $C-V_{B F}$ os principais parâmetros, incluindo a concentração efetiva de dopantes no $\mathrm{Si}\left(\mathrm{N}_{\mathrm{A}}\right)$, espessura equivalente elétrica do $\mathrm{SiO}_{2}$ (EOT), tensão de banda plana $\left(\mathrm{V}_{\mathrm{FB}}\right)$ e densidade de estados de superfície $\left(D_{\text {it }}\right)$, apresentados no Apêndice $A$.

Também, neste capítulo vamos apresentar um conjunto variado de curvas C$V_{A F}$ e $C-V_{B F}$ a fim de podermos apreciar a dispersão nos parâmetros capacitância máxima $\left(\Delta \mathrm{C}_{\mathrm{MAX}}\right)$, na tensão de banda plana $\left(\Delta \mathrm{V}_{\mathrm{FB}}\right)$ e na capacitância mínima $\left(\Delta \mathrm{C}_{\mathrm{MIN}}\right)$. Os resultados apontaram uma tendência sistemática na redução da concentração de boro dentro do corpo do Si bem como na redução da densidade de estados de interface $\left(D_{i t}\right)$ com o incremento da dose de nitrogênio. Porém, constatou-se que, com o aumento da dose de nitrogênio, os valores da tensão de banda plana $\left(\mathrm{V}_{\mathrm{FB}}\right)$ se deslocaram para valores mais negativos, bem como ocorreu uma maior dispersão em $V_{\mathrm{FB}}$. $\mathrm{O}$ campo elétrico de ruptura $\left(E_{B R}\right)$ também aumentou com o aumento da dose de nitrogênio.

Vamos mostrar no presente capítulo que a fabricação de capacitores MOS com porta de Si-poli $\mathrm{P}^{+}$, com dopagem do Si-poli realizada por aplicação de SOG DE BORO (onde a fonte SOG é considerada como uma fonte "inesgotável" de dopante) apresenta-se equiparável aos capacitores MOS fabricados com porta de Si-poli $\mathrm{N}^{+}$quando se utiliza dose de nitrogênio superior a $1.10^{15}$ e inferior a $5.10^{15}$ at.cm $^{-2}$, mantendo-se o pico de nitrogênio próximo da interface $\mathrm{SiO}_{2} / \mathrm{Si}$. 


\subsection{Difusão de boro em capacitores MOS com ou sem nitrogênio.}

A tabela 5.1 apresenta os valores da resistência de folha $\left(R_{\text {sh }}\right)$ para uma estrutura

$\mathrm{Si}$-poli/ $\mathrm{SiO}_{2} / \mathrm{Si}$ sem implantação de nitrogênio. Nesta tabela constam os valores de "R $\mathrm{R}_{\text {sh }}$ " do Si-poli e os valores da " $\mathrm{R}_{\text {sh" }}$ na superfície do Si após a remoção do Si-poli e do $\mathrm{SiO}_{2}$, conforme descreve o item 4.2.3. Utilizando as eq.(3.2) e eq.(3.3), obteve-se a concentração volumétrica de boro do Si-poli ( $\left.P_{\text {poli }}\right)$. Os resultados estão apresentados na tabela 5.1

Tabela $5.1-R_{\text {sh }}$, $P_{\text {poli }}$ e mobilidade para após difusão nas temperaturas a 950, 1000, 1050 e $1100^{\circ} \mathrm{C}$ por $30 \mathrm{~min}$. O valor inicial de $R_{\text {sh }}$ do Si-p foi de $212 \pm 4$ [ohm/quad].

\begin{tabular}{|c|c|c|c|c|}
\hline $\begin{array}{c}\text { Temperatura } \\
{\left[{ }^{\circ} \mathbf{C}\right]}\end{array}$ & $\begin{array}{c}\mathbf{R}_{\text {sh }} \\
\text { [ohm/quad] } \\
\text { Si-poli }\end{array}$ & $\begin{array}{c}\boldsymbol{\mu}\left[\mathbf{c m}^{2} / \mathbf{V} . \mathbf{s}\right] \\
\mathbf{S i} \text {-poli }\end{array}$ & $\begin{array}{c}\mathbf{P}_{\text {poli }} \\
{\left[\mathbf{1 . 1 0 ^ { 2 0 }} \mathbf{a t}_{\mathbf{c}} \mathbf{c m}^{\mathbf{3}}\right]}\end{array}$ & $\begin{array}{c}\mathbf{R}_{\text {sh }} \\
\text { [ohm/quad] } \\
\text { Si-p }\end{array}$ \\
\hline $\mathbf{9 5 0}$ & $120 \pm 6$ & 20 & 0,76 & $198 \pm 9$ \\
\hline $\mathbf{1 0 0 0}$ & $95 \pm 4$ & 20 & 0,97 & $174 \pm 3$ \\
\hline $\mathbf{1 0 5 0}$ & $72 \pm 6$ & 20 & 1,3 & $158 \pm 6$ \\
\hline $\mathbf{1 1 0 0}$ & $45 \pm 4$ & 20 & 2,0 & $148 \pm 6$ \\
\hline
\end{tabular}

É interessante destacar que a resistência de folha do Si-poli decai com o aumento da temperatura na faixa de $950{ }^{\circ} \mathrm{C}$ a $1100{ }^{\circ} \mathrm{C}$ indicando que a difusão de boro foi mais intensa nas temperaturas maiores. Por outro lado, a concentração volumétrica de boro tende a aumentar com a diminuição da resistência de folha como era de se esperar. Observe que o $\mathrm{P}_{\text {poli }}$ ficou inferior ao limite de solubilidade sólida do boro no Si-poli $\left(4.10^{20}\right.$ at. $\left.\mathrm{cm}^{-3}\right)$. Também, é importante chamar a atenção para o fato da " $R_{\text {sh" }}$ " do silício reduzir progressivamente com o aumento da temperatura de difusão. Tal fato indica que $\mathrm{o}$ boro além de atingir $\mathrm{o} \mathrm{SiO}_{2}$ de porta também chega a difundir no substrato de silício. 
A escolha da receita de difusão deve apresentar:

a. Menor valor de " $\mathrm{R}_{\mathrm{sh}}$ " do Si-poli;

b. Dopagens tais que eliminem o efeito da depleção do Si-poli;

c. Eficiência da barreira de oxinitreto de silício contra a difusão do boro, ao utilizar uma fonte infinita de dopante.

A camada nitretada junto à interface $\mathrm{Si}-$ poli/ $/ \mathrm{SiO}_{2}$ irá impedir com eficiência a difusão de átomos de boro implantados no Si-poli até a temperatura de $1050{ }^{\circ} \mathrm{C}$ de forma a obter concentrações de boro acima de $1.10^{20} \mathrm{at} / \mathrm{cm}^{3}$. Observe-se que sem a camada nitretada a receita de difusão a $1100{ }^{\circ} \mathrm{C}$ provoca uma variação de $30 \%$ na " $\mathrm{R}_{\mathrm{sh}}$ " do $\mathrm{Si}$ (tabela 5.1 ).

Para avaliar a eficiência da camada nitretada como barreira à difusão de boro, processamos amostras implantadas com nitrogênio como indicado nas tabelas 5.2 e 5.3. O perfil de boro foi obtido ao longo do Si-poli conforme procedimento descrito no item 3.3.1.1. Nas tabelas 5.2 e 5.3 são apresentados os valores médios da " $\mathrm{R}_{\mathrm{sh}}$ " ao longo do $\mathrm{Si}$-poli e na superfície do $\mathrm{Si}$, respectivamente, para as quatro doses de nitrogênio implantadas. A difusão do boro, para a dopagem do Si-poli, foi realizada a $1050^{\circ} \mathrm{C}$ por $30 \mathrm{~min}$ difusão. Utilizando as eq.(3.4) e eq.(3.5), obteve-se a concentração volumétrica de boro no Si-poli $\left(P_{\text {poli }}\right)$. Para cada uma das doses foram feitas dez medidas para cada camada removida, aonde foi adotado um tempo de $20 \mathrm{~min}$ de corrosão que corresponde a $(42,2 \pm 1,3) \mathrm{nm}$ de Si-poli removido, totalizando oito pontos. Utilizando as eq.(3.4) e eq.(3.5), foi feito um gráfico da concentração de boro ao longo do filme de Si-poli, conforme apresenta a figura 5.1. 
Tabela 5.2 - Profundidade removida e valor de $R_{\text {sh }}$ para cada uma das quatro doses utilizadas.

\begin{tabular}{|c|c|c|c|c|}
\hline $\begin{array}{c}\text { Dose/ } \\
\text { Profundidade } \\
\text { [nm] }\end{array}$ & $\begin{array}{c}1.10^{13} \text { at } / \mathrm{cm}^{2} \\
\mathrm{R}_{\mathrm{sh}}[\mathrm{ohm} / \text { quad] }\end{array}$ & $\begin{array}{c}1.10^{14} \mathrm{at} / \mathrm{cm}^{2} \\
\mathrm{R}_{\text {sh }}[\mathrm{ohm} / \text { quad] }\end{array}$ & $\begin{array}{c}1.10^{15} \mathrm{at} / \mathrm{cm}^{2} \\
\mathbf{R}_{\mathrm{sh}}[\text { ohm } / \text { quad] }\end{array}$ & $\begin{array}{c}5.10^{15} \text { at } / \mathrm{cm}^{2} \\
\mathbf{R}_{\text {sh }}[\text { ohm/quad] }\end{array}$ \\
\hline 340 & $70 \pm 4$ & $75 \pm 5$ & $80 \pm 5$ & $105 \pm 11$ \\
\hline 298 & $45 \pm 6$ & $49 \pm 7$ & $52 \pm 8$ & $57 \pm 9$ \\
\hline 256 & $53 \pm 10$ & $57 \pm 8$ & $60 \pm 10$ & $66 \pm 11$ \\
\hline 213 & $63 \pm 11$ & $68 \pm 10$ & $72 \pm 10$ & $80 \pm 10$ \\
\hline 171 & $78 \pm 9$ & $85 \pm 7$ & $89 \pm 10$ & $99 \pm 10,1$ \\
\hline 129 & $105 \pm 8$ & $113 \pm 8$ & $118 \pm 7$ & $132 \pm 7$ \\
\hline 87 & $156 \pm 10$ & $168 \pm 10$ & $175 \pm 10$ & $188 \pm 9$ \\
\hline 45 & $173 \pm 10$ & $174 \pm 9$ & $176 \pm 10$ & $197 \pm 10$ \\
\hline 2,4 & $183 \pm 11$ & $190 \pm 11$ & $199 \pm 9$ & $205 \pm 11$ \\
\hline
\end{tabular}

Após o último ponto, foi feita a remoção do restante do Si-poli utilizando a solução de $1 \mathrm{DLV} / 50 \quad \mathrm{HNO}_{3} / 20 \mathrm{H}_{2} \mathrm{O}$ seguido por um enxágüe em água DI terminando em um "dip" em BHF. Após a remoção do $\mathrm{SiO}_{2}$, foram realizadas dez medidas de " $\mathrm{R}_{\mathrm{sh}}$ " na superfície do $\mathrm{Si}$ e nas costas a fim de avaliar quanto boro difundiu para o $\mathrm{Si}$. A tabela 5.3 apresenta os valores médios para cada caso.

Tabela 5.3 - Medida de $R_{\text {sh }}$ na superfície do Si e nas costas para cada uma das quatro doses utilizadas.

\begin{tabular}{|c|c|c|c|c|}
\hline Dose & $\begin{array}{c}1.10^{13} \mathrm{at} / \mathrm{cm}^{2} \\
\mathbf{R}_{\mathrm{sh}}[\mathrm{ohm} / \mathrm{quad}]\end{array}$ & $\begin{array}{c}1.10^{14} \mathrm{at} / \mathrm{cm}^{2} \\
\mathrm{R}_{\mathrm{sh}}[\mathrm{ohm} / \mathrm{quad}]\end{array}$ & $\begin{array}{c}1.10^{15} \mathrm{at} / \mathrm{cm}^{2} \\
\mathrm{R}_{\mathrm{sh}}[\mathrm{ohm} / \mathrm{quad}]\end{array}$ & $\begin{array}{c}5.10^{15} \mathrm{at} / \mathrm{cm}^{2} \\
\mathbf{R}_{\mathrm{sh}}[\mathrm{ohm} / \text { quad] }\end{array}$ \\
\hline $\begin{array}{c}\text { Na superfície } \\
\text { do Si }\end{array}$ & $148,8 \pm 2,6$ & $166,4 \pm 1,1$ & $180,9 \pm 2,2$ & $182,9 \pm 1,9$ \\
\hline costas & $150,9 \pm 2,6$ & $168,7 \pm 4,3$ & $185,3 \pm 4,5$ & $185 \pm 4,7$ \\
\hline
\end{tabular}




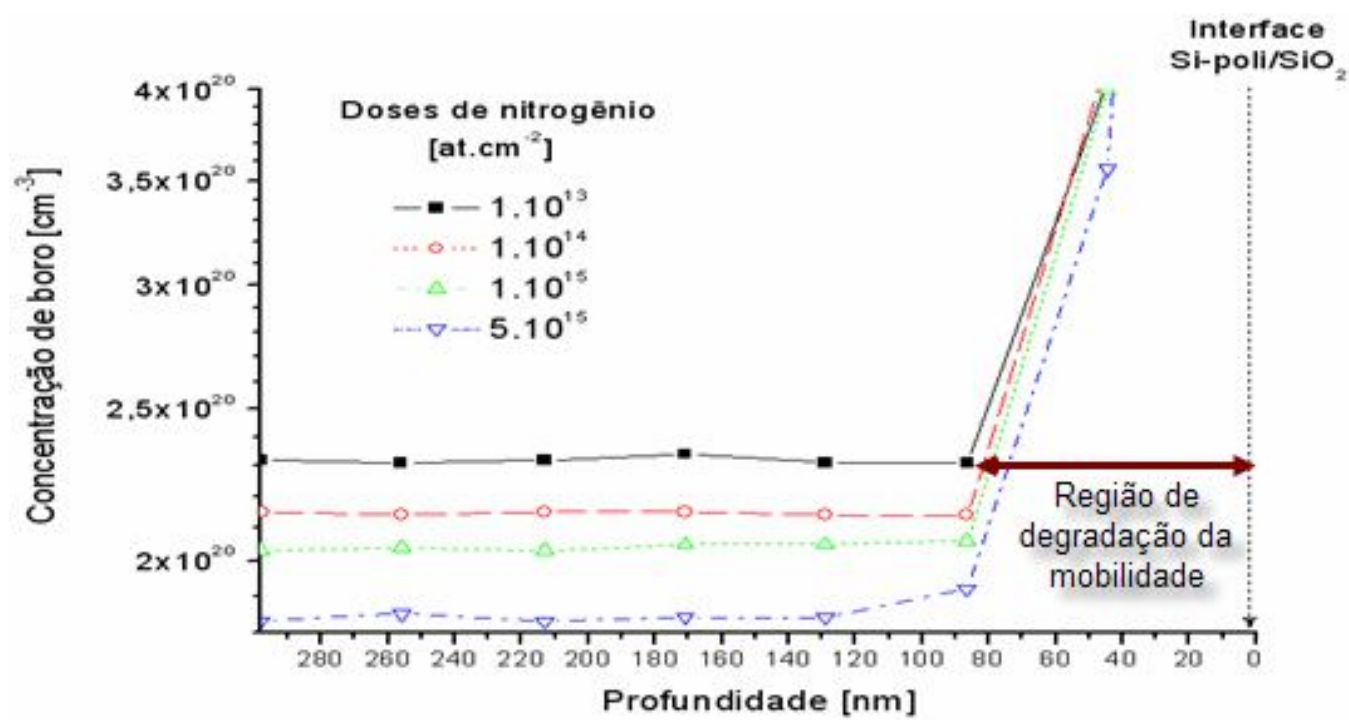

Figura 5.1 - Gráfico da concentração de boro ao longo do Si-poli. A mobilidade adotada foi de $20 \mathrm{~cm}^{2} / \mathrm{Vs}$.

Analisando os resultados apresentados na tabela 5.2 e com o auxílio da figura 5.1 podemos notar que as concentrações de boro ao longo do Si-poli $\left(P_{\text {poli }}\right)$ são superiores a $5.10^{19} \mathrm{at}_{\mathrm{cm}} \mathrm{cm}^{-3}$. Uma outra observação que pode ser feita é que, quanto maior a dose de nitrogênio menor é $P_{\text {poli }}$ ao longo do Si-poli devido possivelmente a uma degradação na mobilidade com o aumento da dose de nitrogênio a qual não foi contabilizada. Utilizamos em todos os cálculos do gráfico da figura 5.1 uma mobilidade de $20 \mathrm{~cm}^{2} / \mathrm{N} . \mathrm{S}$ (SETO, 1975, RODRIGUES, 2006). Próximo à interface Si-poli/SiO $\mathrm{Si}_{2}$ ocorreu um aumento abrupto na concentração de boro, devido também a degradação da mobilidade. Por outro lado, observa-se na tabela 5.3 , que os valores de " $R_{s h}$ " na superfície do Si permaneceram idênticos aos das costas. Considerando os desvios das medidas, podemos afirmar que não ocorreu difusão do boro para a o Si, a partir do Si-poli. 


\subsubsection{Medidas $\mathrm{C}-\mathrm{V}_{\mathrm{AF}}$}

Nas medidas $\mathrm{C}-\mathrm{V}_{\mathrm{AF}}$ é interessante reparar a dispersão nos valores da capacitância máxima ( $\left.\mathrm{C}_{\mathrm{MAX}}\right)$, da tensão de banda plana $\left(\mathrm{V}_{\mathrm{FB}}\right)$ e da capacitância $\left(\mathrm{C}_{\mathrm{MIN}}\right)$. As figuras $5.2,5.3,5.4$ e 5.5 apresentam as curvas $\mathrm{C}-\mathrm{V}_{\mathrm{AF}}$ para cada uma das doses de nitrogênio empregadas.

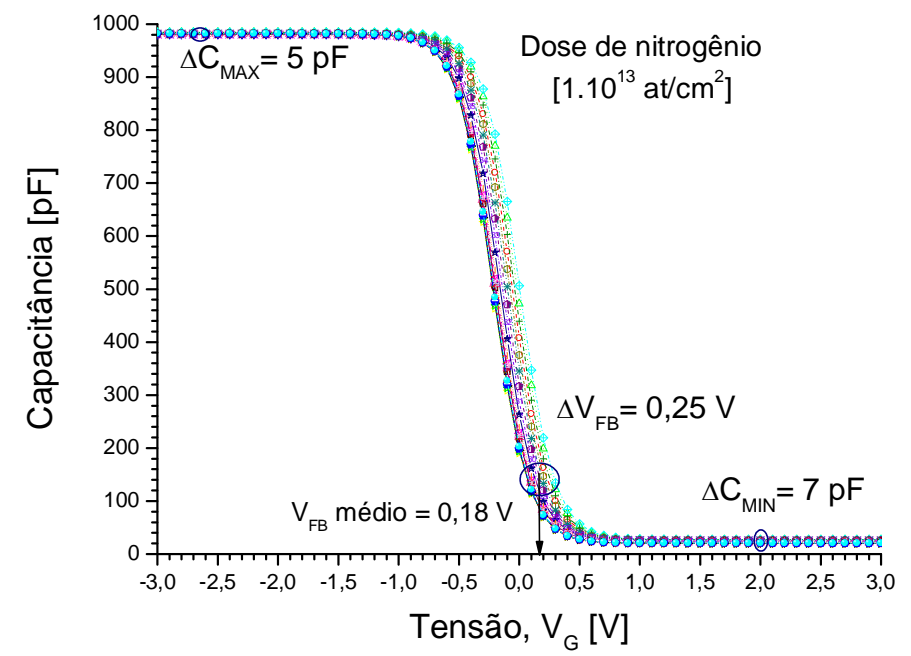

Figura 5.2 - Curvas $C-V_{\mathrm{AF}}$ para a dose de $1.10^{13}$ at. $\mathrm{cm}^{-2}$. 


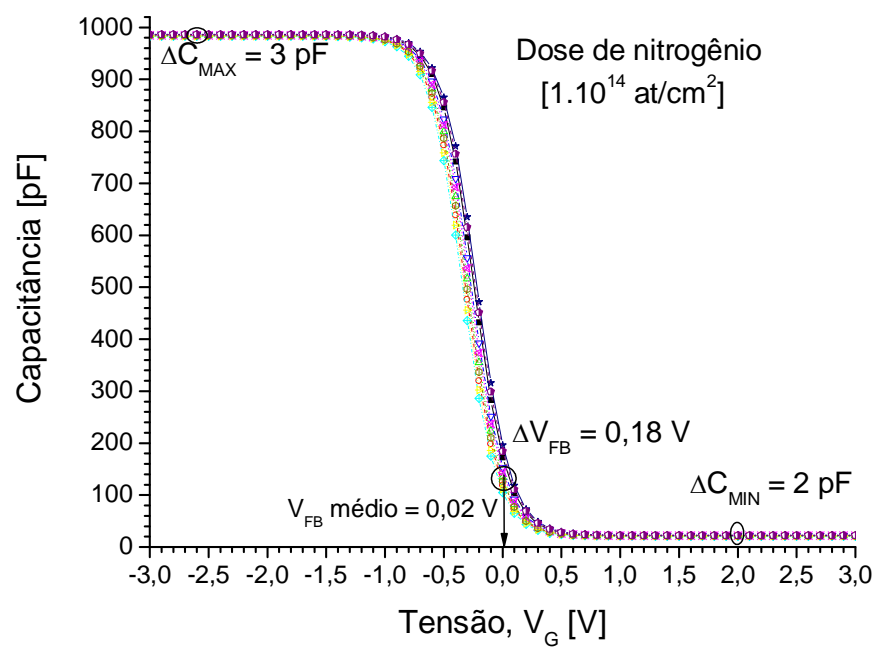

Figura 5.3 - Curvas $C-V_{\mathrm{AF}}$ para a dose de $1.10^{14}$ at. $\mathrm{cm}^{-2}$.

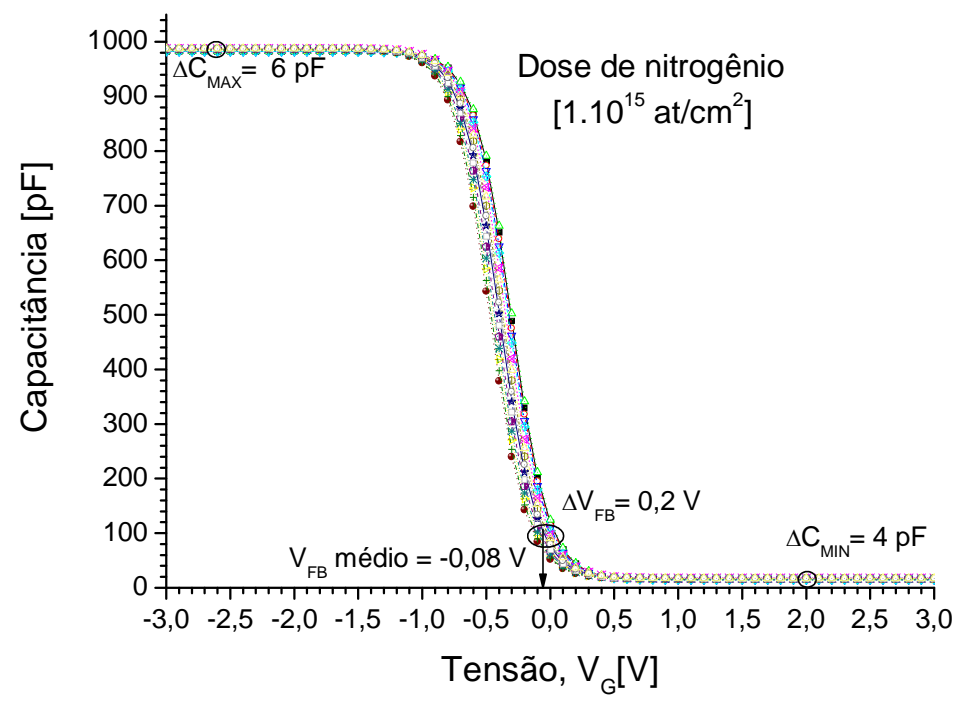

Figura 5.4 - Curvas $\mathrm{C}-\mathrm{V}_{\mathrm{AF}}$ para a dose de $1.10^{15}$ at. $\mathrm{cm}^{-2}$. 


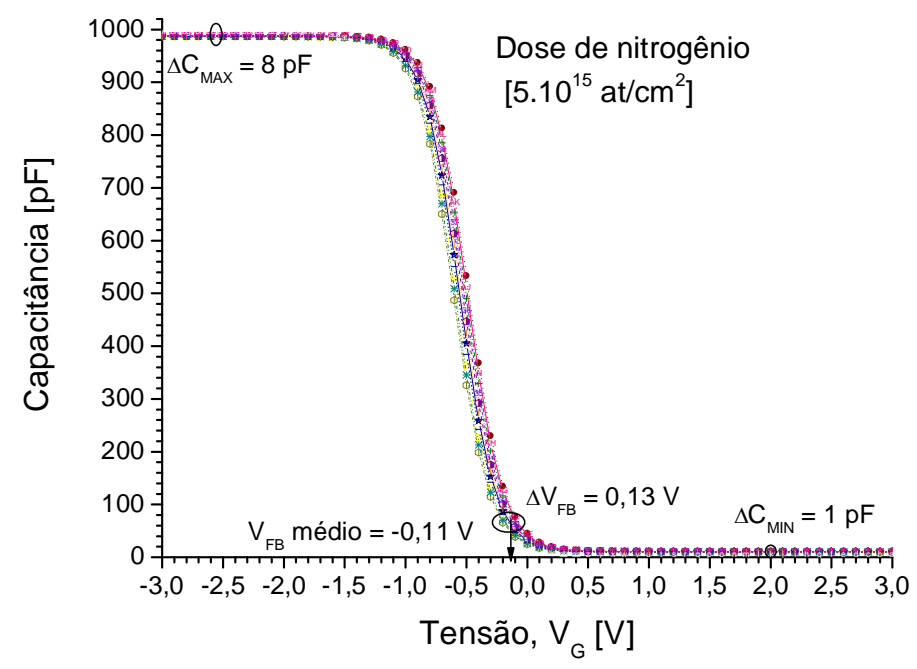

Figura 5.5 - Curvas C-V $\mathrm{V}_{\mathrm{AF}}$ para a dose de $5.10^{15}$ at. $\mathrm{cm}^{-2}$.

Através das figuras (5.2 a 5.5) analisando as dispersões em " $\mathrm{C}_{\text {MAX", " }} \mathrm{C}_{\text {MIN" }} \mathrm{e}$ " $\mathrm{V}_{\mathrm{FB}}$ " podemos afirmar que as mesmas são pequenas como indicado nas figuras. A dispersão em " $\mathrm{C}_{\mathrm{MAx}}$ " deve-se a flutuações na espessura do $\mathrm{SiO}_{2}$. A dispersão em " $\mathrm{C}_{\text {MIN" }}$ deve-se a pequenas variações na dopagem. A variação em " $\mathrm{V}_{\mathrm{FB}}$ " e na carga efetiva do $\mathrm{SiO}_{2}$ depende da implantação de nitrogênio, como ficará mais claro a seguir.

Foi observado que o valor médio da tensão de banda plana varia com a dose de nitrogênio (veja figuras de 5.2 a 5.5). A figura 5.6 mostra as curvas $C-V_{A F}$ típicas para cada dose de nitrogênio com " $\mathrm{V}_{\mathrm{FB}}$ " próximo da média, também para cada dose. Isto é, foram selecionadas curvas típicas com " $\mathrm{V}_{\mathrm{FB}}$ " em cada média. 


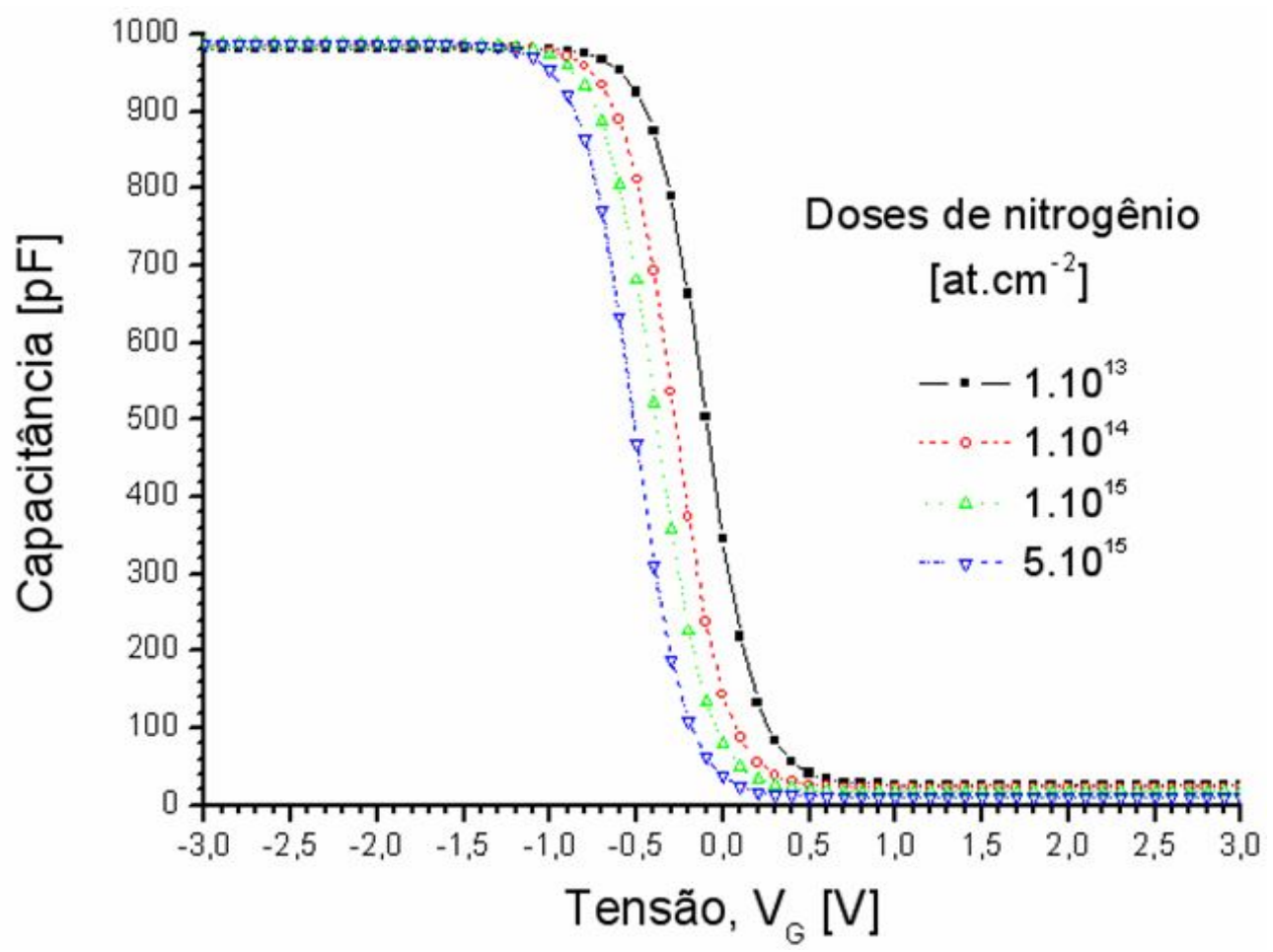

Figura 5.6 - Medidas $C-V_{A F}$ representativas para as quatro doses de nitrogênio empregadas.

Montamos a tabela 5.4 onde estão indicados "EOT", " $\mathrm{N}_{\mathrm{A}}$ ", " $\mathrm{V}_{\mathrm{FB}}$ " e $\Delta \mathrm{V}_{\mathrm{FB}}$ para cada dose de nitrogênio empregada.

Tabela 5.4 - Parâmetros extraídos das curvas C- $\mathrm{V}_{\mathrm{AF}}$.

\begin{tabular}{|c|c|c|c|c|}
\hline $\begin{array}{c}\text { Doses } \\
{[\mathbf{a t . c m}}\end{array}$ & $\begin{array}{c}\text { EOT } \\
\text { [nm] }\end{array}$ & $\begin{array}{c}\mathbf{N}_{\mathbf{A}} \\
{\left[\mathbf{1 . 1 0 ^ { 1 5 }} \mathbf{a t . c m}^{-3}\right]}\end{array}$ & $\begin{array}{c}\mathbf{V}_{\mathrm{FB}} \\
\text { [V] }\end{array}$ & $\begin{array}{c}\Delta \mathbf{V}_{\mathrm{FB}} \\
{[\mathbf{V}]}\end{array}$ \\
\hline $\mathbf{1 . 1 0}^{13}$ & 2,9 & 7,7 & $0,18 \pm 0,13$ & 0,25 \\
\hline $\mathbf{1 . 1 0}^{14}$ & 2,9 & 4,9 & $0,02 \pm 0,09$ & 0,18 \\
\hline $\mathbf{1 . 1 0}^{15}$ & 2,9 & 2,9 & $-0,08 \pm 0,1$ & 0,20 \\
\hline $\mathbf{5 . 1 0}^{15}$ & 2,9 & 0,95 & $-0,11 \pm 0,07$ & 0,13 \\
\hline
\end{tabular}

Uma primeira consideração a ser feita é que a grande maioria dos capacitores MOS medidos (> 30/lâmina) apresentaram valores de " $\mathrm{V}_{\mathrm{FB}}$ " reprodutíveis e valores de " $\mathrm{C}_{\text {MAX" }}$ " (capacitância máxima) e " $\mathrm{C}_{\text {MIN" }}$ (capacitância mínima) com patamares bem estáveis. 
Para as curvas $\mathrm{C}-\mathrm{V}_{\mathrm{AF}}$ típicas, levantadas para as diferentes doses de nitrogênio, observa-se que quanto maior a dose de nitrogênio utilizada menores serão os valores de " $\mathrm{N}_{\mathrm{A}}$ " dos capacitores MOS (tabela 5.4). A explicação para esse fenômeno reside no fato, de que, a concentração de nitrogênio ao longo das interfaces $\mathrm{Si}$-poli// $\mathrm{SiO}_{2}$ e $\mathrm{SiO}_{2} / \mathrm{Si}$ aumenta com a dose de nitrogênio, o que possivelmente resulta tanto em maior quantidade de defeitos na rede como menor quantidade de dopantes ativos na rede. Observe que essa comparação se torna valida já que os valores de $R_{\text {sh }}$ no substrato de $\mathrm{Si}$ (ou das costas) das quatro lâminas utilizadas são próximos ( $20 \%$ de variação), conforme tabela 5.3.

Observa-se que as curvas C-V estão deslocadas para a esquerda com o aumento da dose de nitrogênio o que indica que, quanto maior a dose de nitrogênio, mais negativo torna-se " $\mathrm{V}_{\mathrm{FB}}$ ". Esse fenômeno pode ser justificado pelo aumento de " $\mathrm{Q}_{\mathrm{s}}$ " no corpo do dielétrico de porta devido ao aumento da concentração de nitrogênio nas proximidades da interface $\mathrm{SiO}_{2} / \mathrm{Si}$. 


\subsubsection{Medidas $\mathrm{C}-\mathrm{V}_{\mathrm{BF}}$}

Nas medidas $\mathrm{C}-\mathrm{V}_{\mathrm{BF}}$ é importante também observar a dispersão nos valores da capacitância máxima $\left(\mathrm{C}_{\mathrm{MAX}}\right)$, tensão de banda plana $\left(\mathrm{V}_{\mathrm{BF}}\right)$ e da capacitância mínima $\left(C_{M I N}\right)$. As figuras $5.7,5.8,5.9$ e 5.10 apresentam as curvas $C-V_{A F}$ para cada uma das doses de nitrogênio empregadas.

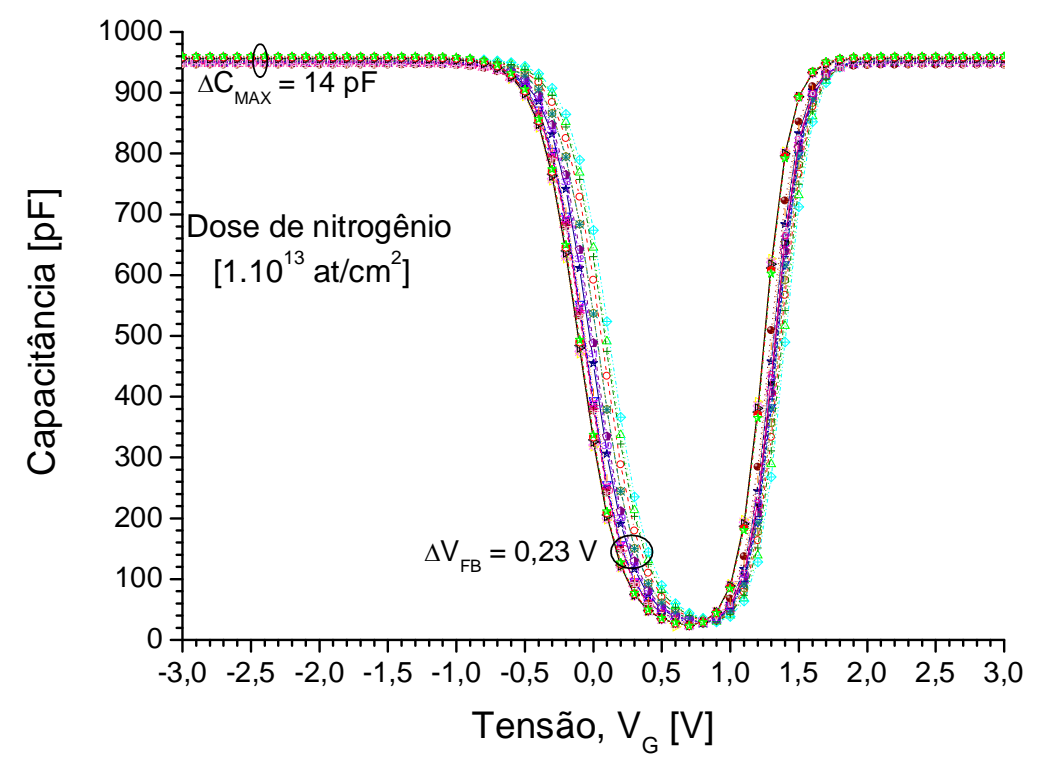

Figura 5.7 - Medidas $\mathrm{C}-\mathrm{V}_{\mathrm{BF}}$ para a dose de $1.10^{13} \mathrm{at} / \mathrm{cm}^{2}$. 


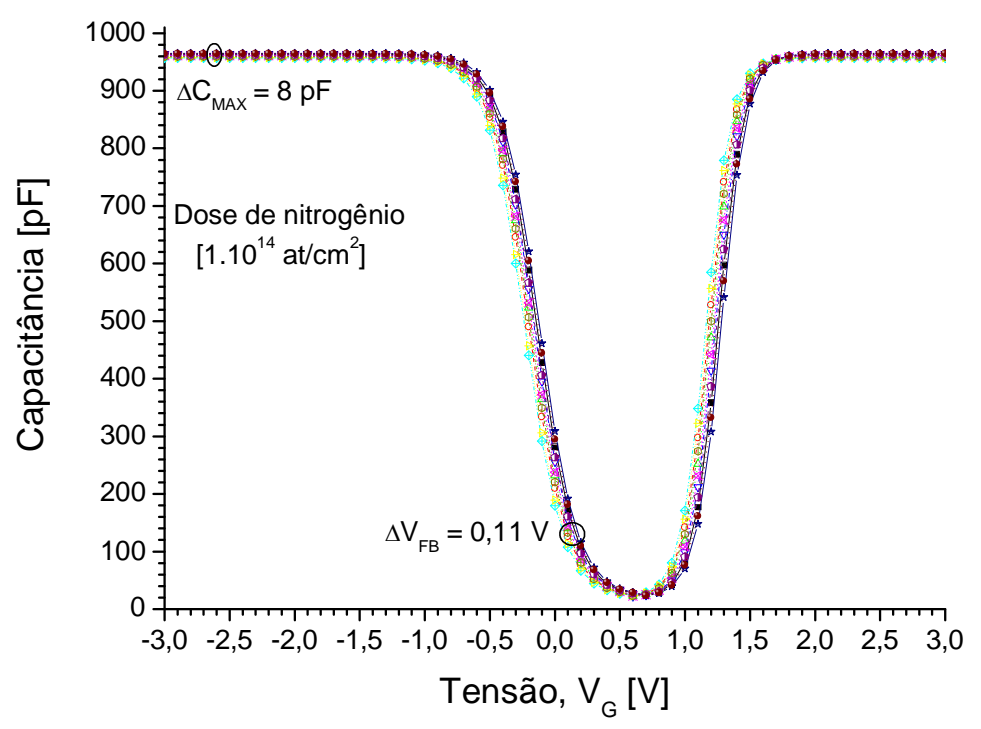

Figura 5.8 - Medidas $C-V_{B F}$ para a dose de $1.10^{14} \mathrm{at} / \mathrm{cm}^{2}$.

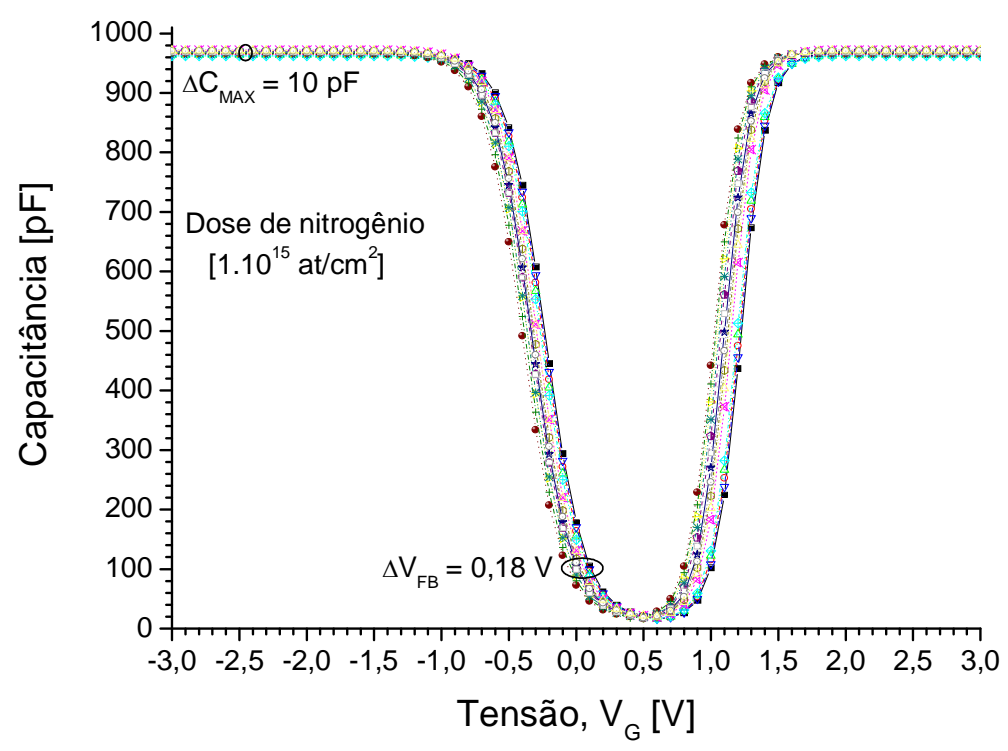

Figura 5.9 - Medidas $C-V_{B F}$ para a dose de $1.10^{15} \mathrm{at} / \mathrm{cm}^{2}$. 


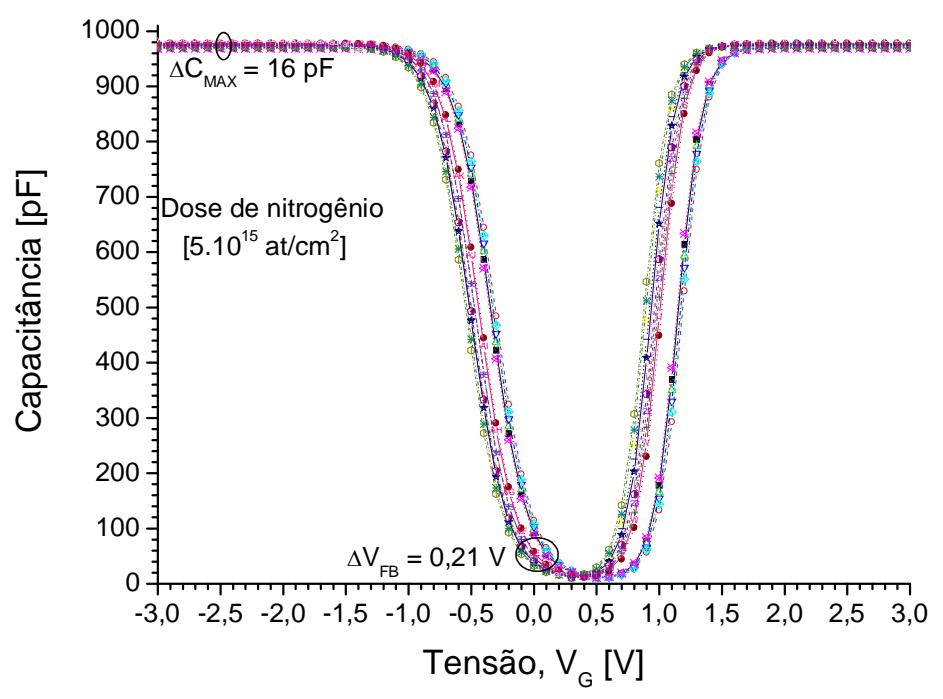

Figura 5.10 - Medidas $\mathrm{C}-\mathrm{V}_{\mathrm{BF}}$ para a dose de $5.10^{15} \mathrm{at} / \mathrm{cm}^{2}$.

Destacamos que para a extração das curvas de capacitância versus tensão em alta freqüência, existe no equipamento HP4280 uma ferramenta que permite que sejam compensadas eventuais capacitâncias parasitas permitindo assim uma extração mais precisa. No entanto, o mesmo não ocorre no HP4140. Portanto, fizemos o casamento das regiões de acumulação e banda plana das curvas capacitância versus tensão de alta e baixa freqüência. Tal implementação permitiu a extração da densidade de estados de interface. De forma a corrigir a capacitância parasita da curva de baixa freqüência, consideramos a capacitância em acumulação da curva em alta freqüência como correta de forma que a curva em baixa freqüência foi deslocada de um certo valor de modo a obter um casamento perfeito, conforme apresenta a figura 5.11 . 


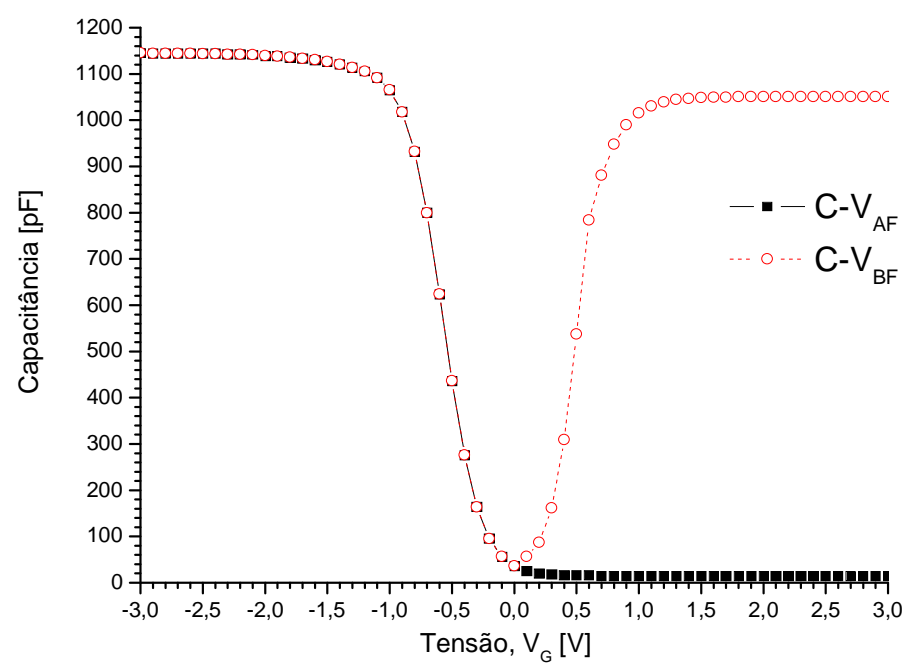

Figura 5.11 - Curvas $C-V_{A F}$ e $C-V_{B F}$ do capacitor MOS. A curva $C-V_{B F}$ foi corrigida da capacitância parasitária.

Assim como no caso das curvas de alta freqüência, foi observado que o valor médio da tensão de faixa plana varia com a dose de nitrogênio (veja figuras 5.7 a 5.10). A figura 5.12 mostra as curvas $C-V_{B F}$ típicas para cada dose de nitrogênio com " $\mathrm{V}_{\mathrm{FB}}$ " próximo da média, também para cada dose. Isto é, foram selecionadas curvas típicas com " $\mathrm{V}_{\mathrm{FB}}$ " perto de cada média. 


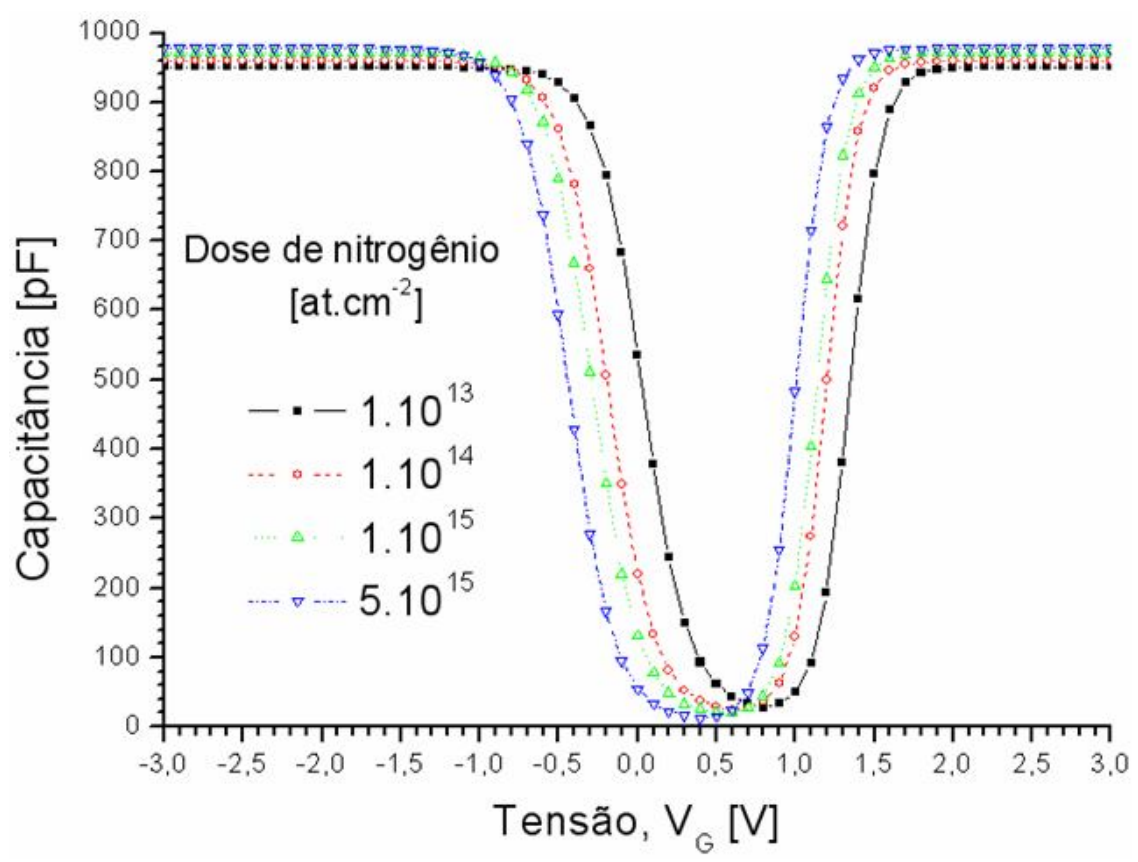

Figura 5.12 - Medidas $\mathrm{C}-\mathrm{V}_{\mathrm{BF}}$ representativas para as quatro doses de nitrogênio empregadas.

Tabela 5.5: Parâmetros extraídos das curvas $\mathrm{C}-\mathrm{V}_{\mathrm{BF}}$.

\begin{tabular}{|c|c|c|c|c|}
\hline $\left.\begin{array}{c}\text { Doses } \\
{[\mathbf{a t . c m}}\end{array} \mathbf{- 2}^{-2}\right]$ & $\begin{array}{c}\mathrm{EOT} \\
{[\mathbf{n m}]}\end{array}$ & $\begin{array}{c}\mathbf{D}_{\mathrm{IT}} \\
{\left[\mathbf{1 . 1 0 ^ { 1 0 }} \mathbf{e V}^{-1} \cdot \mathbf{c m}^{-2}\right]}\end{array}$ & $\begin{array}{c}\mathbf{V}_{\mathrm{FB}} \\
{[\mathbf{V}]}\end{array}$ & $\begin{array}{c}\Delta \mathbf{V}_{\mathrm{FB}} \\
{[\mathbf{V}]}\end{array}$ \\
\hline $\mathbf{1 . 1 0}^{13}$ & 2,9 & 2,25 & $0,28 \pm 0,12$ & 0,23 \\
\hline $\mathbf{1 . 1 0}^{14}$ & 2,9 & 1,63 & $0,12 \pm 0,06$ & 0,11 \\
\hline $\mathbf{1 . 1 0}^{15}$ & 2,9 & 1,32 & $0,04 \pm 0,09$ & 0,18 \\
\hline $\mathbf{5 . 1 0}^{15}$ & 2,9 & 0,78 & $0,01 \pm 0,11$ & 0,21 \\
\hline
\end{tabular}

Comparando as tabelas 5.4 e 5.5, observam-se valores de " $\mathrm{V}_{\mathrm{FB}}$ " médios distintos extraídos das curvas $C-V_{A F}$ e $C-V_{B F}$, para cada dose de nitrogênio sendo que a diferença fica maior para maiores doses de nitrogênio porque possivelmente os defeitos introduzidos pela implantação no óxido de porta e no silício induzem valor efetivo de carga que depende da freqüência da medida C-V. 


\subsubsection{Medidas I-V}

Os resultados das curvas I-V para capacitores com porta de Si-poli $\mathrm{P}^{+}$ implantados com nitrogênio, são apresentados na figura 5.13, nas condições de acumulação ou inversão. Das curvas I-V foi extraído o campo elétrico de ruptura $\left(\mathrm{E}_{\mathrm{BR}}\right)$ das medidas.

Tabela 5.6 - Dados de $E_{B R}$ para 30 capacitores em cada uma das doses de nitrogênio empregadas.

\begin{tabular}{|c|c|}
\hline $\begin{array}{c}\text { Capacitor MOS com } \\
\text { porta de Si-poli } \mathbf{P}^{+}\end{array}$ & $\begin{array}{c}\mathrm{E}_{\mathrm{BR}}[\mathrm{MV} / \mathrm{cm}] \\
\text { Valores médios } \\
\begin{array}{c}\text { Doses de } \\
\text { Nitrogênio }\left[\mathbf{c m}^{-2}\right]\end{array}\end{array}$ \\
\hline $\mathbf{1 . 1 0}^{13}$ & $14,3 \pm 5$ \\
\hline $\mathbf{1 . 1 0}^{14}$ & $16,5 \pm 3$ \\
\hline $\mathbf{1 . 1 0}^{15}$ & $19,3 \pm 2$ \\
\hline $\mathbf{5 . 1 0}^{15}$ & $21,0 \pm 2$ \\
\hline
\end{tabular}

Neste trabalho não se constatou diferença substancial no valor de " $E_{B R}$ " quanto ao tipo de polarização empregada para a realização da medida I-V (acumulação ou inversão), conforme apresenta a figura 5.13. Ou seja, as duas interfaces $\mathrm{Si}$-poli/ $/ \mathrm{SiO}_{2}$ e a $\mathrm{SiO}_{2} / \mathrm{Si}$ apresentam características muito boas quanto à rugosidade. Uma outra constatação, que pode ser verificada pela tabela 5.6 é que quanto maior dose de nitrogênio empregada maiores são os valores de " $E_{\mathrm{BR}}$ ". 

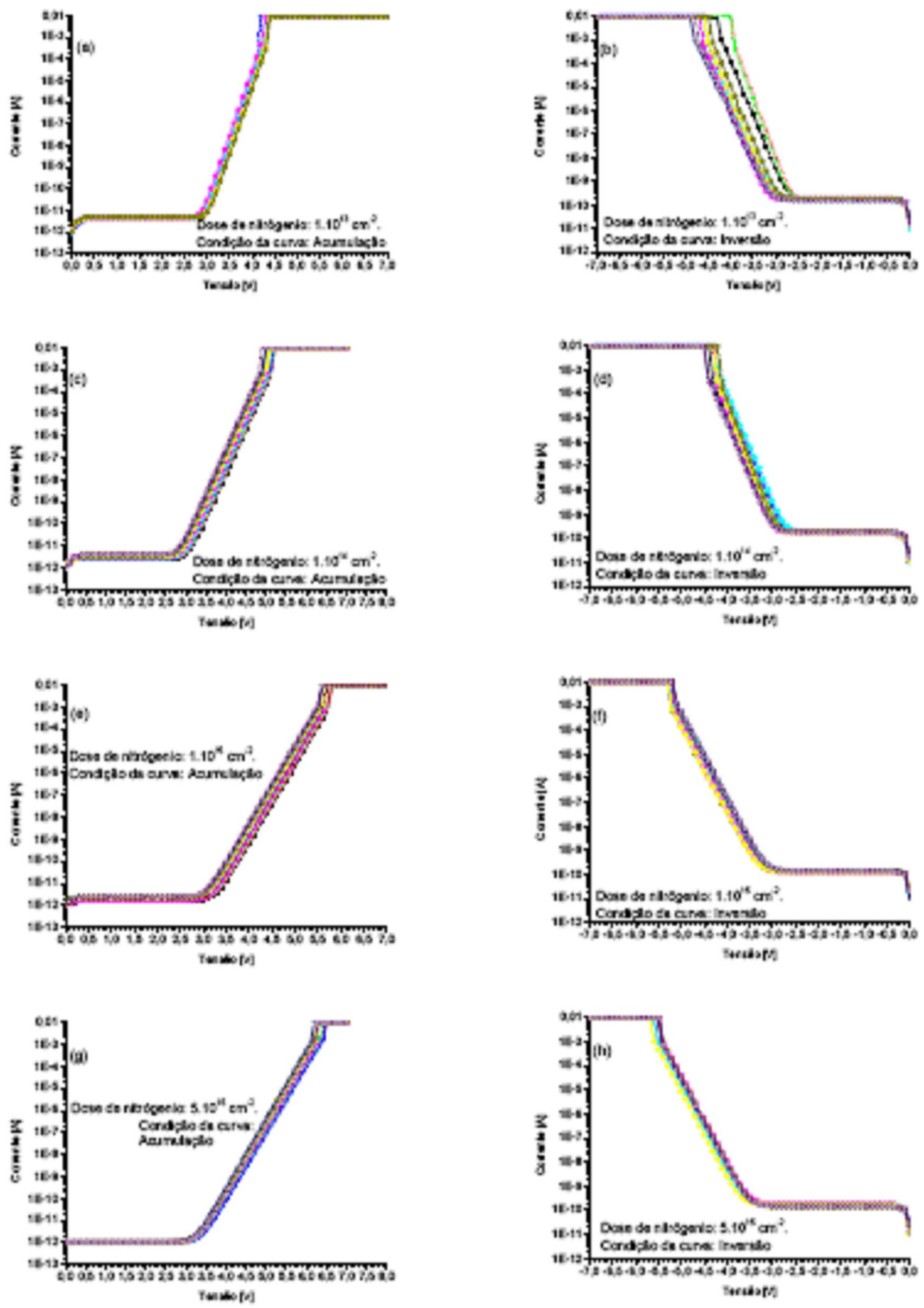

Figura 5.13 - Medidas I-V típicas em capacitores com Si-poli $\mathrm{P}^{+}$com diferentes doses de nitrogênio, polarizados na acumulação ou inversão. 


\subsection{Medidas C-V e I-V em capacitores MOS com Si-poli $\mathrm{N}^{+}$}

Optando pelo mesmo modo de análise feito para as curvas C-V com a estrutura Sipoli $\mathrm{P}^{+}$, iremos também reparar nas medidas $\mathrm{C}-\mathrm{V}_{\mathrm{AF}}$ a dispersão nos valores da capacitância máxima $\left(\mathrm{C}_{\mathrm{MAX}}\right)$, na dispersão na tensão de banda plana $\left(\mathrm{V}_{\mathrm{BF}}\right)$ e na dispersão dos valores da capacitância $\left(\mathrm{C}_{\mathrm{MIN}}\right)$. As figuras 5.14 e 5.15 apresentam as curvas $\mathrm{C}-\mathrm{V}_{\mathrm{AF}}$ e $\mathrm{C}-\mathrm{V}_{\mathrm{BF}}$ representativas para capacitores MOS com porta de Si-poli $\mathrm{N}^{+}$.

Os resultados para os capacitores MOS com porta de Si-poli $\mathrm{N}^{+}$são:

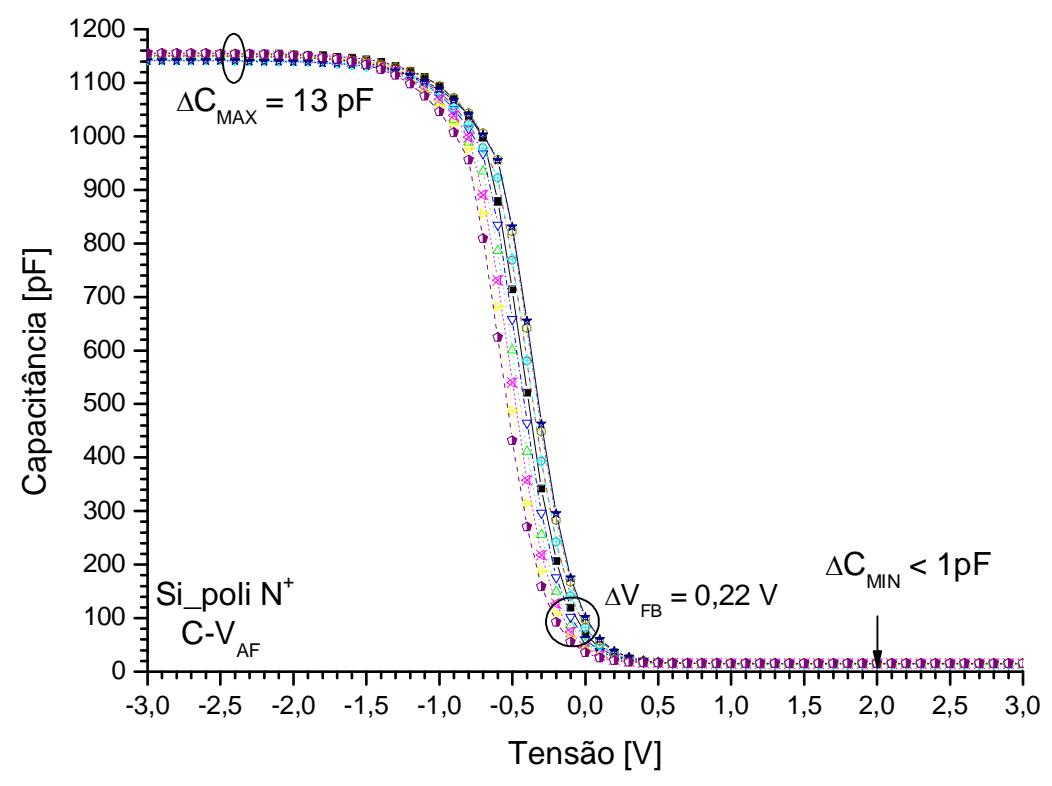

Figura 5.14 - Curvas C- $\mathrm{V}_{\mathrm{AF}}$ para capacitores MOS fabricados com porta de Si-poli $\mathrm{N}^{+}$. 


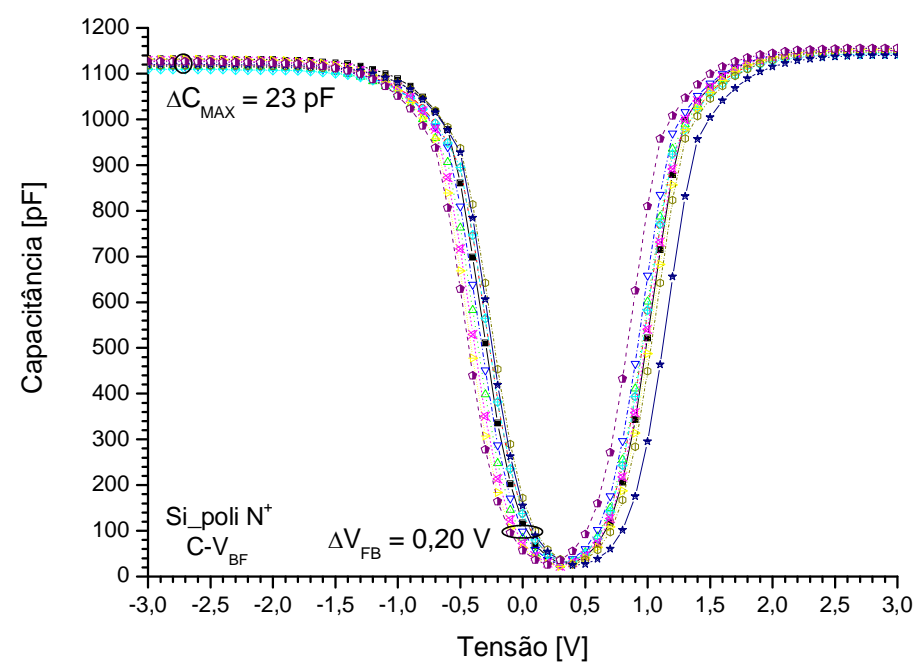

Figura 5.15 - Curvas $C-\mathrm{V}_{\mathrm{BF}}$ para capacitores MOS fabricados com porta de Si-poli $\mathrm{N}^{+}$.

Através das figuras 5.14 e 5.15 analisando as dispersões em " $\mathrm{C}_{\mathrm{MAX}}$ " nas curvas $\mathrm{C}-\mathrm{V}_{\mathrm{AF}}$, podemos afirmar que $\triangle \mathrm{C}_{\mathrm{MAX}}$ é bem menor do que as curvas $\mathrm{C}-\mathrm{V}_{\mathrm{BF}}$ observadas para os capacitores MOS com porta de Si-poli $\mathrm{P}^{+}$(figuras 5.2 a 5.5). $\mathrm{E}$ as dispersões em $\mathrm{V}_{\mathrm{FB}}$ estão próximos da função trabalho $\left(\Phi_{\mathrm{MS}}\right)$.

Observou-se também que a maioria dos capacitores MOS medidos (> 30) apresentaram valores " $\mathrm{C}_{\text {MAX" }}$ " (capacitância máxima) e " $\mathrm{C}_{\mathrm{MIN}}$ " (capacitância mínima) com patamares bem estáveis. A tabela 5.7 apresenta os parâmetros extraídos das curvas $\mathrm{C}-\mathrm{V}_{\mathrm{AF}}\left(\mathrm{EOT}, \mathrm{N}_{\mathrm{A}}\right.$ e $\left.\Delta \mathrm{V}_{\mathrm{FB}}\right)$ e $\mathrm{C}-\mathrm{V}_{\mathrm{BF}}\left(\mathrm{D}_{\mathrm{it}}\right)$. Também nesta tabela consta o valor médio do campo elétrico de ruptura, extraído das curvas I-V, conforme apresenta a figura 5.16 .

Comparando a tabela 5.7 com os dados da tabela 5.6 percebemos que somente a dose de nitrogênio de $5.10^{15}$ at. $\mathrm{cm}^{-2}$ se compara com os resultados dos capacitores produzidos com porta de Si-poli $\mathrm{N}^{+}$, essa comparação também se estende ao parâmetro " $D_{\text {it }}$ " para essa mesma dose de nitrogênio mencionada. 


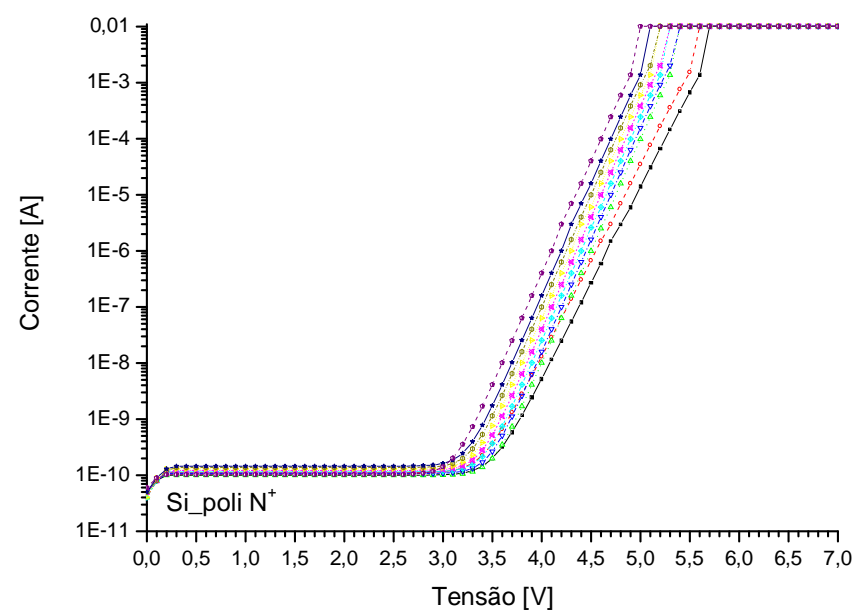

Figura 5.16 - Medidas I-V em capacitores MOS com porta de Si-poli N ${ }^{+}$polarizados na acumulação.

Tabela 5.7 - Parâmetros extraídos das curvas C- $\mathrm{V}_{\mathrm{AF}}$, C- $\mathrm{V}_{\mathrm{BF}}$ e I-V.

\begin{tabular}{|c|c|c|c|c|c|c|}
\hline Medidas & $\begin{array}{c}\mathrm{EOT} \\
{[\mathrm{nm}]}\end{array}$ & $\begin{array}{c}\mathrm{N}_{\mathrm{A}} \\
{\left[\mathbf{1 . 1 0} \mathbf{1 0}^{15} \mathbf{c m}^{-3}\right]}\end{array}$ & $\begin{array}{c}\Delta \mathbf{V}_{\mathrm{FB}} \\
{[\mathrm{V}]}\end{array}$ & $\begin{array}{c}\mathbf{V}_{\mathrm{FB}} \\
{[\mathrm{V}]}\end{array}$ & $\begin{array}{c}\mathbf{D}_{\mathrm{it}} \\
{\left[1.10^{10} \mathbf{e V}^{-1} \cdot \mathbf{c m}^{-2}\right]}\end{array}$ & $\begin{array}{c}\mathbf{E}_{\mathrm{BR}} \\
{[\mathrm{MV} / \mathbf{c m}]}\end{array}$ \\
\hline Médias & 2,6 & 2,1 & 0,22 & $-0,1 \pm 0,08$ & 1,11 & 20 \\
\hline
\end{tabular}




\section{CONSIDERAÇÕES FINAIS}

\subsection{Conclusões}

Neste trabalho foram estudadas as características elétricas das estruturas Si-poli $\mathrm{P}^{+} / \mathrm{SiO}_{2} / \mathrm{Si}$, previamente implantada com nitrogênio, e a estrutura Si-poli $\mathrm{N}^{+} / \mathrm{SiO}_{2} / \mathrm{Si}$ através das medidas I-V, C-V e resistência de folha, pelo método de quatro pontas. Tomou-se um imenso cuidado com as etapas iniciais para a fabricação da estrutura Si-poli/ $\mathrm{SiO}_{2} / \mathrm{Si}$ bem como na etapa de limpeza de pré-oxidação. Com relação à limpeza química, utilizamos a receita RCA com algumas modificações em relação à receita padrão, a fim de promover a menor rugosidade na superfície do Si. Na seqüência, foi realizado o processo de oxidação térmica do $\mathrm{Si}$ em um ambiente que produz óxidos ultrafinos ( 2,6 nm) com excelentes propriedades físico-químicas, que é a oxidação pirogênica.

Neste trabalho realizamos o estudo das receitas de difusão térmica do boro, a fim de avaliar a receita que resulta em menores valores da resistência de folha na superfície do $\mathrm{Si}$, menor carga de boro inserida no substrato do $\mathrm{Si}$ após o processo de difusão de boro no Si-poli. Neste ponto, há uma diferenciação importante deste trabalho com os demais até agora reportados: a dopagem do Si-poli foi realizada com SOG de boro, que implica em uma fonte supersaturada de boro, onde utilizamos uma receita de difusão que permite num teste efetivo da barreira de oxinitreto de silício. Os outros trabalhos aplicam o processo de implantação iônica para realizar a dopagem do Si-poli. 


\subsection{SUGESTÕES PARA TRABALHOS FUTUROS}

Como continuidade aos estudos realizados, propomos fabricar transistores PMOS de modo a avaliar outros parâmetros relevantes incluindo mobilidade, transcondutância, corrente na região de sublimiar, etc.

Outros pontos importantes a serem estudados são:

a) estudo da influência da dose de implantação de nitrogênio na mobilidade do transistor PMOS;

b) estudo da influência da dose de implantação de nitrogênio na reprodutibilidade da tensão de limiar;

c) estudo da reprodutibilidade da dopagem do Si-poli utilizando implantação iônica de boro ao invés de SOG de boro imediatamente após implantação iônica de nitrogênio;

d) repetição dos itens mencionados acima para óxidos de porta $\mathrm{SiO}_{2}$ com espessura de $1 \mathrm{~nm}$. 


\section{BIBLIOGRAFIA}

AKERMAK, T. Molecular atomic oxygen as the transported species in oxidation of silicon. Journal of the Electrochemical Society, Pennington, v.147, n.5, p.18821887, 2000.

ALBERTIN, K.F. Estudo e Fabricação de capacitores MOS com camada isolante de $\mathrm{SiO}_{\mathbf{x}} \mathrm{N}_{\mathbf{y}}$ depositada por PECVD. Dissertação (Mestrado), EPUSP, 2003.

APTE, P.P; KUBOTA, T; SARASWAT, K.C. Constant current stress breakdown in ultra thin $\mathrm{SiO}_{2}$ films. Journal of the Electrochemical Society, v.140, n.3, p.770-773, 1993.

ARORA, N.D; RIOS, R; HUANG, C.L. Modeling the polysilicon depletion effect and its impact on submicrometer CMOS circuit performance. IEEE Transactions on Electron Devices, v.42, n.5, p.935-943, 1995.

BAUER, J. Cho. et al. Implantation of nitrogen into polysilicon to suppress boron penetration through the gate oxide. Int. Conf Ion Implantation Technol Proc, Kyoto, Japan. p.30, 1998.

BAUMVOL, I.J.R Effects of the surface deposition of nitrogen on the thermal oxidation of silicon in $\mathbf{O}_{2}$. Journal of Applied Physic, Woodbury, v.83, n.10, p.5579$5581,1998$.

BRAGA, A.B. Spreading resistance probing. Monografia, UNICAMP, setembro, 1990.

BROWN, D.M; CHEZZO, M; PIMBLEY, J. Trends in advanced process technology - Submicrometer CMOS device design and process requirements. Proceedings of the IEEE, v.74, n.12, p.1678-1702, 1986. 
BUCHANAN, D.A; LO, S.H. Growth, characterization and the limits of ultrathin SiO2 based dielectrics for future CMOS applications. In: Massoud, H.Z et al. The physics and chemistry of $\mathrm{SiO}_{2}$ and the $\mathrm{Si}^{-\mathrm{SiO}_{2}}$ interface. Pennington: The Electrochemical Society, v.3, p.3-14, 1996.

BUCHANAN, D.A. Scaling the dielectric: materials, integration and reliability. IBM Journal of Research and Development, Armonk, v.43, n.3, p.245-264, 1999.

CEILER, M.F. et al. Plasma-enhanced chemical vapor deposition at low temperatures. Journal Electrochemical Society, v.142, n.6, 1995.

$\mathrm{CHOI}$, Chang-Hoon et al: Gate length dependent polysilicon depletion effects. IEEE Electron Device Letters, v.23, n.4, p.224-226, 2002.

CLERC, R. et al. Capacitance-Voltage (C-V) characterization of $20 \AA$ thick gate oxide: parameter extraction and modeling. Microelectronics Reliability, v.40, n.4-5, p.571-575, 2000.

DEAL, B.E; GROVE, A.S. General relationship for the thermal oxidation of silicon. Journal of Applied Physics, New York, v.36, n.12, p.3770-3778, 1965.

DECLERK, G; VAN OVERSTRAETEN; BROUX, G. Measurement of low densities of surface states at the Si-SiO ${ }_{2}$-interface. Solid State Electronics, v.16, p.14511460, 1973.

DEPAS, M. et al. Determination of tunneling parameters in ultra-thin oxide layer poly-Si/SiO $2 /$ Si structures. Solid-State Electronics, v.38, n.8, p.1465-1471, 1995.

DIMITRIJEV, S. Understanding semiconductor devices. New York: Oxford University Press, 2000.

DOMÍNGUEZ, C; et al. The effect of rapid thermal annealing on properties of plasma enhanced CVD silicon oxide films. Thin Solid Films, v.346, p.202-206, 1999.

FELDMAN, L.C; GUSEV, E.P; GARFUNKEL, E. Ultrathin dielectrics in silicon microelectronics: an overview. In: GARFUNKEL, E.L. et al. Fundamentals aspects of ultrathin dielectrics on Si-based devices. Dordrecht: Kluwer, p.1-24, 1998. 
FELDMAN, L.C. Fundamental aspects of silicon oxidation. Berlin: SpringerVerlag, (Springer series in materials science, v.46) 2001, cap.1, p.1-11.

FERREIRA, E. C. Obtenção e caracterização de filmes de silício policristalino para aplicação em tecnologia MOS porta de silício. Dissertação (Mestrado), Unicamp, 1987.

FRANK, D.J. et al. Device scaling limits of Si MOSFETs and their application dependencies. Proceedings of the IEEE, New York, v.89, n.3, p.259-288, 2001.

GHIBAUDO, G. et al. Gate dielectrics for ultimate CMOS technologies limitations and alternative solutions. Comptest-Rendus de 1' Académie des Sciences Paris, v.1, n.7, p.911-927, 2000.

GREEN, M.L. et al. Thermal routes to ultrathin oxynitride. In: GARFUNKEL, E.L et al. Fundamentals aspects of ultrathin dielectrics on Si based devices. Dordrecht: kluwer, p.181-190, 1998.

Green, M. L. Ultra thin ( $<4 \mathrm{~nm}) \mathrm{SiO}_{2}$ and $\mathrm{Si}-\mathrm{O}-\mathrm{N}$ gate dielectric layers of silicon microelectronics: Understanding the processing structure, and physical and electrical limits. J. App. Phys, Applied Physics Review, v.90, n.5, p.2057-2121, 2001.

GUSEV, E.P. et al. Growth and characterization of ultra thin nitrided silicon oxide films. IBM Journal of Research and Development, Armonk, v.43, n.3, p.265286, 1999.

GUSEV, E.P. et al. High-resolution depth profiling in ultrathin $\mathrm{Al}_{2} \mathrm{O}_{3}$ films on $\mathrm{Si}$. Applied Physics Letters, Melville, v.76, n.2, p.176-178, 2000. 
HABAS, P.; SELBERHERR, S. On the effect of non-degenerate doping of polysilicon gate in thin oxide MOS device - analytical modeling. Solid State Electronics, v.33, n.12, p.1539-1544, 1990.

HAMANN, D.R. Diffusion of atomic oxygen in $\mathrm{SiO}_{2}$. Physical Review Letters, Woodbury, v.81, n.16, p.3447-3450, 1998.

HARARI, E.J. Conduction and trapping of electrons in highly stressed ultra thin films of thermal $\mathrm{SiO}_{2}$. App. Phys. Lett, v.30, n.11, p.601, 1977.

HATTANGADY, S.V. et al. Ultrathin nitrogen profile engineered gate dielectric films. In: International Electron Devices Meeting, 1996, San Francisco, Technical digest. New York: IEEE, p.495-498, 1996.

HERDEN, M. et al. Suppression of boron penetration through thin gate oxide by nitrogen implantation into the gate electrode. Solid State Electronics, v.45, p.1251-1256, 2001.

HIROSE, M. et al. Fundamental limit of gate oxide thickness scaling in advance MOSFETs. Semiconductor Science and Technology, Bristol, v.15, n.5, p.485-490, 2000.

HUANG, et al. Measurements and modeling of MOSFETs I-V characteristics with polysilicon depletion effect. IEEE Electronics Letters, v.40, n.12, p.2330-2337, 1993.

IMAI, M. et al. The change of surface microroughness on epitaxial growth process. ECS 1998, Spring Meeting, n.508, 1998.

Intel Corp. Disponível em http://www.intel.com/research/silicon (Acesso: 21/05/2008)

JOSHI, D. P; SRIVASTAVA, R. S. A model of electrical conduction in polycrystalline silicon. IEEE, Trans. Elect. Devices, EDL 31, n.7, p.920-927, 1984.

KAGESHIMA, H; SHIRAISHI, K; UEMATSU, M. Universal theory of silicon oxidation rate and importance of interfacial Si emission. Japanese Journal of Applied Physics, Tokyo, v.38, n.9A/B, p.L971-L974, 1999. 
KAMINS, T. I. Polycrystalline silicon for integrated circuit and displays. Kluwer Academic Publishers, $2^{\circ}$ ed, 1998.

KINGON, A. I; MARIA, J. P; STREIFFE, S. K.: Alternative dielectrics to silicon of dioxide for memory and logic devices. Nature, v.406, p.1302; 2000.

KRAFT, R. et al. Surface nitridation of silicon dioxide with a high density nitrogen plasma. Journal of Vacuum Science and Technology B, Woodbury, v.15, n.4, p.967-970, 1997.

LEE, W.C; HU, C. Modeling CMOS tunneling currents through ultrathin gate oxide due to conduction and valence-band electron and hole tunneling. IEEE Transactions on Electron Devices, v.48, n.7, p.1366-1373, 2001.

LEI, T.F. et al. Characterization of polysilicon oxide thermally grown and deposited on electronics roughness. IEEE Trans. On Electron Devices, v.45, n.4, 1998.

LIN, C. et al. Reliability of gate oxide grown on nitrogen implanted Si substrates. Applied Physics Letters, Woodbury, v.69, n.24, p.3701-3703, 1996.

LIOU, J.J. et al. Influence of polysilicon-gate depletion on the subthreshold behavior of submicron MOSFETs. Microelectronics Reliability, v.42, n.3, p.343347, 2002.

LO, S-H; BUCHANAN, D.A; TAUR, Y. Modeling and characterization of quantization, polysilicon depletion, and direct tunneling effects in MOSFETs with ultrathin oxides. IBM Journal of Research and Development, v.43, n.3, p.1-9, 1999. 
LU, N.C.C.; GERZBERG, L.; MEINDL, J.D. A quantitative model of the effect of grain size on the resistivity of polycrystalline silicon resistors. IEEE Trans. Electron Device. EDL 1, n.3, p.38-41, 1980.

LU, N. C. C; GEZRBERG, L; LU, C. H; MEINDL, J. D. A new conduction model for polycrystalline silicon films. IEEE, Trans. Elect. Devices, ed.2, n.4, p.95-98, 1981.

LU, C.Y. et al. Anomalous C-V characteristics of implanted poly MOS structure in $\mathbf{n}+\mathbf{p}+$ dual gate CMOS technology. IEEE Electron Device Letters, v.10, n.5, p.192-194, 1989.

$\mathrm{LU}$, Q. et al. Molybdenum metal gate MOS technology for post $\mathrm{SiO}_{2}$ gate dielectrics. Technical Digest of the IEDM, p.641-644, 2000.

LUCOVSKY, G; TSU, D.V. Plasma enhanced chemical vapor deposition differences between direct and remote plasma excitation. Journal Vacuum Sci. Technology, v.A5, n.4, p. 2231, 1987.

MANERA, G.A. Dielétricos de porta de oxinitreto de silício obtidos por plasma ECR. Dissertação (Mestrado), UNICAMP, 2004.

MERTENS, P. W. et al. Advanced cleaning growth of ultra thin gate oxide, Microelectronic Engineering, p.48, 1999.

MEURIS, P.; et al; The relationship of the silicon surface roughness and gate oxide integrity in $\mathrm{NH}_{4} \mathrm{OH} / \mathrm{H}_{2} \mathrm{O}_{2}$ Mixture. Jpn. J. Appl. Phys, v.31, part 2, 1992.

MIAN, C.S; YIN, I.S.F. Nitrogen in ultrathin gate oxide: its profile and functions. Solid-State Electronics, v.43, p.1997-2003, 1999.

MOGAMI, T. et al. Hot carrier effects in surface-channel PMOSFETs with $\mathrm{BF}_{2}$ or boron implanted gates. IEDM Tech Dig 1991, p.533-536.

MOORE, G.E. Cramming more components onto integrated circuits. Electronics, New York, v.38, n.8, p.114-117, 1965.

MULLER, D.A. et al. The electronic structure at the atomic scale of ultrathin gate oxides. Nature, London, v.399, n.6738, p.758-761, 1999. 
NGUYEN, T. et al. New leakage mechanism in sub-5 $\mathrm{nm}$ oxynitride dielectrics. App. Phys. Lett., v.63, n.14, p.1972, 1993.

NICOLLIAN, E. H; BREWS, J. R. MOS physics e technology; New York, Wiley Interscience Publication, EDL 2; 1982.

NOGUEIRA, W.A. Obtenção de óxidos de porta MOS ultrafinos: influência da limpeza química e estudo da ruptura dielétrica. Tese (Doutorado), EPUSP, 2003.

ONO, Y.; MA, Y.; HSU, S.T. Ultra thin gate oxide with shallow nitrogen implants as effective barriers to boron diffusion. In: Huff, H.R. et.al. (Eds). Ultra thin $\mathrm{SiO}_{2}$ and high $\mathbf{k}$ materials for ULSI gate dielectrics. Warrendale: Materials Research Society, 1999, p.39-44, MRS Symposium proceedings, v.567.

PASQUARELLO, A; GRIFFIN, P.B; PLUMMER, J.D. Interface structure between silicon and its oxide by first principles molecular dynamics. Nature, London, v.396, n.5, p.58-60, 1998.

PEDRINE, A.G. Deposição de silício policristalino por LPCVD. Dissertação (Mestrado), USP, 1993.

PFIESTER, J. et al. The effect of boron penetration on $\mathbf{p}^{+}$polysilicon gated PMOS device. IEEE Trans Electron Devices, v.37, p.1842, 1990.

PLUMMER, J.D. Oxidation kinetics: from Deal-Grove to VLSI process models. In: MASSOUD, H.Z et al. The physics and chemistry of $\mathrm{SiO}_{2}$ ant the $\mathrm{Si}^{-\mathrm{SiO}_{2}}$ interface. Pennington: The Electrochemical Society, v.3, p.129-142, 1996.

Plummer, J.D.; Griffin, P.B. Proceedings of IEEE. v.89, n.3, 2000. 
Plummer, J.D.; Griffin, P.B. Material and process limits in silicon VLSI technology. Proceedings of the IEEE, New York, v.89, n.3, p.240-258, 2001.

PRETORIUS, R; STRYDOM, W; MAYER, J.W; COMBRIE, C. ${ }^{31}$ Si tracer studies of the oxidation of $\mathbf{S i}, \mathrm{CoSi}_{2}$ and PtSi. Physical Review B, New York, v.22, n.4, p.1885-1891, 1980.

RANGEL, Elidiane Cipriane. Implantação iônica em filmes finos depositados por PECVD. Tese (doutorado), Instituto de Física "Gleb Wataghin", UNICAMP, 1999.

RIOS, R.; ARORA, N.D.; HUANG, C.L. An analytic polysilicon depletion effect model for MOSFETs. IEEE Electron Device Letters, v.15, n.4, p.129-131, 1994.

ROBERTSON, J. Electronic structure and band offsets of high-dielectricconstant gate oxides. MRS Bulletin, Pittsburgh, v.27, n.3, p.217-221, 2002.

RODRIGUES, Michele. Caracterização elétrica de capacitores obtidos através de tecnologia ultra-submicrométrica. Dissertação (Mestrado), EPUSP, 2006.

RUDOLPH Research Ind. Auto El MS manual (NIR - 3), 1989.

SCHUEGRAF K.F. and $\mathrm{HU}$ C. Hole injection $\mathrm{SiO}_{2}$ breakdown model for very low voltage lifetime extrapolation. IEEE Trans. On Electron Device, v.41, n.5, p.761, 1994.

SCHULZ, Max. The end of the road for silicon. Nature, v.399, p.729, 1999.

SETO, J. Y. W. The electrical properties of polycrystalline silicon films. J. App. Physics Lett, v.46, n.12, p.5247-5254, 1975. 
SHIMADA, $H$. et al. Threshold voltage adjustment in SOI MOSFETs by employing tantalum for gate material. International Electron Devices Meeting, p.881-884, 1995.

SMITH, J. P.; ECCLESTON, W.; BROWN, P. D.; HUMPREYS, C. J. Electronic and structural properties of partially crystallized silicon produced by solid-phase crystallizations of as-deposited amorphous silicon. J. Electrochemical. Soc, v.146, 1999.

SOLEIMANI, H.R.; DOYLE, B.S.; PHILIPOSSIAN, A. Formation of ultra thin nitrided $\mathrm{SiO}_{2}$ oxides by direct nitrogen implantation into silicon. Journal of the Electrochemical Society, Pennington, v.142, n.8, p.L132-L134, 1995.

SOLOMON, P.M.E. Scaling CMOS to the limit. IBM Journal of Research and Development, Armonk, v.46, n.2/3, p.119-120, (Special issue) 2002.

STATHIS, J.H. Reliability limits for the gate oxide insulator in CMOS technology. IBM Journal of Research and Development, Armonk, v.46, n.2/3, p.265286, 2002.

STONEHAM, A.M; GROVENOR, C.R.M; CEREZO, A. Oxidation and structure of silicon/oxide interface. Philosophical Magazine B, London, v.60, n.2, p.189-212, 1987.

TEIXEIRA, R.C. et al. Deposition and characterization of LPCVD polycrystalline silicon. Proceedings of COBEM, v.19, p.62-70, 2001.

THOMPSON, S; PACKAN, P; BOHR. MOS scaling: Transistor challenges for the $21^{\text {st }}$ century. Intel Technology Journal, v.2, n.3, 1998.

TOQUETTI, Leandro Zeidan. Estudo teórico-experimental da obtenção de oxinitreto de silício de porta MOS ultrafinos. Tese (doutorado), Engenharia Elétrica, USP, 2005. 
WILK, G.D; WALLACE, R.M; ANTHONY, J.M. High-k gate dielectrics: Current status and materials properties considerations. Journal of Applied Physics, v.89, n.10, p.5243-5275, 2001.

WONG, H.S.P. Beyond the conventional transistor. IBM journal of research and development, Armonk, v.46, n.2/3, p.133-168, 2002.

WONG, Hei; IWAI, Hiroshi: "On the scaling issues and high-k replacement of ultra thin gate dielectrics for nanoscale MOS transistors". Microelectronic Engineering, v.83, p.1867-1904, 2006.

WU, Y; LUCOVSKY, G. Ultrathin nitride/oxide (N/O) gate dielectrics for $\mathbf{p} \pm$ polysilicon gated PMOSFETs prepared by a combined remote plasma enhanced CVD/thermal oxidation process. IEEE Electron Dev Lett, v.19, n.10, p.367-369, 1998.

WU, Y; LUCOVSKY, G. Improvement of gate dielectrics reliability for $\mathbf{p}^{+}$poly MOS devices using remote PECVD top nitride deposition on ultra-thin (2.4-6 nm) gate oxides. Microelectronics Reliability, v.39, p.365-372, 1999.

XUAN, P.; BOKOR, J. Investigation of NiSi and TiSi as CMOS gate materials. IEEE Electron Device Letters, v.24, n.10, p.634-636, 2003.

YARON, G; FROHMAN-BENTCHKOWSKY, D. Capacitance voltage characterization of poly $\mathrm{Si}_{-} \mathrm{SiO}_{2}$-Si structures. Solid State Electronics, v.23, n.5, p.433-439, 1980.

ZHOU, J.H. et al. Transport properties of microelectronics silicon at low temperatures. Semiconductors, v.32, n.8, p.807-811, 1998. 


\section{APÊNDICE A - EXTRAÇÃO DE PARÂMETROS DA CURVA C-V}

\section{A.1 - Parâmetros da curva $\mathrm{C}-\mathrm{V}_{\mathrm{AF}}$}

Este item apresenta uma pequena revisão sobre o equacionamento para a caracterização de capacitores MOS (NICOLLIAN, 1982). Os parâmetros importantes extraídos neste trabalho foram:

1. A espessura do óxido $\left(\mathrm{t}_{\mathrm{ox}} \sim \mathrm{EOT}\right)$

Uma vez conhecendo a área do capacitor, é possível obter a espessura do óxido, através da eq.(a.1).

$C_{o x}=\frac{\varepsilon_{o x} \cdot \varepsilon_{o} \cdot A}{t_{o x}}=C_{M A X}$

2. Dopagem do substrato $\left(\mathrm{N}_{\mathrm{A}}\right)$

Primeiramente deve-se obter a capacitância do silício $\left(\mathrm{C}_{\mathrm{Si}}\right)$ da curva $\mathrm{C}-\mathrm{V}_{\mathrm{AF}}$ conjuntamente com a eq.(a.2). Em seguida, deve-se obter à largura (W) na situação de inversão através da eq.(a.3). Após, deve-se realizar interações com a eq.(a.4) pois o potencial de superfície $\left(\psi_{\mathrm{s}}\right)$ descrito na eq.(a.5) também depende de " $\mathrm{N}_{\mathrm{A}}$ ". $\mathrm{A}$ eq.(a.6) é resultado da manipulação das eq.(a.4) e eq.(a.5) para a obtenção de "N ${ }_{A}$ ".

$$
\begin{aligned}
& C_{S_{i}}=\frac{1}{A} \cdot\left(\frac{C_{M A X} \cdot C_{M I N}}{C_{M A X}-C_{M I N}}\right) \\
& C_{S_{i}}=\frac{\varepsilon_{S} \cdot \varepsilon_{o}}{W} \\
& W=\sqrt{\frac{2 \cdot \varepsilon_{S_{i}} \cdot \varepsilon_{o} \cdot 2 \psi_{S}}{q N_{A}}}
\end{aligned}
$$




$$
\psi_{B}=\frac{K T}{q} \cdot \ln \frac{N_{A}}{n_{i}}
$$

$$
N_{A}=\frac{2 \cdot \varepsilon_{s} \cdot \varepsilon_{o}}{q W^{2}} \cdot \frac{2 \cdot K T}{q} \cdot \ln \frac{N_{A}}{n i}
$$

3. Tensão de banda plana $\left(\mathrm{V}_{\mathrm{FB}}\right)$

A obtenção da capacitância de banda plana $\left(\mathrm{C}_{\mathrm{FB}}\right)$, na eq.(a.7), se dá após a obtenção da espessura do óxido ( $\left.\mathrm{t}_{\mathrm{ox}}\right)$ na eq.(a.1) e a dopagem do substrato $\left(\mathrm{N}_{\mathrm{A}}\right)$ na eq.(a.6).

$$
C_{F B}=A . \frac{\varepsilon_{o} \cdot \varepsilon_{o x}}{t_{o x}+\frac{\varepsilon_{o x}}{\varepsilon_{S}} \cdot \sqrt{\frac{K T \cdot \varepsilon_{S}}{q^{2} \cdot N_{A}}}}
$$

Tendo $\mathrm{C}_{\mathrm{FB}}$ pode se obter $\mathrm{V}_{\mathrm{FB}}$ na curva $\mathrm{C}-\mathrm{V}_{\mathrm{AF}}$.

\section{Carga no óxido (Qss)}

Tendo os valores de " $\mathrm{V}_{\mathrm{FB}}$ ", a função trabalho do material de porta e a função trabalho do semicondutor, pode-se obter "Qss" utilizando a eq.(a.8). Deve-se lembrar que, para material de porta de silício policristalino $\mathrm{N}^{+}$a diferença da função trabalho $\left(\Phi_{\mathrm{MS}}\right)$ é dado pela eq.(a.9) para material de porta de silício policristalino $\mathrm{P}^{+} \mathrm{a}$ diferença da função trabalho é dada pela eq.(a.10). Os valores de $Q_{s s}$ não foram extraídos neste trabalho, já que, por se tratar de um óxido ultrafino, faz com que a diferença $\left(\Phi_{\mathrm{MS}}-\mathrm{V}_{\mathrm{FB}}\right)$ seja maior do que realmente o é. 


$$
\begin{aligned}
& \frac{Q_{s s}}{q}=\frac{\left(\phi_{M S}-V_{F B}\right)}{q} \frac{\varepsilon_{o} . \varepsilon_{o x}}{t_{o x}} \\
& \phi_{M S}=\phi_{S i_{-} p o l i N^{+}}-\psi_{S}=-0,55-\psi_{S} \\
& \phi_{M S}=\phi_{S i_{-} p o l i P^{+}}-\psi_{S}=+0,55-\psi_{S}
\end{aligned}
$$




\section{A.2 Extração de $D_{i t}$ na curva $C-V_{B F}$}

O valor da densidade de armadilhas de interface próximo ao meio da banda proibida pode ser obtido pela eq.(a.11) (DECLERK, 1973).

$D_{i t}=\left(\frac{\frac{C_{M I N}{ }_{B F}}{C_{M A X_{B F}}}}{1-\frac{C_{M I N_{B F}}}{C_{M A X_{B F}}}}-\frac{\sqrt{\frac{1}{2}\left(\frac{N_{A}}{n_{i}}+\frac{n_{i}}{N_{A}}\right)} \cdot 1,26 \cdot 10^{3} \cdot t_{o x}}{1+0,542 \cdot \ln \left(\frac{N_{A}}{n i}\right)-0,0115 \cdot\left(\ln \left(\frac{N_{A}}{n i}\right)\right)^{2}}\right) \cdot \frac{\varepsilon_{o} \cdot \varepsilon_{o x}}{q \cdot t_{o x}}$

onde $C_{M A X}$ e $C_{M I N}$ são respectivamente a capacitância máxima e mínima observada na curva de capacitância versus tensão de baixa freqüência, conforme mostra a figura A.1.

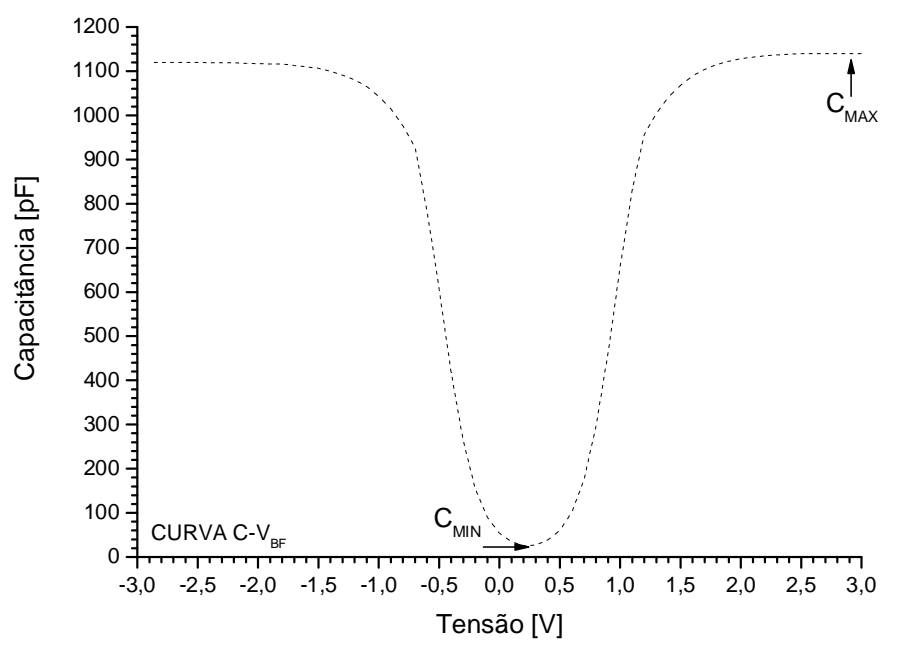

Figura A.1 - Curva C- $\mathrm{V}_{\mathrm{BF}}$ apresentando os parâmetros $\mathrm{C}_{\mathrm{MAX}}$ e $\mathrm{C}_{\mathrm{MIN}}$ a serem extraídos da curva. 


\section{APÊNDICE B - SIMULAÇÃO SRIM}

O SRIM (Stopping and Range of lons Matter) é um conjunto de programas que calcula a distribuição dos íons nas camadas da matéria (sólida ou gasosa) além dos danos por espalhamento, ionização, produção de fônons e uma descrição detalhada dos átomos no alvo, através do uso da mecânica quântica de colisões dos íons. A base destes cálculos é eficiente, pois levam em consideração as interações destes íons com a matéria através de algoritmos estatísticos, descrevendo em detalhes os fenômenos físicos das interações íon-matéria envolvidos.

O programa SRIM simula, numa estrutura qualquer, até oito camadas, com as mais diversas constituições de materiais e estados físicos (sólido e/ou gasoso). Para essas camadas, devem ser fornecidos a espessura, a densidade de cada elemento utilizado, a composição estequiométrica e os respectivos pesos atômicos para cada material utilizado na camada, conforme apresenta a figura B.1. É necessário informar também qual o elemento a ser implantado, bem como os respectivos parâmetros como o peso atômico, numero atômico, número de íons (no máximo $10^{7}$ íons) energia dos íons (na faixa de 10 eV a 2 GeV/íon) e o ângulo de incidência.

Os parâmetros de entrada apresentados na figura B.1 foram utilizados neste trabalho. O SRIM permite a escolha da saída de dados desejados. Neste trabalho, optou-se por utilizar a distribuição de íons implantados, onde se obtém a profundidade e o número de íons ao longo da estrutura, gerando um gráfico $3 D$ dos átomos/volume $x$ átomos/superfície, conforme apresenta as figuras 4.2 e B.2. Com essa distribuição, pode se obter a concentração volumétrica de nitrogênio no alvo apenas multiplicando a átomos/volume x átomos/superfície (valores apresentados no eixo y) pela dose desejada. $O$ valor de energia $110 \mathrm{keV}$ resulta no pico mais nitrogênio mais próximo da interface $\mathrm{Si}-\mathrm{poli} / \mathrm{SiO}_{2}$. 


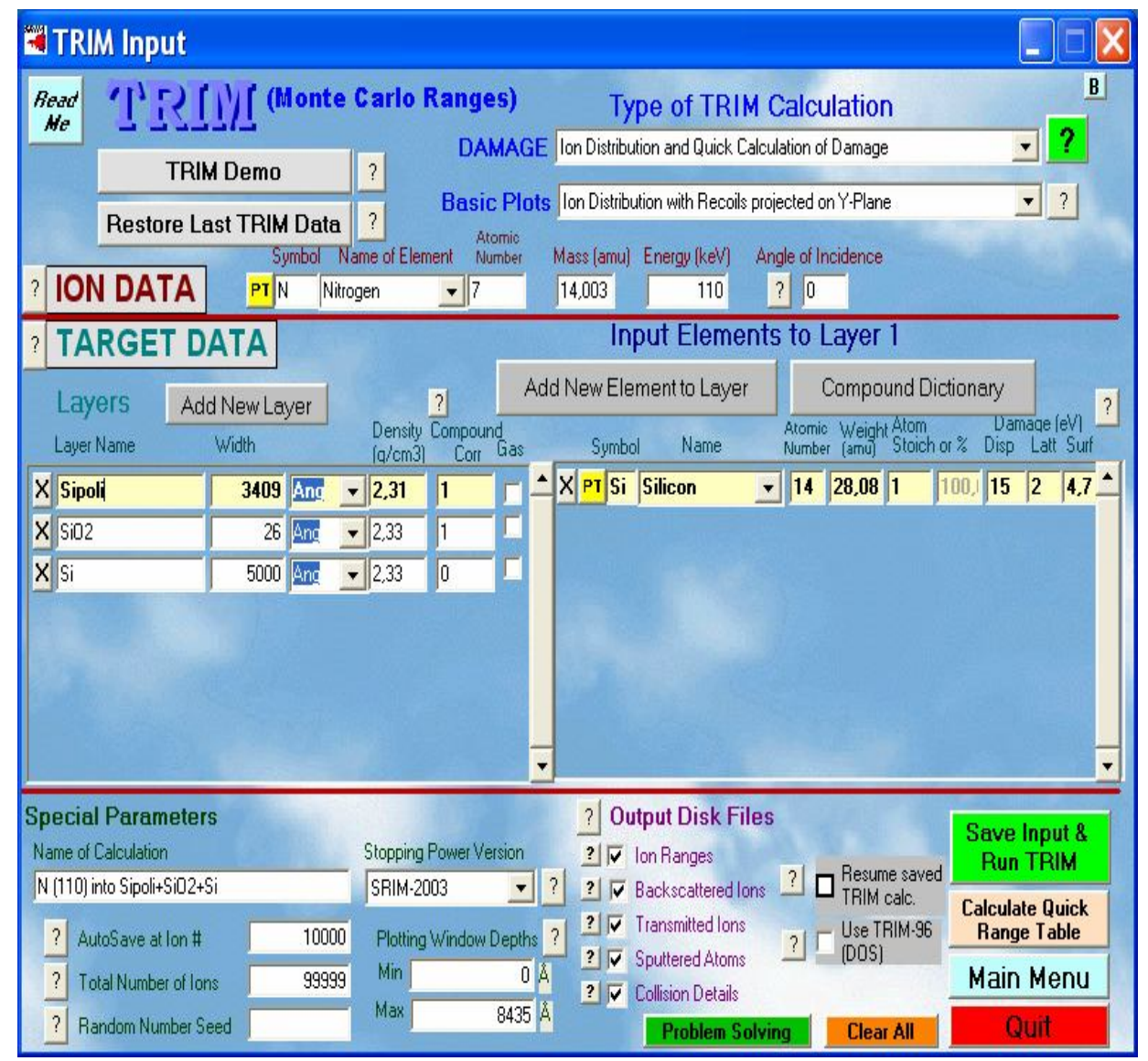

Figura B.1 - Painel de entrada de parâmetros para a simulação SRIM utilizada neste trabalho. 


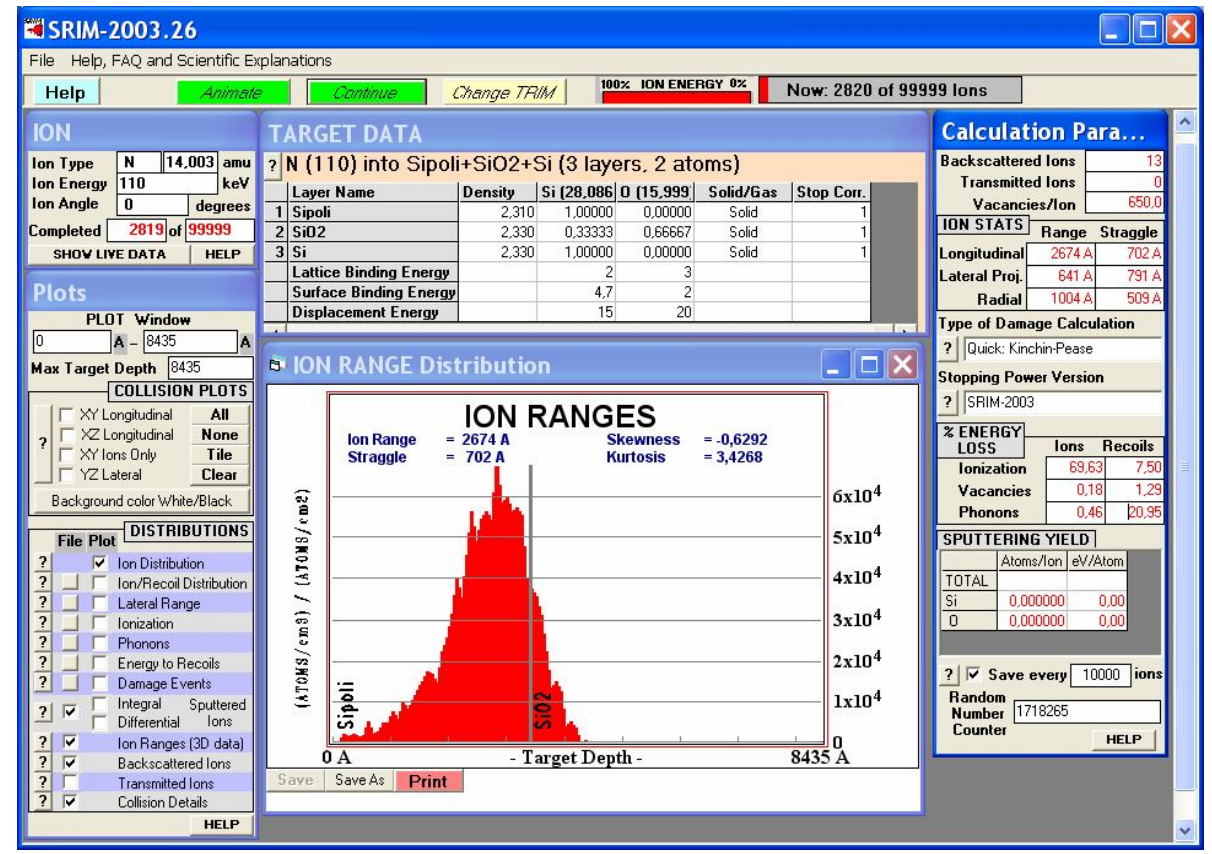

Figura B.2 - Painel de saída de dados para a simulação SRIM. Desses dados, somente o gráfico (lon Range) é utilizado neste trabalho. 